\title{
ROBERTO CHAVES CASTRO
}

\section{Circulação periférica em pacientes com insuficiência aórtica crônica e indicação de troca valvar}

Tese apresentada à Faculdade de Medicina da Universidade de São Paulo para obtenção do Título de Doutor em Medicina 
Circulação periférica em pacientes com insuficiência aórtica crônica e indicação de troca valvar 


\section{ROBERTO CHAVES CASTRO}

\section{Circulação periférica em pacientes com insuficiência aórtica crônica e indicação de troca valvar}

Tese apresentada à Faculdade de Medicina da Universidade de São Paulo para obtenção do Título de Doutor em Ciências

Área de concentração: Cardiologia

Orientador: Professor Doutor Max Grinberg

Co-Orientadora: Professora Doutora Sílvia H. Gelás Lage

SÃO PAULO - SP

2005 
A Deus, minha rocha.

À minha esposa Milene, o amor de minha vida, e minha filha Débora que me ensina a viver. 
"Guarda com toda a diligência o teu coração, porque dele procedem as fontes da vida".

Provérbios 4:23 


\section{AGRADECIMENTOS}

Ao meu orientador, Professor Doutor Max Grinberg, pela confiança que sempre depositou em mim. Professor, médico e administrador competente, mestre com as palavras, com ele aprendi sobre ciência médica e humana.

À minha co-orientadora, Professora Doutora Sílvia H. G. Lage, pelo exemplo de generosidade. Sua atitude foi fundamental no incentivo a que concluísse este trabalho e despertasse para a vocação científica.

Aos colegas da Unidade Clínica de Valvopatia do Instituto do Coração, que me acolheram e ensinaram com amizade: Dr. Luiz Francisco Cardoso, Dr. Flávio Tarasoutchi, Dr. Roney Orismar Sampaio, Dr. Nelson Elias, Dr. Paulo de Lara Lavítola, Dra. Berta Paula Napchan Boer, Dr. Eduardo Giusti Rossi, Dra. Solange Desiree Avakian, Dr. Guilherme Sobreira Spina, Dr. Marcelo Nigri e Dr. André Moreira Bento. A oportunidade do convívio profissional e pessoal com cada um é inesquecível.

Ao Dr. Marcelo Luiz Campos Vieira e Dra. Márcia Azevedo Caldas, do Serviço de EcoDopplercardiografia, pela realização e interpretação dos exames. 
Ao Dr. José Cláudio Meneghetti e Dra. Maria Clementina Pinto Giorgi, do Serviço de Radioisótopos, pela análise dos exames de ventriculografia radioisotópica.

À secretária Mônica Udo Junqueira Kondo, Mônica Moreira Julião e a auxiliar de pesquisa Rute Mello Diniz Ribeiro, que supriram com eficiência $\mathrm{o}$ apoio técnico necessário, criando um vínculo de cumplicidade $\mathrm{e}$ companheirismo.

Aos funcionários do Instituto do Coração, em especial ao Sr. Marco Antônio de Oliveira, que demonstraram dedicação não só ao trabalho, mas sobretudo ao ser humano.

Aos pacientes voluntários desta pesquisa, que nos fazem viver a verdadeira emoção da medicina, a de lutar pela vida. 


\title{
SUMÁRIO
}

\author{
Lista de Abreviaturas \\ Lista de Figuras \\ Lista de Tabelas \\ Lista de Gráficos \\ Lista de Quadros \\ Resumo \\ Summary
}

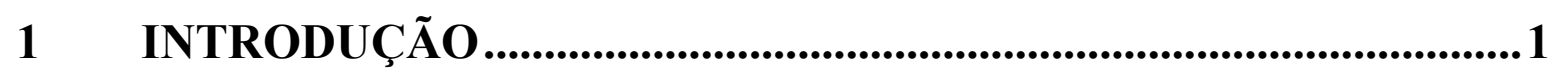

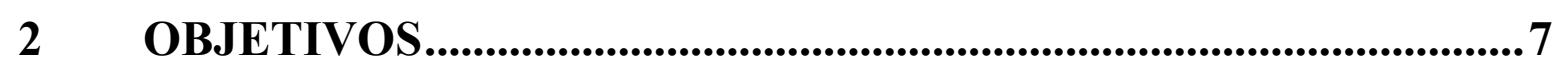

3 CASUÍSTICA E MÉTODOS..........................................................9

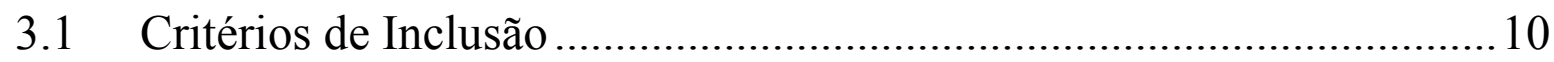

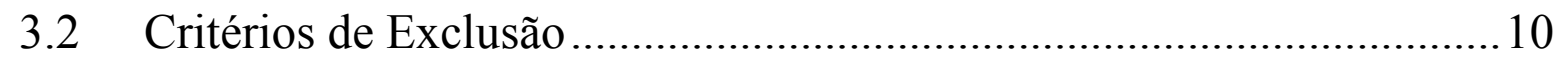

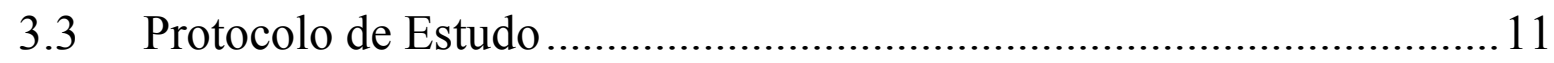

3.3.1 Avaliação da Pressão Arterial Diastólica............................................13

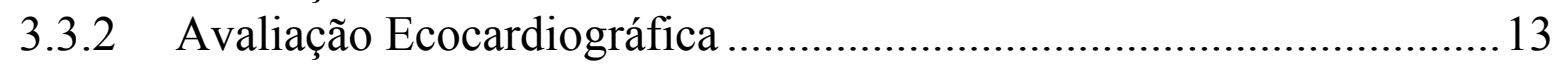

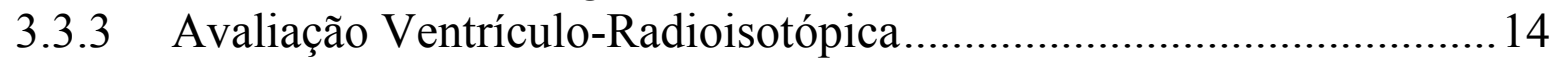

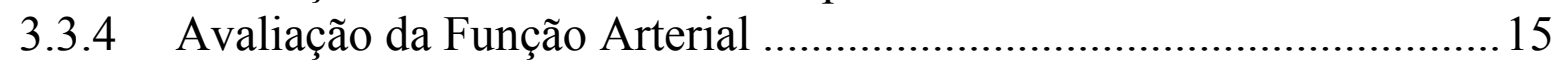

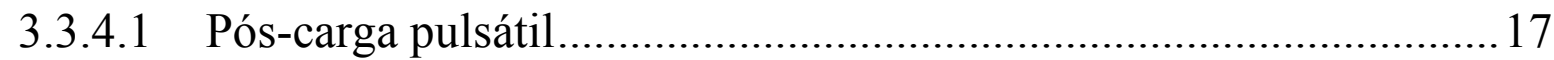

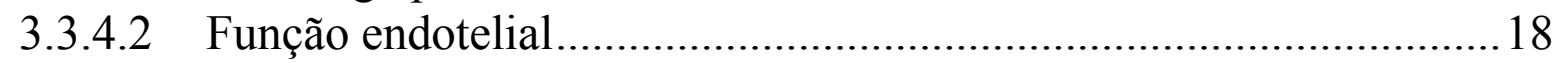

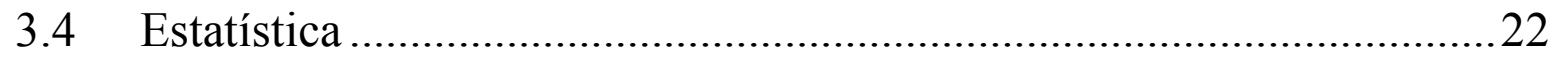

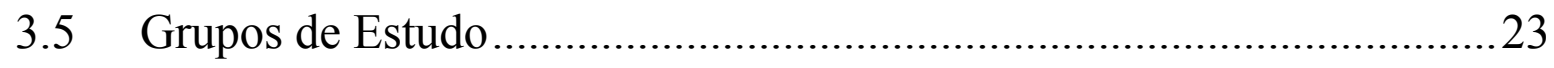

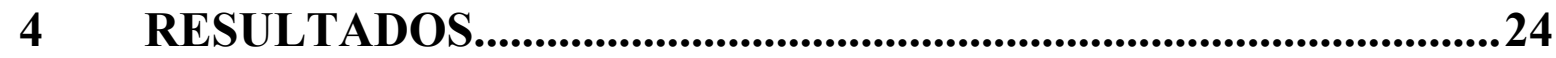

4.1 Pressão Arterial Diastólica ...................................................................25

4.2 Variáveis Ecocardiográficas e Ventrículo-Radioisotópica ....................26

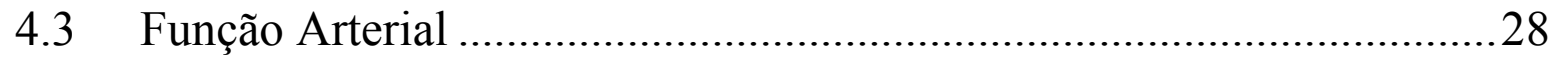




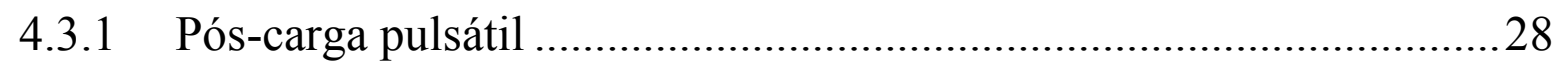

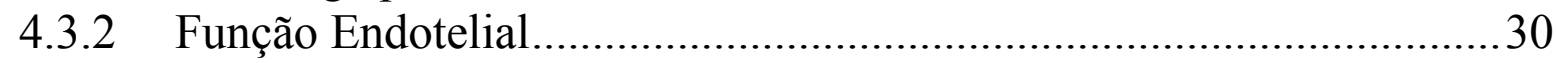

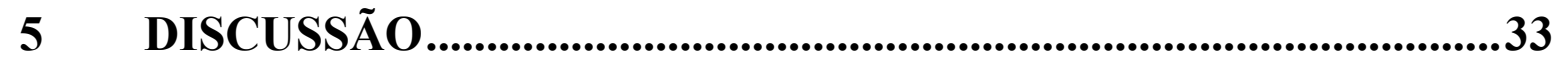

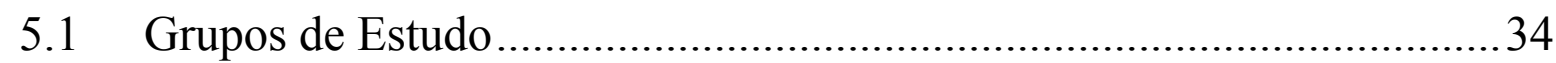

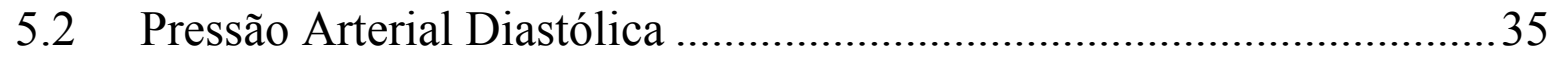

5.3 Variáveis Ecocardiográficas e Ventrículo-Radioisotópica .....................37

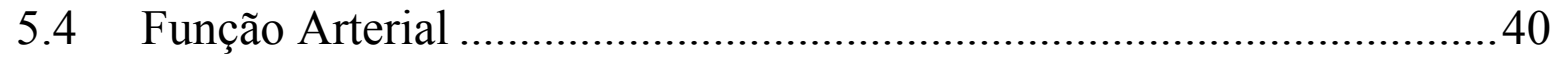

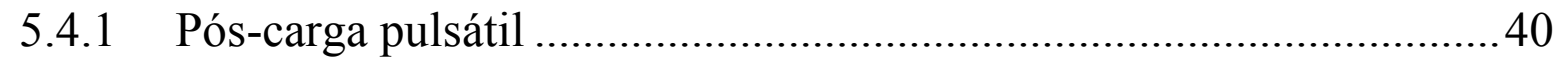

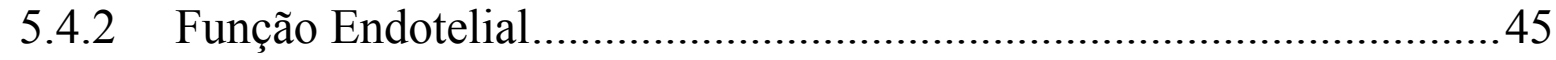

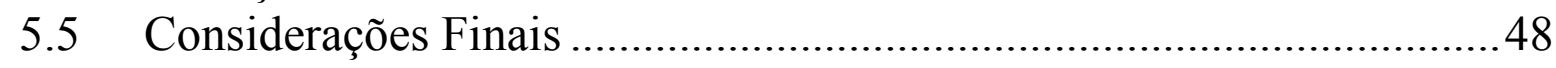

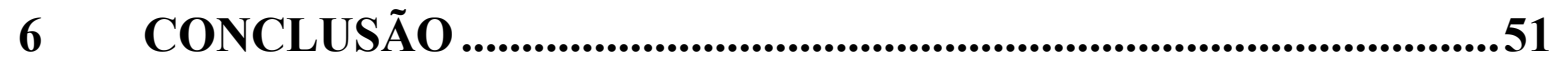

$7 \quad$ ANEXOS ..........................................................................................................53

8 REFERÊNCIAS BIBLIOGRÁFICAS............................................62 Apêndice 


\section{LISTA DE ABREVIATURAS}
AST área de seção transversa do vaso
$\Delta \mathbf{d} \quad$ fração de encurtamento do ventrículo esquerdo
Dd diâmetro diastólico
DDVE diâmetro diastólico final do ventrículo esquerdo
DFM dilatação fluxo-mediada
DNM dilatação nitrato-mediada
Ds diâmetro sistólico
DSVE diâmetro sistólico final do ventrículo esquerdo
FEVE fração de ejeção do ventrículo esquerdo
HAS hipertensão arterial sistêmica
IFS índice de fluxo sistólico
MPRÉ momento pré-operatório
M1 momento 1 mês após cirurgia
M3 momento 3 meses após cirurgia
M6 momento 6 meses após cirurgia
PAD pressão arterial diastólica
PAS pressão arterial sistólica
SC superfície corporal
Vmáx velocidade máxima de fluxo 


\section{LISTA DE FIGURAS}

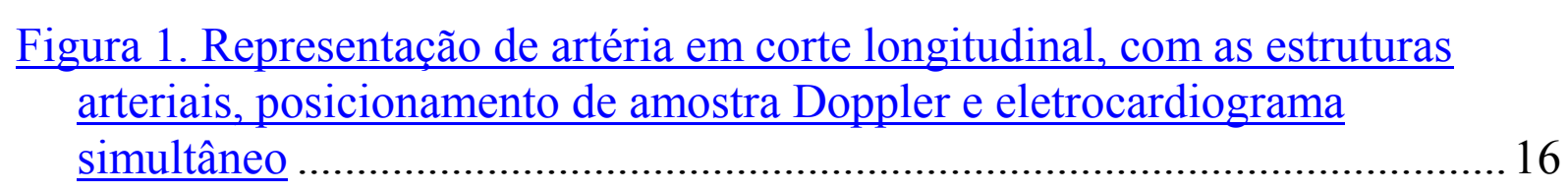

Figura 2. Representacão de artéria carótida comum em corte longitudinal e registro eletrocardiográfico, delimitando fronteiras para a medida do diâmetro diastólico.....

Figura 3. Representação da curva de variação da velocidade do fluxo arterial com delineamento do pico sistólico............................................................ 19

Figura 4. Representação da curva de variação da velocidade do fluxo arterial com delineamento do pico sistólico após liberação da oclusão .....................

Figura 5. Representação fotográfica da artéria carótida comum em corte longitudinal, delimitando fronteiras para a medida do diâmetro vascular na condição BASAL 1 . ...............................................................................

Figura 6. Representação fotográfica da curva de variação da velocidade do fluxo braquial com delineamento do pico sistólico após liberacão da oclusão na condição DFM................................................................................. 


\section{LISTA DE QUADROS}

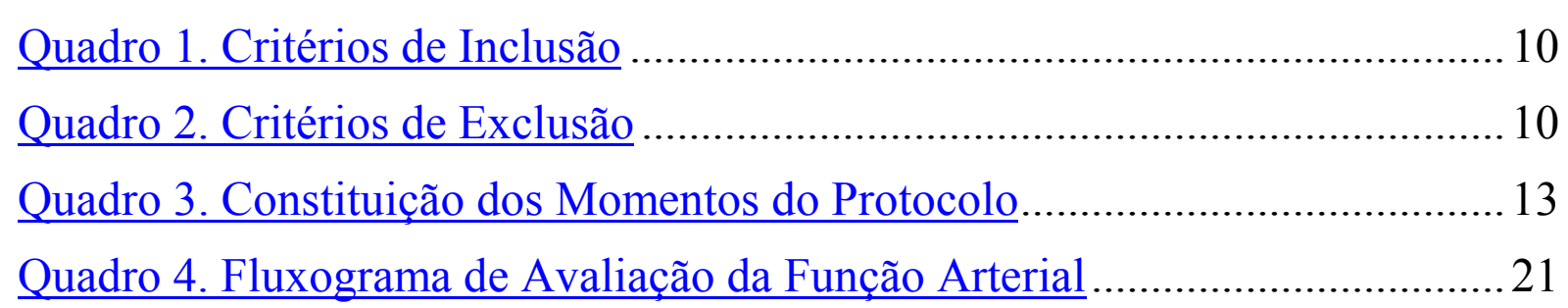




\section{LISTA DE GRÁFICOS}

Gráfico 1. Pressão arterial diastólica média em cada grupo, nos diversos

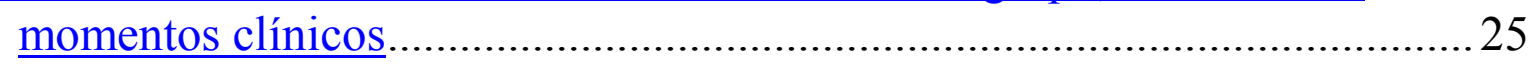

Gráfico 2. Diâmetro sistólico médio do ventrículo esquerdo em cada grupo, no

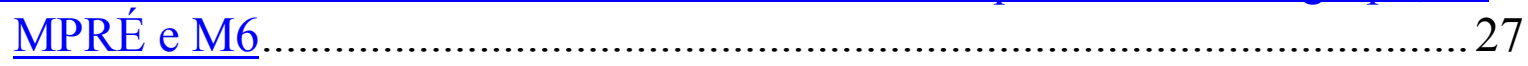

Gráfico 3. Relação entre o diâmetro sistólico médio do ventrículo esquerdo e a superfície corporal de cada grupo, no MPRÉ e M6 ........................................ 27

Gráfico 4. Diâmetro diastólico médio do ventrículo esquerdo em cada grupo, no

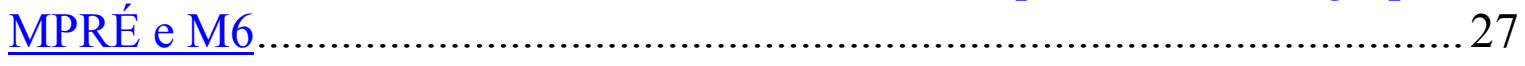

Gráfico 5. Relação entre o diâmetro diastólico médio do ventrículo esquerdo e a superfície corporal de cada grupo, no MPRÉ e M6 .................................... 77

Gráfico 6. Fração de encurtamento média do ventrículo esquerdo em cada grupo, no MPRÉ e M6 ......................................................................... 8

Gráfico 7. Fracão de ejecão média do ventrículo esquerdo em cada grupo, no

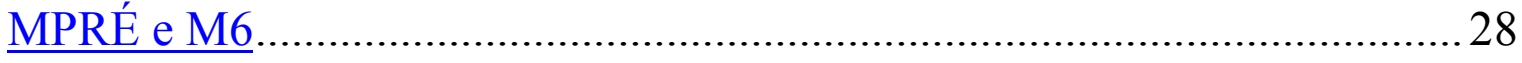

Gráfico 8. Complacência média em cada grupo, no MPRÉ e M6..................... 9

Gráfico 9. Distensibilidade média em cada grupo, no MPRÉ e M6 ................. 9

Gráfico 10. Variação percentual do diâmetro médio da artéria braquial em cada grupo, nas condições analisadas, no MPRÉ e M6 .................................... 30

Gráfico 11. Índice de fluxo sistólico braquial médio em cada grupo, nas condições analisadas, no MPRE e M6 ................................................ $\beta 1$ 


\section{LISTA DE TABELAS}

Tabela 1 - Características clínicas dos grupos $\mathrm{G}>50$ e $\mathrm{G}<50$ no pré-operatório.

Tabela 2. Pressão arterial diastólica média dos grupos $\mathrm{G}>50$ e $\mathrm{G}<50$ nos momentos clínicos analisados............................................................

Tabela 3 - Variáveis ecocardiográficas e ventrículo-radioisotópica dos grupos G>50 e G<50 no MPRÉ E M6 .............................................................. 6

Tabela 4 - Pós-carga pulsátil arteriais dos grupos G $>50$ e $\mathrm{G}<50$ no MPRÉ e Mb

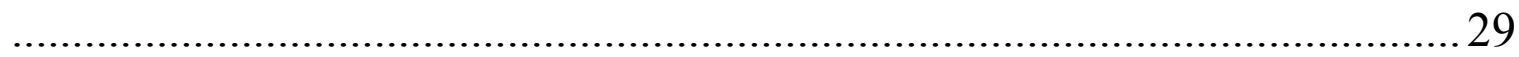

Tabela 5 - Variação percentual do diâmetro da artéria braquial dos grupos

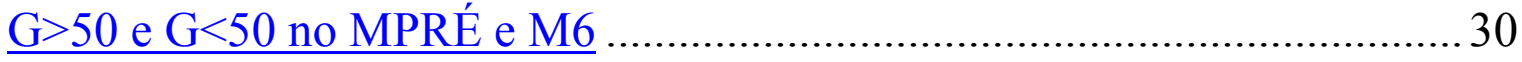

Tabela 6 - Índice de fluxo sistólico da artéria braquial dos grupos G $>50$ e G $<50$ ho MPRÉ e M6....................................................................................... $\$ 1$ 


\section{RESUMO}

CASTRO RC. Circulação periférica em pacientes com insuficiência aórtica crônica e indicação de troca valvar. São Paulo: Tese (Doutorado) Universidade de São Paulo; 2005.

Introdução: Percentual expressivo das informações sobre a sobrevida de pacientes com insuficiência aórtica é proveniente apenas da participação do ventrículo esquerdo, inexistindo definição quanto ao papel da chamada função arterial. Consequiência da conveniência em se utilizar exames de baixo risco e da dificuldade na interpretação da pós-carga pelos métodos tradicionais. $\mathrm{O}$ recente aperfeiçoamento da ultra-sonografia permitiu de forma direta e acurada a análise estrutural e funcional do vaso, não havendo sido testada neste modelo.

Casuística e Métodos: Estudamos 36 pacientes com insuficiência aórtica sintomática e indicação de troca valvar, divididos em um grupo com pressão arterial diastólica (PAD) superior a $50 \mathrm{mmHg}(\mathrm{G}>50)$ e outro com $\mathrm{PAD}$ inferior a $50 \mathrm{mmHg}(\mathrm{G}<50)$. Os pacientes foram avaliados no pré-operatório imediato e seis meses após a cirurgia. A função arterial compreendeu a análise da complacência, da distensibilidade, e da função endotelial pela dilatação fluxo-mediada (\%DFM) - endotélio-dependente - e nitrato-mediada (\%DNM) endotélio-independente -, obtidas por ultra-sonografia de alta resolução.

Objetivos: Avaliar em portadores de insuficiência aórtica crônica sintomática em classe funcional II para insuficiência cardíaca e indicação de troca valvar o comportamento de póscarga pulsátil das artérias elásticas e a função endotelial.

Resultados: A complacência no pré-operatório ( $\mathrm{G}>50=7,03 \pm 2,82 ; \mathrm{G}<50=13,73 \pm 5,18 \mathrm{~N}^{-}$ $\left.{ }^{1} \mathrm{~m}^{4} 10^{-10}\right)$ e pós $\left(\mathrm{G}>50=5,33 \pm 2,39 ; \mathrm{G}<50=7,28 \pm 4,61 \mathrm{~N}^{-1} \mathrm{~m}^{4} 10^{-10}\right)$, e a distensibilidade no pré $\left(\mathrm{G}>50=19,55 \pm 10,30 ; \mathrm{G}<50=49,23 \pm 24,18 \mathrm{~N}^{-1} \mathrm{~m}^{4} 10^{-10}\right)$ e pós $(\mathrm{G}>50=15,72 \pm 7,80$; $\left.\mathrm{G}<50=25,78 \pm 16,88 \mathrm{~N}^{-1} \mathrm{~m}^{4} 10^{-10}\right)$ foram maiores no grupo $\mathrm{G}<50(\mathrm{p}<0,001)$. A \%DFM no pré e no pós-operatório do $\mathrm{G}>50(3,59 \pm 3,72$ e $4,85 \pm 4,91)$ e do $\mathrm{G}<50(5,43 \pm 5,54 ; 7,15 \pm 6,82)$ foram baixas e a $\% \mathrm{DNM}$ no pré e pós do $\mathrm{G}>50(6,58 \pm 7,48 ; 10,51 \pm 9,61)$ e do $\mathrm{G}<50$ $(7,25 \pm 6,30 ; 11,53 \pm 10,19)$ foram normais, sem evidência de diferença de comportamento entre os momentos avaliados $(\mathrm{p}=0,6866)$.

Conclusão: A complacência e a distensibilidade foram maiores no grupo com menor PAD. A complacência e a distensibilidade arterial diminuíram após a correção cirúrgica da insuficiência aórtica em ambos os grupos, e de forma mais importante no grupo $\mathrm{G}<50$. A disfunção endotelial foi presente em insuficiência aórtica crônica sintomática independente do nível da pressão arterial diastólica e persistiu ao menos até o $6^{\circ}$ mês após a cirurgia.

Palavras-Chave: insuficiência aórtica, complacência, distensibilidade, função endotelial. 


\section{SUMMARY}

CASTRO RC. Peripheral circulation in patients with chronic aortic insufficiency and valve replacement indication. São Paulo: Thesis (Doctorate) University of São Paulo; 2005.

Introduction: A significant percentage of information about the outlive of patients with aortic insufficiency derives only from the action of the left ventricle without definition of the arterial function. Results from the convenience of using low risk examinations and the difficulty of interpreting the after-load by traditional methods. The recent improvement of ultrasonography made possible a direct, accurate, functional and structural analysis of the vessel, yet to be tested in this disease.

Methods: 36 patients with symptomatical AI and in need of valve replacement were analyzed. One group had diastolic blood pressure (DBP) above $50 \mathrm{mmHg}(\mathrm{G}>50)$ and the other one below $50 \mathrm{mmHg}(\mathrm{G}<50)$. The patients were checked twice: immediately before the surgery and six months after it. The arterial function comprised the analysis of compliance and distensibility, and the evaluation of the endothelial function through the flow-mediated dilatation (\%DFM) -endothelium dependent- and nitrate-mediated dilatation (\%DNM) endothelium independent- obtained by means of high resolution ultrasound.

Objectives: To analyze the behavior of the pulsatile afterload and endothelial function in symptomatic chronic aortic insufficiency patients with class II for heart failure and surgical indication for valve replacement.

Results: The compliance in the pre $\left(\mathrm{G}>50=7.03 \pm 2.82 ; \mathrm{G}<50=13.73 \pm 5.18 \mathrm{~N}^{-1} \mathrm{~m}^{4} 10^{-10}\right)$ and in the post-op $\left(\mathrm{G}>50=5.33 \pm 2.39 ; \mathrm{G}<50=7.28 \pm 4.61 \mathrm{~N}^{-1} \mathrm{~m}^{4} 10^{-10}\right)$, and distensibility in the pre $\left(\mathrm{G}>50=19.55 \pm 10.30 ; \mathrm{G}<50=49.23 \pm 24.18 \mathrm{~N}^{-1} \mathrm{~m}^{4} 10^{-10}\right)$ and in the post-op $(\mathrm{G}>50$ $\left.=15.72 \pm 7.80 ; \mathrm{G}<50=25.78 \pm 16.88 \mathrm{~N}^{-1} \mathrm{~m}^{4} 10^{-10}\right)$ were higher in group $\mathrm{G}<50(\mathrm{p}<0.001)$. The $\% \mathrm{DFM}$ in the pre and post-op of group $\mathrm{G}>50(3.59 \pm 3.72 ; 4.85 \pm 4.91)$ and group $\mathrm{G}<50$ $(5.43 \pm 5.54 ; 7.15 \pm 6.82)$ was low, and the \%DNM in the pre and post-op of group G>50 $(6.58 \pm 7.48 ; 10.51 \pm 9.61)$ and group $\mathrm{G}<50(7.25 \pm 6.30 ; 11.53 \pm 10.19)$ was normal, with no difference of behavior between the two time points $(\mathrm{p}=0.6866)$.

Conclusion: The compliance and distensibility were higher among the group with lower DBP. Both decreased after surgical correction in the two groups, more importantly in group $\mathrm{G}<50$. Endothelial dysfunction was present in chronic aortic insufficiency no matter the level of diastolic blood pressure and persisted until six months after surgery.

Key words: aortic insufficiency, compliance, distensibility, endothelial function. 
A insuficiência aórtica crônica é valvopatia com fisiopatologia complexa em decorrência da associação de sobrecargas de volume e pressão (Forman et al., 1980). Ela apresenta expressiva repercussão hemodinâmica com evolução prolongada em decorrência de eficiente conjunto de adaptações cardíacas - expressas como remodelação do ventrículo esquerdo - e nãocardíacas - com destaque para a circulação periférica (Wisenbaugh et al., 1984; Ross, 1985).

A compreensão da integração entre os mecanismos, cardíacos e não-cardíacos, de adaptação facilita a aplicação de estratégias diagnósticas que visam decisões terapêuticas a cada momento de sua história natural.

Percentual expressivo das informações sobre sintomas e sobrevida advém somente da participação do mecanismo cardíaco. Não há igual atenção sobre a circulação periférica, mesmo sendo o coração unido à árvore aórtica para formar o sistema circulatório e ela interferir no componente pulsátil do fluxo sangüíneo, na diminuição do gradiente de pressão diastólico, na abertura precoce da valva aórtica, na redução da pós-carga do ventrículo esquerdo e, por conseguinte, no seu desempenho (Ross, 1976; Weaver et al., 1977).

Este fato é conseqüência da conveniência em se utilizar exames de baixo risco no seguimento desses pacientes e da dificuldade na interpretação da pós-carga pelos métodos tradicionais, que avaliam seu componente não-pulsátil; pois a resistência periférica é usualmente medida de maneira invasiva, calculada 
em função da média da pressão aórtica e do débito cardíaco (Stevenson \& Fonarow, 1992), que não é constante através do ciclo cardíaco na regurgitação aórtica, em que durante a diástole, mas não na sístole, um conduto é aberto através da valva insuficiente (Welch et al., 1957).

A pós-carga pulsátil tem demonstrado constância e correlação estreita com a resistência sistêmica, responde a alterações patológicas precocemente, antes mesmo da resistência periférica, e parece ser a melhor forma de se avaliar os pacientes com insuficência aórtica por desempenhar a função de elo no acoplamento entre o ventrículo esquerdo e a circulação periférica, mesmo em valvopatas (Merillon et al., 1978; Eaton et al., 1993; Razzolini et al., 1999). É caracterizada pelo conceito de distensibilidade e complacência arterial, ou seja, a variação de diâmetro sofrida por um grande vaso frente a uma variação de pressão transmural sobre suas paredes, determinada pelos componentes estruturais da parede arterial e pelo tônus da musculatura lisa (Van Merode et al., 1988).

Normalmente, encontra-se nesses pacientes um incremento na complacência arterial (Kopel et al., 2001), que se acredita ser um mecanismo compensatório capaz de diminuir o fluxo regurgitante e melhorar o desempenho cardíaco (Greenberg et al.,1981). De maneira contraditória, há também relatos de valores inadequadamente normais (Razzolini et al., 1994), que possivelmente poderiam corresponder a indivíduos de uma faixa etária mais avançada pela redução no conteúdo vascular de elastina e aumento do colágeno (Kelly et al., 1989; Safar et al., 1992; Gerhard et al., 1996), ou a portadores de tônus vascular aumentado em decorrência da incapacidade de vasodilatação adequada (Yin \& Ting, 1992; Avolio et al., 1985). 
Os componentes da parede vascular - endotélio, músculo liso, fibroblastos, fibras elásticas e colágeno - relacionam-se em um complexo sistema de interações de forma a conferir aos vasos sensibilidade às mudanças teciduais, promovendo transformações adaptativas através da produção de mediadores químicos (Hirschi et al., 2002). Dentre todos estes, o endotélio é considerado o elemento mais importante do sistema vascular. Produtor do denominado fator de relaxamento endotelial (EDRF), ele apresenta papel significativo no controle do tônus vasomotor (Furchgott \& Zawadzki, 1980).

A estimulação crônica das células endoteliais pelo estresse de cisalhamento e fluxo exacerbados resulta em dano à função endotelial, prejudicando a capacidade das células endoteliais em produzir agentes vasodilatadores ou levando-as a um aumento na formação de vasoconstritores (Johns, 1991). A lesão do endotélio resulta em elevação do tônus vasomotor, formação de tampões hemostáticos e reparação vascular. As células endoteliais regeneradas que repõem o endotélio desnudado não apresentam função normal e respondem de forma diferente do endotélio intacto a fatores vasoativos (Vapaatalo et al., 2001; Ali et al., 2002). Portanto, em condições patológicas onde a resposta vascular frente a estímulos esteja alterada, ocorrem também mudanças na pós-carga pulsátil (Katz et al., 1992; Lage et al., 1994; Ramsey et al., 1995).

Uma vez caracterizada a importância da pós-carga pulsátil e da função endotelial, cumpre analisar quais métodos poderiam ser de fato úteis e eficazes no dia-a-dia do seguimento de portadores de insuficência aórtica.

Diversos modelos foram empregados, incluindo a velocidade de transmissão da onda de pressão de pulso, a medida simultânea de pressão 
arterial e fluxo sangüíneo com derivação de impedância arterial, a análise matemática do decaimento da curva de pressão arterial e reflexão de onda (Milnor, 1975; Pepine et al., 1978; Merrilon et al., 1984; Finkelstein et al., 1985; Laskey et al., 1990; Finkelstein et al., 1992), e a utilização do Doppler pulsátil (Safar et al., 1981; Hoeks et al., 1985; Hoeks et al., 1992).

$\mathrm{O}$ recente aperfeiçoamento das imagens arteriais bidimensionais obtidas por ultra-sonografia de alta resolução aliada ao sistema Doppler (Barber et al., 1974), ao contrário dos anteriores, permitiu de forma acurada, através do diâmetro arterial e da espessura da parede de grandes artérias superficiais nas condições de expansão sistólica e de relaxamento diastólico, a análise estrutural e funcional do vaso com melhor entendimento das alterações hemodinâmicas (Lage et al., 1994; Kopel \& Lage, 1995). Por este método, a complacência e distensibilidade arterial têm sido acessadas de forma direta e não-invasiva na artéria carótida e a função endotelial pela dilatação fluxo-mediada na artéria braquial (Safar et al., 1981; Laurent et al., 1990).

Estudos clínicos e experimentais têm avaliado a função endotelial em indivíduos normais e portadores de diversas nosologias, principalmente no que diz respeito à liberação de fatores vasodilatadores, como o EDRF, recentemente aceito como sendo o óxido nítrico, ou outro composto nitrogenado muito próximo (Vallance et al., 1989; Lowendtein et al., 1994). A vasodilatação fluxo-mediada das artérias de condutância é um processo fisiológico que permite a esses vasos acomodar alterações de fluxo por meio de aumento de seu diâmetro e requer, para isto, integridade endotelial (Rubanyi et al., 1986; Griffith et al., 1987), não havendo sido ainda testada no modelo de insuficência aórtica. 
Uma recente contribuição ao conhecimento da participação da circulação periférica na insuficência aórtica resultou da comparação entre 14 pacientes assintomáticos e sintomáticos em nossa instituição, observando-se relação inversa entre nível de distensibilidade arterial e manifestação de sintomas, transformando-se em um dos fatores de influência da desadaptação clínica nos portadores de insuficência aórtica crônica (Kopel et al., 2001).

Seguindo a mesma linha de raciocínio, o entendimento da influência da função arterial, que corresponde ao conjunto da pós-carga pulsátil e da função endotelial, poderia permitir nestes pacientes $o$ futuro monitoramento e intervenção precoce com o fim de alcançar um acoplamento arterial ótimo, retardo na necessidade de cirurgia pela demora no desenvolvimento de sintomas e no estabelecimento da disfunção cardíaca (Greenberg et al., 1981; Sconamiglio et al., 1994).

Revisão extensa da literatura indicou não existir nenhuma definição quanto ao seu papel nesta população de forma prospectiva, considerando-se o aumento na pós-carga como fator conhecido no desencadeamento da descompensação dos pacientes com refluxo aórtico (Welch et al.,1957).

Este estudo representa a primeira investigação da função arterial nestes casos, utilizando-se de técnica não-invasiva e de boa reprodutibilidade. 


\section{OBJETIVOS}


Avaliar em portadores de insuficência aórtica crônica em classe funcional II para insuficiência cardíaca e indicação de troca valvar:

1. O comportamento da pós-carga pulsátil das artérias elásticas;

2. A função endotelial pela vasodilatação fluxo-mediada das artérias de condutância. 
3 CASUÍSTICA E MÉTODOS 
O protocolo de estudo foi aprovado pela Comissão de Ética para análise de projetos de pesquisa do Hospital das Clínicas da Faculdade de Medicina da Universidade de São Paulo. Antes de seu início, obteve-se de cada paciente o consentimento pós-informação.

\subsection{Critérios de Inclusão}

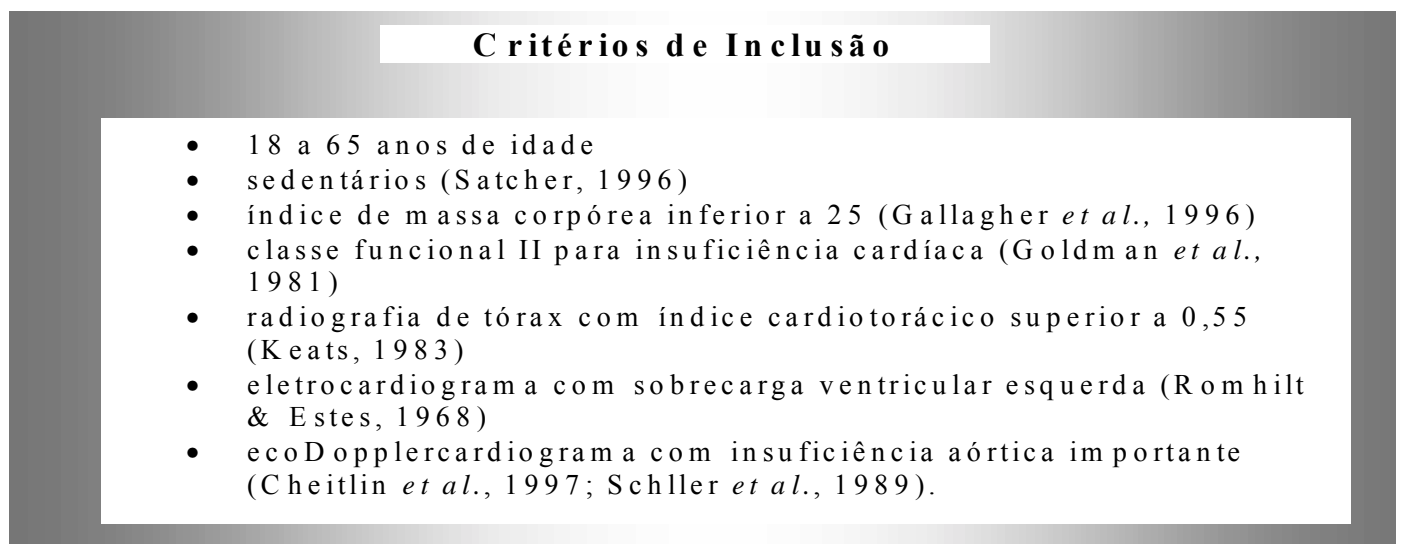

QUADRO 1. Critérios de Inclusão

\subsection{Critérios de Exclusão}

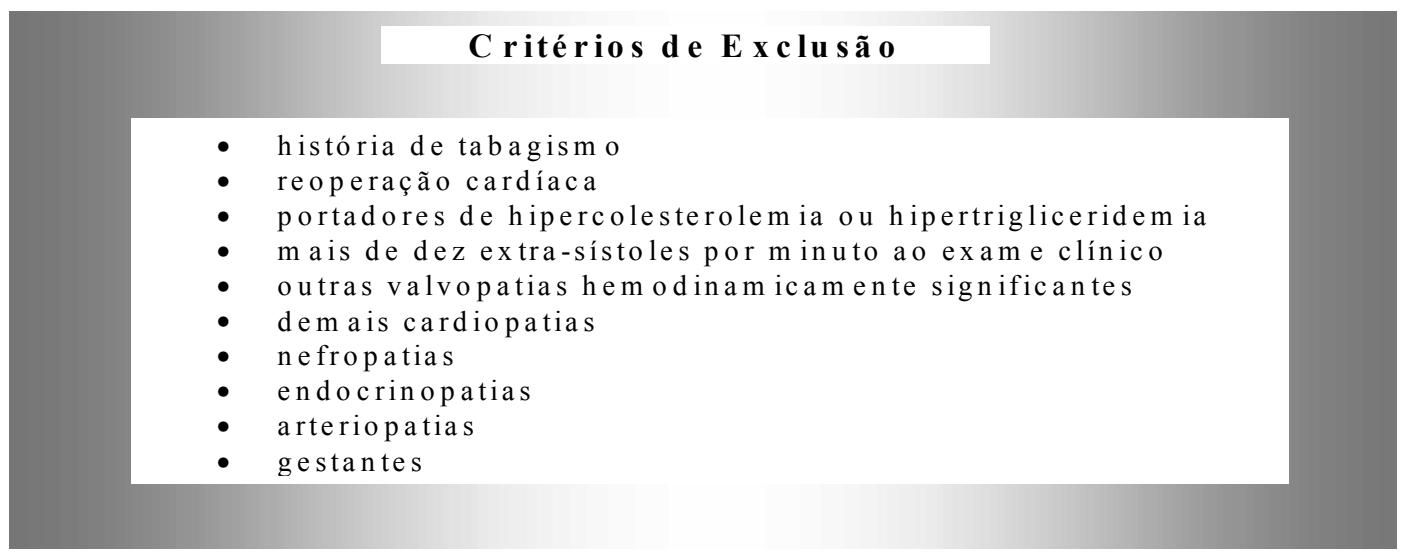

QUADRO 2. Critérios de Exclusão 


\subsection{Protocolo de Estudo}

Foram estudados prospectivamente pacientes com insuficência aórtica crônica sintomática e indicação cirúrgica para troca valvar, selecionados de maneira consecutiva no Ambulatório da Unidade Clínica de Valvopatias do Instituto do Coração, de 15 de janeiro de 2002 a 15 de janeiro de 2003.

A coleta de dados foi realizada através de anamnese direcionada à obtenção de informações sobre a idade, sexo, cor e antecedente familiar de hipertensão arterial sistêmica.

Procedeu-se à avaliação pré-operatória da pressão arterial, ecocardiográfica, ventrículo-radioisotópica e da função arterial após a suspensão de qualquer medicamento com ação cardiovascular específica, pelo tempo de quatro vezes a sua meia-vida. A avaliação da pressão arterial e da função arterial foi efetuada pelo mesmo observador, e as demais por dois médicos cegos quanto aos grupos, especialistas nas respectivas áreas e, em caso de discordância, por um terceiro profissional da mesma instituição, prevalecendo a opinião da maioria na falta de consenso.

Visando reconhecer distintos comportamentos da circulação periférica, separou-se os pacientes em dois grupos de acordo com o registro da média da pressão diastólica obtida durante a avaliação da pressão arterial no pré-operatório (de Andrade et al., 1985). O grupo G>50 englobou aqueles com média igual ou superior a $50 \mathrm{mmHg}$, e o grupo $\mathrm{G}<50$ os que a mantinham em nível inferior a $50 \mathrm{mmHg}$.

Todos os pacientes foram pesados e medidos em aparelho da marca Filizola, modelo Personal Line, aferido pelo Instituto Nacional de Pesos e 
Medidas, para a obtenção da superfície corporal (DuBois \& DuBois, 1916) empregada no cálculo de variáveis de exames de cardioimagem no dia de sua execução.

A indicação de cirurgia obedeceu às normas da Unidade Clínica de Valvopatias do Instituto do Coração (Pomerantzeff et al., 1997).

Os pacientes foram seguidos no pós-operatório com retorno ambulatorial ao fim do $1^{\circ}, 3^{\circ}$ e $6^{\circ}$ mês. Este intervalo foi estipulado considerando-se período mínimo admitido para regressão de parâmetros préoperatórios e recuperação da agressão cirúrgica (Gaasch et al., 1978; Bonow et al., 1985; Krayenbuehl et al., 1989).

A avaliação da pressão arterial foi realizada periodicamente em todos os retornos dos pacientes, enquanto as avaliações ecocardiográfica, ventrículo-radioisotópica e da função arterial foram repetidas ao fim do $6^{\circ}$ mês.

Portanto, o protocolo caracterizou quatro momentos básicos para comparação entre pontos de evolução de cada grupo:

- Momento Pré-operatório (MPRÉ) - avaliação pré-operatória

- Momento 1 (M1) - avaliação ao fim do $1^{\circ}$ mês após cirurgia

- Momento 3 (M3) - avaliação ao fim do $3^{\circ}$ mês após cirurgia

- Momento 6 (M6) - avaliação ao fim do $6^{\circ}$ mês após cirurgia 


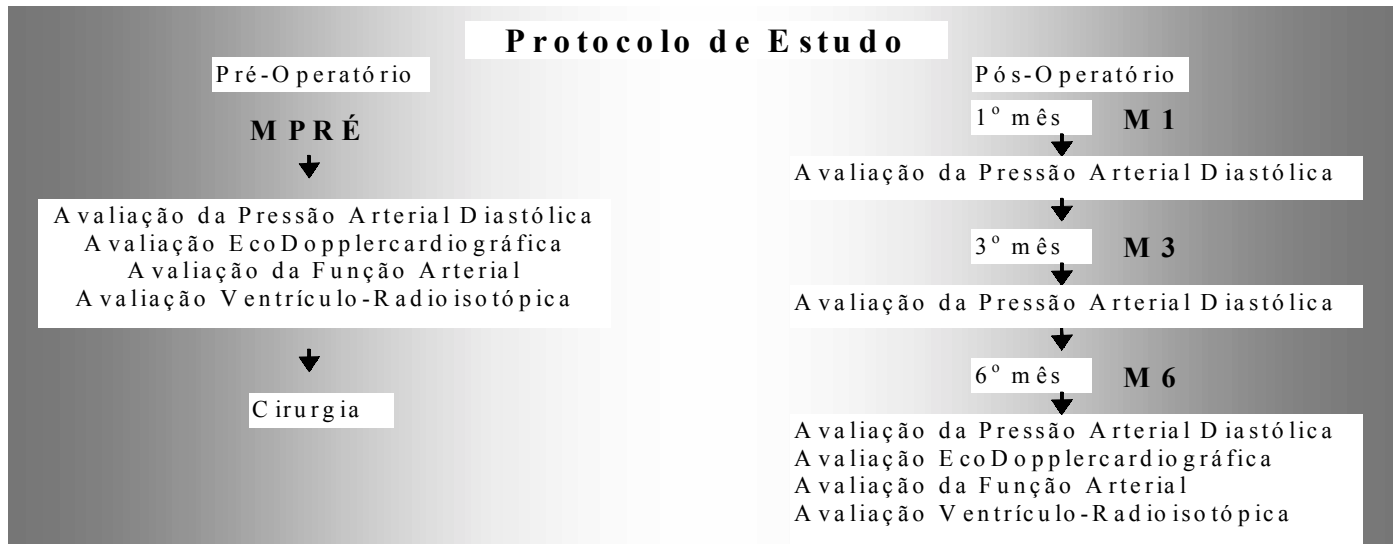

QUADRO 3. Constituição dos Momentos do Protocolo

\subsubsection{Avaliação da Pressão Arterial Diastólica}

A pressão arterial diastólica correspondeu à média de três registros em ambos os membros superiores por três dias consecutivos pela manhã, após quinze minutos de repouso em decúbito à $45^{\circ}$ e com o braço apoiado na altura do coração (Pickering, 1994). O valor considerado foi o verificado na quarta fase de Korotkoff pelo modo auscultatório na fossa antecubital (Weber et al., 1999), com manômetro de coluna de mercúrio da marca K. Takaoka, modelo 203 para adultos.

\subsubsection{Avaliação Ecocardiográfica}

O exame de ecocardiografia transtorácica em repouso utilizou equipamento da marca GE, modelo System Five com transdutor de 1,5 a 3,6 $\mathrm{MHz}$, bidimensional a cores. As interpretações foram feitas segundo as recomendações da Sociedade Americana de Ecocardiografia (Cheitlin et al., 1997; Schller et al., 1989) e houve particular interesse nas variáveis descritas na literatura em trabalhos prospectivos como preditoras de função do ventrículo 
esquerdo em insuficência aórtica crônica após a troca da valva (Kumpuris et al., 1982; Gaasch et al., 1983; Stone et al., 1984; Bonow et al., 1985, 1988) :

- diâmetro sistólico e diastólico final da cavidade do ventrículo esquerdo (DSVE e DDVE),

- relação entre o diâmetro sistólico e diastólico final da cavidade do ventrículo esquerdo e a superfície corporal (DSVE/m2 e DDVE/m2),

- e fração de encurtamento do ventrículo esquerdo $(\Delta \mathrm{d})$.

\subsubsection{Avaliação Ventrículo-Radioisotópica}

O estudo ventrículo-radioisotópico foi efetuado em repouso pela administração venosa de agente redutor (cloreto estanoso - pirofosfato), seguida pela administração de $740 \mathrm{MBq}(20 \mathrm{mCi})$ de pertecnetato de sódio $-{ }^{99 \mathrm{~m}} \mathrm{Tc}$, com o objetivo de realizar a marcação in vivo de hemácias (Ashuurn et al., 1978; Borer et al., 1984). A seguir, realizou-se ventriculografia com o uso de câmara de cintilação de pequeno campo de visão, da marca Siemens, modelo Lem Plus, dotada de um colimador com furos paralelos, de baixa energia e média sensibilidade, acoplada a um computador modelo Max Delta.

As imagens foram produzidas com o paciente deitado, na projeção oblíqua anterior esquerda, no intuito de se ter melhor distinção entre o ventrículo esquerdo e direito. Elas foram analisadas por meio da aquisição seqüencial de vários ciclos cardíacos sucessivamente sobrepostos, até se obter quadros com cerca de 300 mil contagens por intervalo, em matriz de computador de 64 por 64 elementos ("pixels"). Pela monitorização eletrocardiográfica, foram desconsiderados os batimentos irregulares e o processamento das imagens pode ser executado pela aplicação de um filtro 
espacial ("9-point") e temporal, com a delimitação manual das áreas de interesse sobre o ventrículo esquerdo nas fases diastólica e sistólica máximas, utilizandose das imagens de fase e amplitude do estudo.

O cálculo da fração de ejeção do ventrículo esquerdo foi, então, possível por meio da relação dos valores de contagem radioativa encontrada nas áreas de interesse previamente identificadas com a subtração da radiação de fundo (Ashurn et al., 1978; Boucher et al., 1980).

\subsubsection{Avaliação da Função Arterial}

Realizou-se sempre durante o período da manhã, após jejum absoluto e repouso de 8 horas, seguido por dez minutos de descanso desde a entrada no laboratório e o início do exame, em posição supina, num ambiente silencioso, com pouca iluminação, temperatura controlada à $25^{\circ} \mathrm{C}$ e sob monitorização eletrocardiográfica constante (Corretti et al., 2002). As mulheres envolvidas na pesquisa, que se encontravam no período da menacma, foram submetidas ao exame durante o período menstrual (Hashimoto et al., 1995).

A pressão arterial sistêmica foi aferida no membro superior, utilizando-se o método oscilométrico automático não-invasivo (Dinamap 1846, Critikon, Inc., Tampa, FL, USA), simultâneo à aquisição da imagem ultrasonográfica.

Um equipamento de ultra-sonografia de alta resolução vascular (Apogee-800 plus, ATL Inc., Bothell, WA, USA), com transdutor setorial de 5$10 \mathrm{MHz}$ e foco automático, foi utilizado para a aquisição de imagem arterial bidimensional em corte longitudinal e da curva de velocidade do fluxo sangüíneo, pelo Doppler. 
$\mathrm{O}$ transdutor foi posicionado à $90^{\circ}$ do vaso, de modo a permitir a visualização das camadas da parede arterial proximal e distal. A primeira linha ecogênica, da porção externa do vaso para o lúmen, representa a camada íntima, seguindo-se uma linha hipoecogênica referente à média e outra linha ecogênica relativa à adventícia.

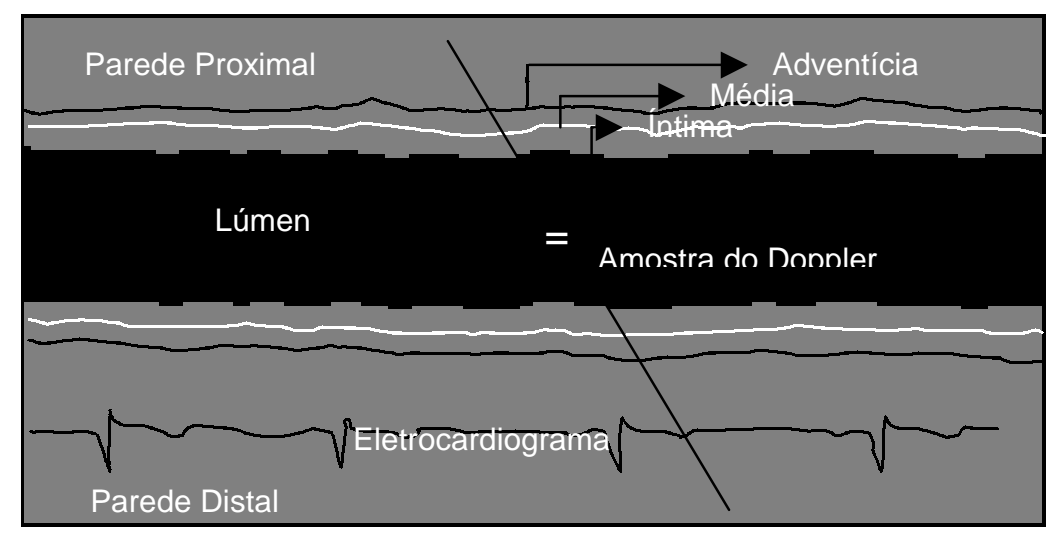

FIGURA 1. Representação de artéria em corte longitudinal, com as estruturas arteriais, posicionamento de amostra Doppler e eletrocardiograma simultâneo

As imagens obtidas foram acopladas ao registro simultâneo do sinal eletrocardiográfico e gravadas em fita de videocassete para seleção e digitalização, utilizando-se a interface MiroVideo DC30 plus (Pinnacle Systems, Sunnyvale, CA, USA) instalada em microcomputador (Pentium II 266) equipado com "video-frame grabber" (Willow Publishers VGA, Willow Peripherals, Inc., Bronx, NY, USA), com posterior determinação do diâmetro e fluxo arterial através de programa de computador desenvolvido no Instituto do Coração especificamente para esta finalidade (Gutierrez et al., 2002).

Em nosso laboratório, estima-se a reprodutibilidade interobservador e intra-observador deste método para a aferição do diâmetro arterial em $1,5 \pm 1,0 \%$ e $1,0 \pm 0,8 \%$, respectivamente (Lage et al., 1993). 


\subsubsection{Pós-carga pulsátil}

Obteve-se duas medidas de diâmetro na condição basal da artéria carótida comum esquerda em sua porção cefálica (BASAL 1 e BASAL 2), cerca de $1 \mathrm{~cm}$ abaixo da bifurcação. Com base no registro eletrocardiográfico, foram selecionadas, para cada uma, três imagens (três batimentos distintos) no momento da expansão sistólica ou de maior diâmetro, correspondente aos primeiros $70 \mathrm{~ms}$ da onda $T$, e três imagens (três batimentos distintos) no momento do relaxamento diastólico ou de menor diâmetro, correspondente ao pico da onda $R$. Uma vez feita a calibração em uma das imagens selecionadas, um algoritmo automático identifica as fronteiras entre as camadas média e íntima na parede proximal e entre a luz e a íntima na parede distal, passando-se então a medir o diâmetro arterial pela distância em milímetros das duas fronteiras.

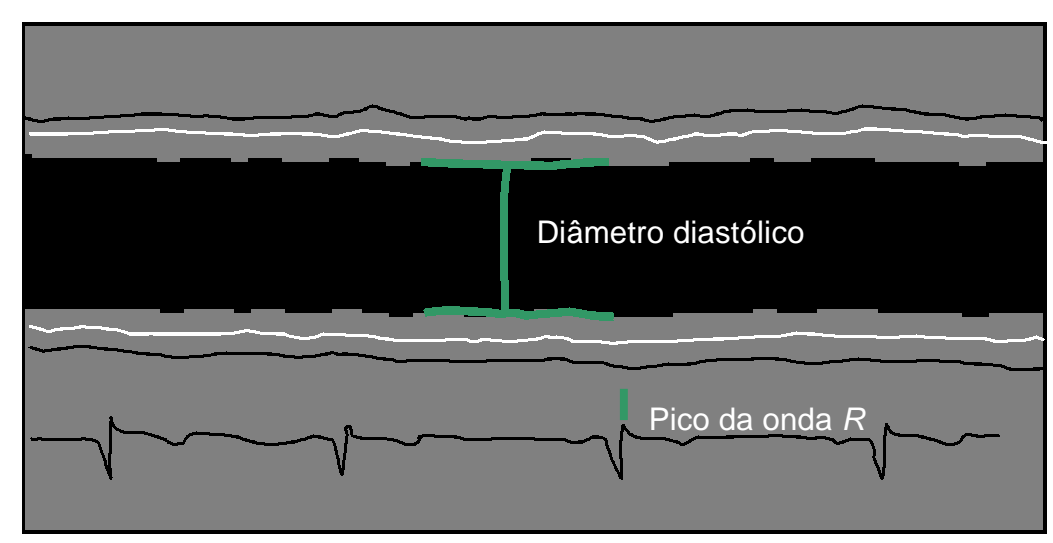

FIGURA 2. Representação de artéria carótida comum em corte longitudinal e registro eletrocardiográfico, delimitando fronteiras para a medida do diâmetro diastólico

A partir da média destas medidas, foram calculadas a complacência e a distensibilidade da artéria carótida comum, de acordo com as seguintes fórmulas (Van Merode et al., 1988): 


$$
\text { Complacência }=\frac{(D s-D d) / D d}{2(P A S-P A D)} \cdot \pi \cdot D d^{2} \cdot 10 \quad\left(\mathrm{~N}^{-1} \cdot \mathrm{m}^{4} \cdot 10^{-10}\right)
$$

Distensibilidade $=2(D s-D d) / D d$

$$
P A S-P A D
$$$$
\left(\mathrm{N}^{-1} \cdot \mathrm{m}^{2} \cdot 10^{-6}\right)
$$

Onde: Ds = diâmetro sistólico da artéria carótida comum ( $\mathrm{mm})$; Dd = diâmetro diastólico da artéria carótida comum $(\mathrm{mm}) ; \mathrm{PAS}=$ pressão arterial sistólica $(\mathrm{mmHg}) ; \mathrm{PAD}=$ pressão arterial diastólica $(\mathrm{mmHg})$.

\subsubsection{Função endotelial}

\section{BASAL}

O diâmetro da artéria braquial esquerda foi obtido com o mesmo transdutor, em freqüência mais alta do que na carótida comum, posicionado aproximadamente $5 \mathrm{~cm}$ distal à prega cutânea antecubital, tendo o membro superior à altura do coração. A fim de garantir que se obtivessem imagens de um segmento reto, em alguns casos se moveu o transdutor no sentido longitudinal da artéria até cerca de 4 a $5 \mathrm{~cm}$ antes da bifurcação da artéria no cotovelo.

O método de análise foi semelhante à da artéria carótida comum, com obtenção de uma medida na condição BASAL da artéria.

Através da imagem bidimensional, posicionou-se a amostra de Doppler pulsátil em posição central na luz da artéria braquial, selecionando-se uma curva de calibração e cinco curvas (cinco batimentos distintos) de velocidade de fluxo. Por meio do programa já mencionado, o observador delineou o pico da velocidade sistólica. Uma vez feita a calibração em uma das imagens selecionadas, a quantificação da velocidade sistólica máxima foi realizada empregando-se um algoritmo automático. A área de secção transversa 
e o índice de fluxo sistólico foram então calculados de acordo com as seguintes fórmulas (Van Merode et al., 1988):

$$
\begin{array}{lc}
\mathrm{AST}=\pi \cdot \text { raio }^{2} & \left(\mathrm{~mm}^{2}\right) \\
\mathrm{IFS}= & \mathrm{AST} \cdot \mathrm{Vmáx} \cdot 0,06 \\
\mathrm{SC} & \left(1 / \mathrm{min} / \mathrm{m}^{2}\right)
\end{array}
$$

Onde: AST = área de secção transversa do vaso, calculando o raio a partir do diâmetro sistólico; IFS = índice de fluxo sistólico; Vmáx = pico da velocidade sistólica (m/s); SC = superfície corporal $\left(\mathrm{m}^{2}\right) ; 0,06$ é fator de conversão necessário para conversão das unidades para $1 / \mathrm{min}$.

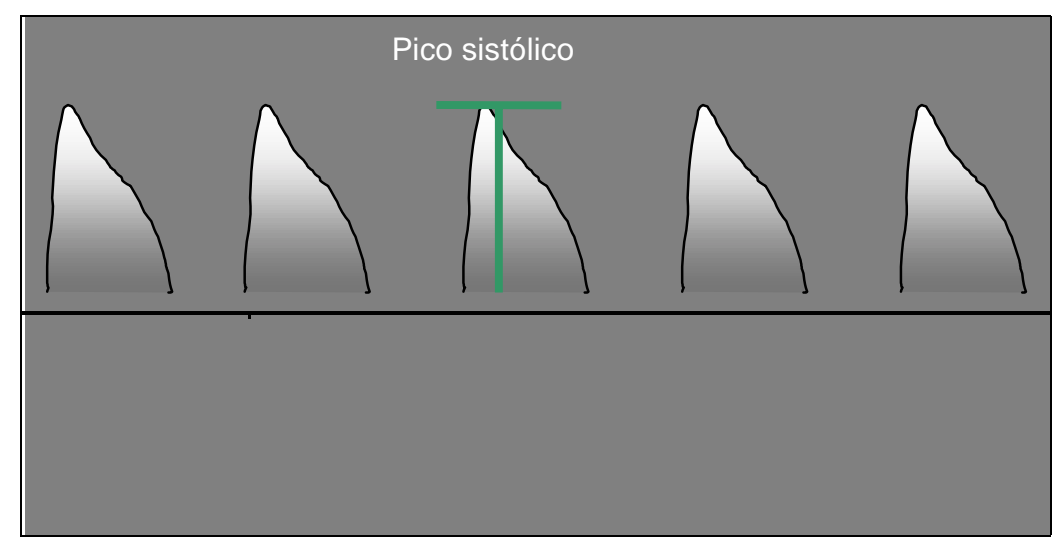

FIGURA 3. Representação da curva de variação da velocidade do fluxo arterial com delineamento do pico sistólico

\section{DILATAÇÃO FLUXO-MEDIADA}

A dilatação fluxo-mediada (DFM) é função endotélio-dependente. A indução de isquemia nos vasos de resistência ocasiona sua dilatação por mecanismos autoregulatórios. Cessada a isquemia, ocorre um aumento no fluxo dos vasos de condução (hiperemia reativa), que respondem à maior força de estresse por cisalhamento com liberação de óxido nítrico, aumentando o GMPc (3'5'-guanosina monofosfato cíclica) e por sua vez provocando o relaxamento da musculatura lisa adjacente (Celermajer, 1997).

A condição DFM compreendeu a avaliação do diâmetro e da velocidade de fluxo na artéria braquial, obtidos aos 5 minutos de insuflação 50 
$\mathrm{mmHg}$ acima da pressão sistólica de manguito para esfigmomanômetro pediátrico, colocado cerca de $2 \mathrm{~cm}$ abaixo da prega cutânea antecubital, seguida por deflação rápida. $\mathrm{O}$ transdutor de ultra-sonografia foi posicionado $8 \mathrm{~cm}$ acima do manguito e, uma vez liberada a oclusão, nesta fase se analisou apenas a curva de velocidade de fluxo do $1^{\circ}$ batimento e o diâmetro nos 60 segundos subseqüentes, quando ocorrem os respectivos picos de aumento (Arwood et al., 1998).

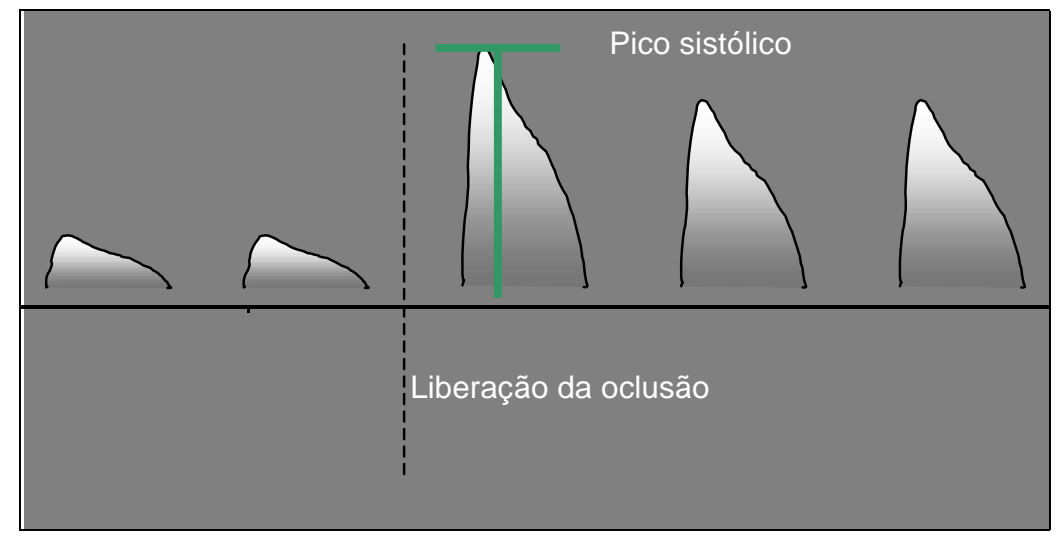

FIGURA 4. Representação da curva de variação da velocidade do fluxo arterial com delineamento do pico sistólico após liberação da oclusão

A análise da variação percentual do diâmetro na condição DFM (\%DFM) foi feita com base em uma condição pós-estímulo comparada ao seu respectivo BASAL. Assim:

$$
\% \mathrm{DFM}=(\mathrm{DFM}-\mathrm{BASAL}) / \mathrm{BASAL} * 100
$$

\section{REPOUSO}

Após quinze minutos, os parâmetros de diâmetro e velocidade de fluxo na artéria braquial foram avaliados na condição REPOUSO, com segurança para refletir o restabelecimento das condições basais (Corretti et al., 2002). 


\section{DILATAÇÃO NITRATO-MEDIADA}

A dilatação nitrato-mediada (DNM) é uma função endotélioindependente. $\mathrm{O}$ uso do nitrato ativa a enzima guanilato-ciclase, com formação de GMPc e relaxamento das células musculares lisas dos vasos. Determina a resposta máxima de vasodilatação obtida e serve como uma medida da função do músculo liso vascular (Celermajer, 1997).

Esta condição compreendeu a avaliação dos parâmetros de diâmetro e fluxo na artéria braquial obtidos na condição imediatamente após 3 minutos da dissolução de $5 \mathrm{mg}$ de nitrato de isossorbida administrados por via sublingual, quando ocorrem os picos de aumento (Arwood et al., 1998).

A análise da variação percentual do diâmetro na condição DNM (\%DNM) foi feita avaliando-se o parâmetro em uma condição pós-estímulo e comparando-o com o seu respectivo BASAL. Assim:

$$
\% \mathrm{DNM}=(\mathrm{DNM}-\mathrm{BASAL}) / \mathrm{BASAL} * 100
$$

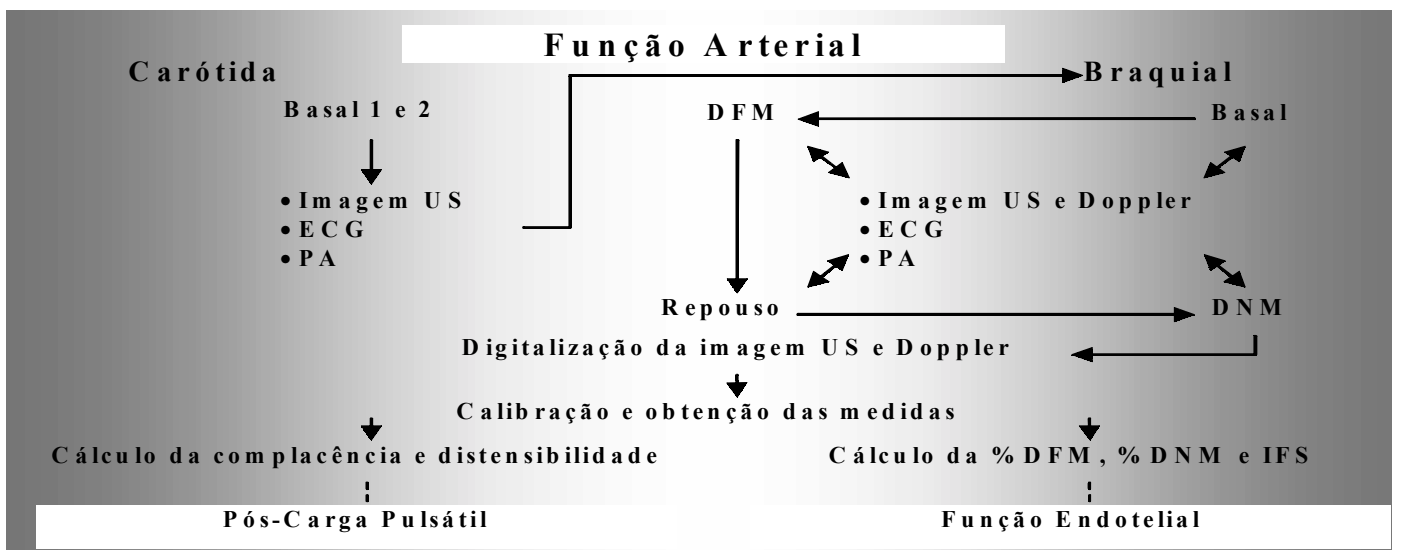

QUADRO 4. Fluxograma de Avaliação da Função Arterial 


\subsection{Estatística}

Inicialmente todas as variáveis foram analisadas descritivamente. A análise das variáveis quantitativas foi feita através da observação dos valores mínimos e máximos, do cálculo de médias e desvios-padrão. Para as variáveis qualitativas, calcularam-se freqüências absolutas e relativas.

O teste $t$ de Student foi usado na análise da hipótese de igualdade entre dois grupos e o teste exato de Fisher na comparação das proporções entre ambos (Rosner, 1986).

A Análise de Variância com medidas repetidas foi empregada na averiguação de comportamento dos grupos, considerando as condições estudadas. Consiste no ajuste de um modelo linear multivariado a partir do qual as seguintes hipóteses foram testadas (Timm, 1975):

- H01: os perfis médios de resposta correspondentes aos grupos são paralelos, ou seja, não existe interação entre o fator grupo e o fator condição de avaliação .

- H02: os perfis médios de resposta são coincidentes, ou seja, não existe efeito do fator grupo.

- H03: os perfis médios de resposta são paralelos ao eixo das abscissas, ou seja, não há efeito do fator condição de avaliação.

As hipóteses $\mathrm{H} 02$ e H03 só foram testadas quando não se rejeitou H01. Caso contrário, foram testadas hipóteses de igualdade entre as condições dentro de cada grupo. No teste das hipóteses, foi utilizada a estatística de Wilks, com a aproximação para a estatística $F$ (Timm, 1975).

O nível de significância utilizado para os testes foi de 5\%. 


\subsection{Grupos de Estudo}

O grupo G>50 ficou constituído por 20 pacientes (55,6\%), com pressão arterial diastólica média igual a 70,20 $\pm 14,84 \mathrm{mmHg}$. O grupo $\mathrm{G}<50$, 16 pacientes (44,4\%), com pressão arterial diastólica média de $45 \pm 3,36 \mathrm{mmHg}$.

Houve duas perdas no grupo $\mathrm{G}>50$ : o paciente número 24 apresentou morte súbita no $1^{\circ}$ mês após a cirurgia e o paciente número 26 faleceu no $5^{\circ}$ mês depois da troca valvar por acidente vascular cerebral.

A análise entre os grupos mostrou que houve semelhança quanto ao sexo e a cor, e diferença em relação à idade e a presença de antecedente familiar de hipertensão arterial sistêmica (Tabela 1).

Os resultados individuais encontram-se no Anexo 1.

TABELA 1 - CARACTERÍSTICAS CLÍNICAS DOS GRUPOS G>50 E G<50 NO PRÉOPERATÓRIO

\begin{tabular}{|c|c|c|c|}
\hline VARIÁVEL & $\begin{array}{c}G>50 \\
(n=20)\end{array}$ & $\begin{array}{c}G<50 \\
(n=16)\end{array}$ & $P$ \\
\hline \multicolumn{4}{|l|}{ Idade (anos) * } \\
\hline $49-65$ & 15 & 4 & \multirow{3}{*}{0,0003} \\
\hline $34-48$ & 5 & 5 & \\
\hline $19-33$ & 0 & 7 & \\
\hline \multicolumn{4}{|l|}{ Sexo } \\
\hline Masculino & 5 & 3 & \multirow{2}{*}{0,709} \\
\hline Feminino & 15 & 13 & \\
\hline \multicolumn{4}{|l|}{ Cor } \\
\hline Branca & 10 & 11 & \multirow{2}{*}{0,068} \\
\hline Não-Branca & 10 & 5 & \\
\hline Antecedente Familiar de HAS & 7 & 0 & 0,011 \\
\hline
\end{tabular}

* Idade média $=45$ anos

HAS = hipertensão arterial sistêmica; $\mathrm{n}=$ número de pacientes. 


\section{RESULTADOS}




\subsection{Pressão Arterial Diastólica}

O grupo $\mathrm{G}<50$ apresentou valores de pressão arterial diastólica menores que os do grupo $\mathrm{G}>50$ em todos os momentos avaliados $(\mathrm{p}<0,001)$, e em ambos os grupos houve diferença nos momentos avaliados entre si $(\mathrm{p}=0,0024)$ com elevação da pressão arterial diastólica no pós-operatório (Tabela 2, Gráfico 1).

Os resultados individuais encontram-se no Anexo 2.

TABELA 2. PRESSÃO ARTERIAL DIASTÓLICA MÉDIA DOS GRUPOS G $>50$ E G $<50$ NOS MOMENTOS CLÍNICOS ANALISADOS

\begin{tabular}{|c|c|c|c|c|}
\hline GRUPO & MPRÉ & M1 & M3 & M6 \\
\hline $\mathrm{G}<50$ & & & & \\
\hline $\begin{array}{l}\text { PAD }(\mathrm{mmHg}) \\
\mathrm{G}>50\end{array}$ & $45,00 \pm 3,36^{a}$ & $74,44 \pm 11,22^{a}$ & $72,69 \pm 11,50^{\underline{a}}$ & $78,25 \pm 13,44^{\mathrm{a}, \mathrm{b}}$ \\
\hline PAD $(\mathrm{mmHg})$ & $70,20 \pm 14,84^{a}$ & $98,89 \pm 11,36^{\underline{a}}$ & $96,58 \pm 11,14^{\underline{a}}$ & $98,56 \pm 13,25^{a}, b$ \\
\hline
\end{tabular}

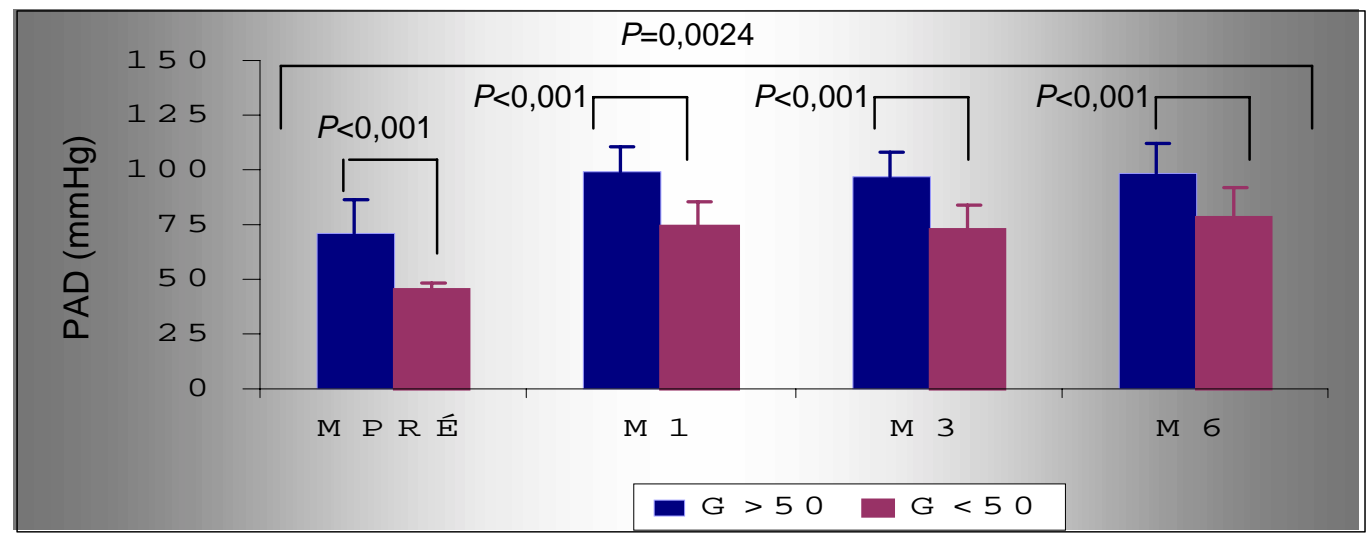

GRÁFICO 1. Pressão arterial diastólica média e desvios-padrão em cada grupo, nos diversos momentos clínicos 


\subsection{Variáveis Ecocardiográficas e Ventrículo-Radioisotópica}

A Tabela 3 sumariza as variáveis decorrentes da avaliação ecocardiográfica e ventrículo-radioisotópica no MPRÉ e no M6 distribuída pelos 2 grupos. Os resultados individuais encontram-se no Anexo 3.

TABELA 3 - VARIÁVEIS ECOCARDIOGRÁFICAS E VENTRÍCULORADIOISOTÓPICA DOS GRUPOS G $>50$ E G $<50$ NO MPRÉ E M6

\begin{tabular}{|c|c|c|c|c|}
\hline \multirow{2}{*}{ VARIÁVEL } & \multicolumn{2}{|c|}{$\mathrm{G}<50$} & \multicolumn{2}{|c|}{$G>50$} \\
\hline & MPRÉ & M6 & MPRÉ & M6 \\
\hline DSVE (mm) & $56,00 \pm 9,76$ & $48,81 \pm 13,17^{b}$ & $47,78 \pm 8,74^{a}$ & $44,06 \pm 14,00^{b}$ \\
\hline DDVE $(\mathrm{mm})$ & $78,75 \pm 7,86$ & $63,75 \pm 10,85^{\mathrm{b}}$ & $66,72 \pm 8,75^{a}$ & $59,00 \pm 12,49^{b}$ \\
\hline DSVE $(\mathrm{mm}) / \mathbf{m}^{2}$ & $3,29 \pm 0,59$ & $2,84 \pm 0,85^{b}$ & $2,72 \pm 0,57^{a}$ & $2,53 \pm 0,80^{b}$ \\
\hline DDVE $(\mathrm{mm}) / \mathrm{m}^{2}$ & $4,66 \pm 0,56$ & $3,68 \pm 0,73^{b}$ & $3,78 \pm 0,59^{a}$ & $3,39 \pm 0,69^{b}$ \\
\hline$\Delta \mathbf{d}(\%)$ & $29,06 \pm 8,30$ & $23,64 \pm 8,62^{b}$ & $28,72 \pm 6,03$ & $26,41 \pm 9,15^{b}$ \\
\hline FEVE $(\%)$ & $50,69 \pm 10,90$ & $48,06 \pm 15,10^{b}$ & $54,22 \pm 6,36$ & $47,11 \pm 11,89^{b}$ \\
\hline
\end{tabular}

No MPRÉ e no M6, as variáveis ecocardiográficas DDVE e $\mathrm{DDVE} / \mathrm{m}^{2}$ foram maiores no grupo $\mathrm{G}<50$ do que no $\mathrm{G}>50(\mathrm{p}=0,0005)$ e o DSVE e o DSVE $/ \mathrm{m} 2$ mostraram-se equivalentes $(p=0,0870)$.

O DSVE e DSVE $/ \mathrm{m}^{2}$ não apresentaram diferença de comportamento $(p=0,2780$ e 0,1469$)$. Ambos diminuíram, nos dois grupos, entre o MPRÉ e o M6 ( $p=0,0015$ e 0,0011) (Gráficos 2 e 3). 


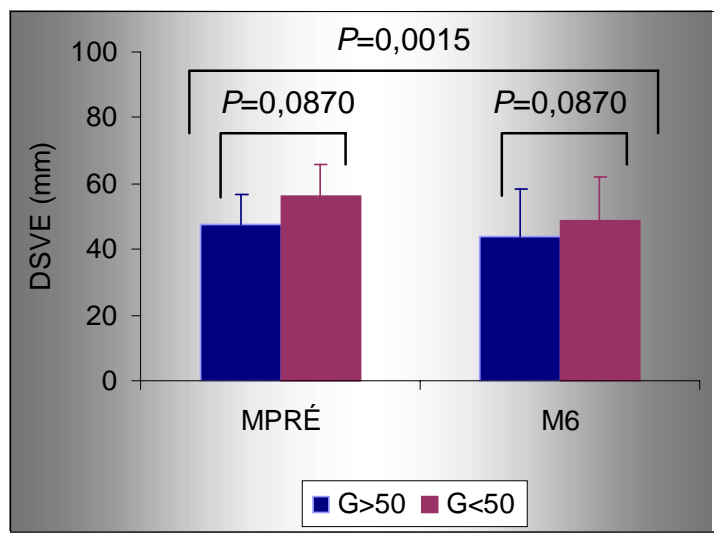

GRÁFICO 2. Diâmetro sistólico médio do ventrículo esquerdo e desvios-padrão em cada grupo, no MPRÉ e M6

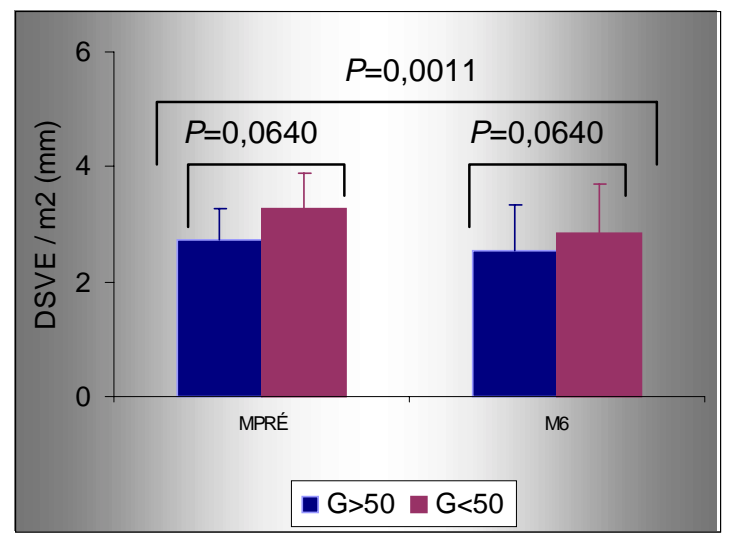

GRÁFICO 3. Relação entre o diâmetro sistólico médio do ventrículo esquerdo pela superfície corporal e desvios-padrão de cada grupo, no MPRÉ e M6

O DDVE e DDVE $/ \mathrm{m}^{2}$ diminuíram $(\mathrm{p}=0,0029$ e 0,0035) entre o MPRÉ e o M6, porém de forma menos acentuada no grupo $G>50(p<0,001)$ (Gráficos 4 e 5).

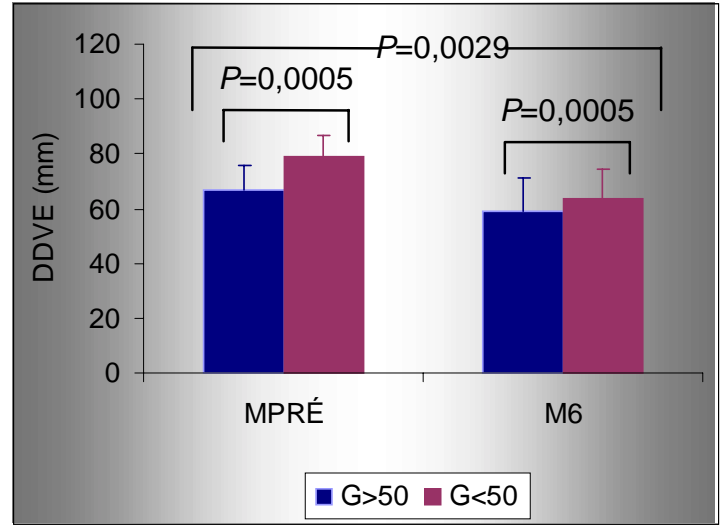

GRÁFICO 4. Diâmetro diastólico médio do ventrículo esquerdo e desvios-padrão em cada grupo, no MPRÉ e M6

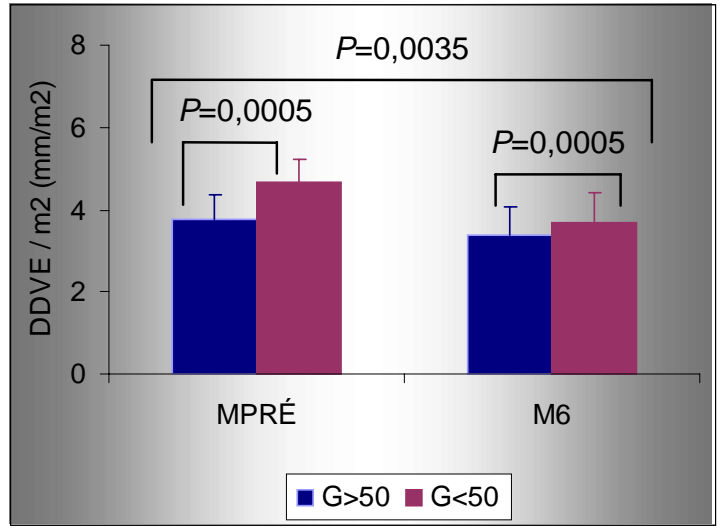

GRÁFICO 5. Relação entre o diâmetro diastólico médio do ventrículo esquerdo pela superfície corporal e desvios-padrão de cada grupo, no MPRÉ e M6

A fração de encurtamento foi semelhante nos grupos $(p=0,7751)$ e decresceu entre o MPRÉ e o M6 em ambos $(p=0,0042)$, sem caracterizar diferença de comportamento ( $\mathrm{p}=0,2241)$ (Gráfico 6).

A fração de ejeção do ventrículo esquerdo pela ventriculografia radioisotópica igualmente apresentou valores semelhantes nos grupos 
$(\mathrm{p}=0,4116)$ e diminuiu entre o MPRÉ e o M6 ( $\mathrm{p}=0,0047)$, também sem caracterizar diferença de comportamento $(\mathrm{p}=0,1707)$ (Gráfico 7).

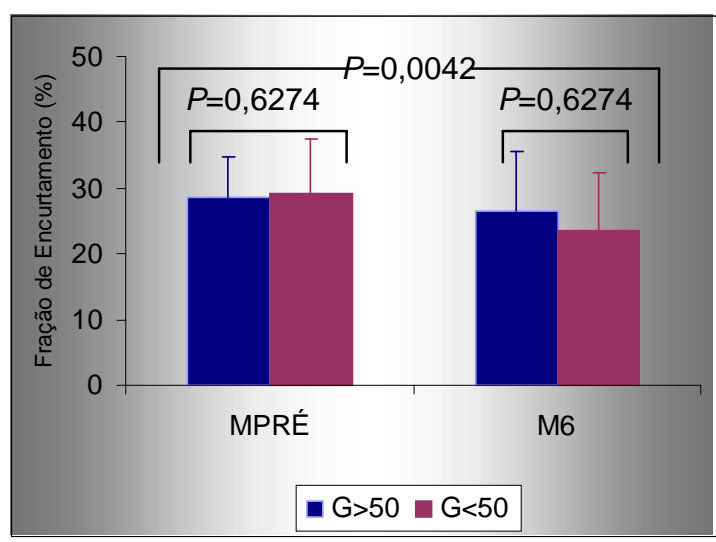

GRÁFICO 6. Fração de encurtamento média do ventrículo esquerdo e desvios-padrão em cada grupo, no MPRÉ e M6

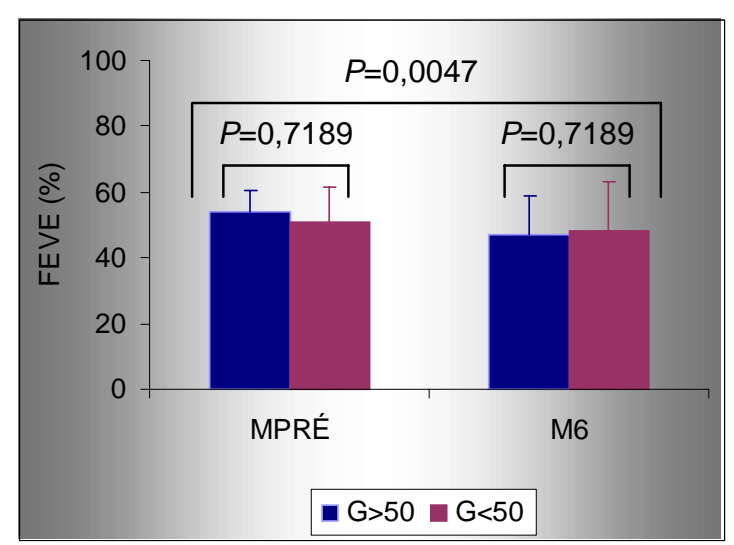

GRÁFICO 7. Fração de ejeção média do ventrículo esquerdo e desvios-padrão em cada grupo, no MPRÉ e M6

\subsection{Função Arterial}

Todos os pacientes colaboraram adequadamente para a obtenção de exames de boa qualidade técnica. Não houve evidência ultra-sonográfica de estreitamento vascular durante os procedimentos.

\subsubsection{Pós-carga pulsátil}

A complacência e distensibilidade apresentaram valores maiores no grupo $\mathrm{G}<50(\mathrm{p}<0,001)$ em todos os momentos avaliados e ambas tiveram comportamentos distintos $(\mathrm{p}=0,0020)$ (Tabela 4$)$.

A complacência arterial no grupo $G>50$ não se alterou entre o MPRÉ e o M6 $(p=0,0930)$ e diminuiu no $G<50(p<0,001)$. De modo semelhante, a distensibilidade também permaneceu estável no grupo $\mathrm{G}>50$ ( $\mathrm{p}=0,1946)$, com redução no $\mathrm{G}<50(\mathrm{p}<0,001)($ Gráficos 8 e 9). 
Os resultados individuais encontram-se no Anexo 4.

TABELA 4 - PÓS-CARGA PULSÁTIL DOS GRUPOS G >50 E G<50 NO MPRÉ E M6

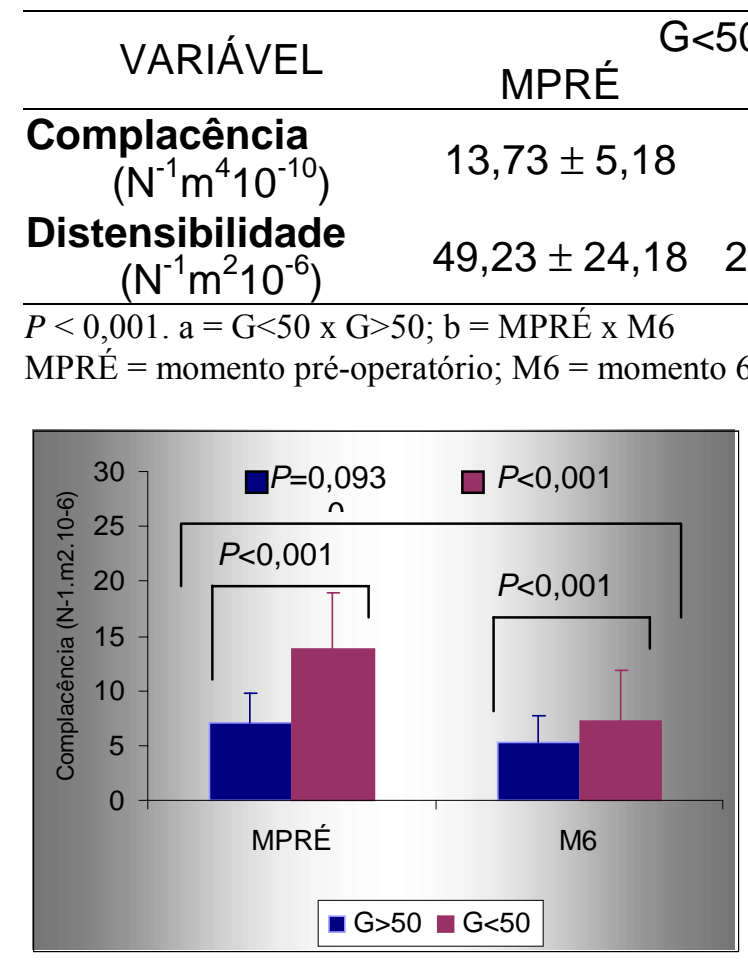

GRÁFICO 8. Complacência média e desviospadrão em cada grupo, no MPRÉ e M6

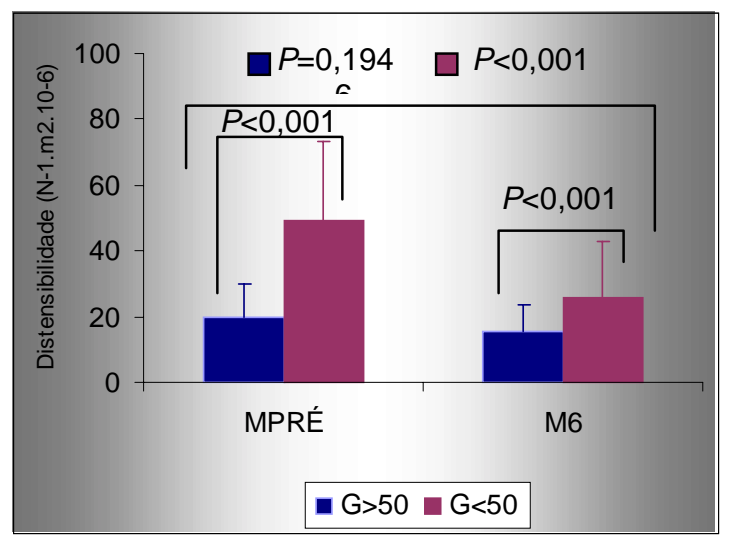

GRÁFICO 9. Distensibilidade média e desviospadrão em cada grupo, no MPRÉ e M6

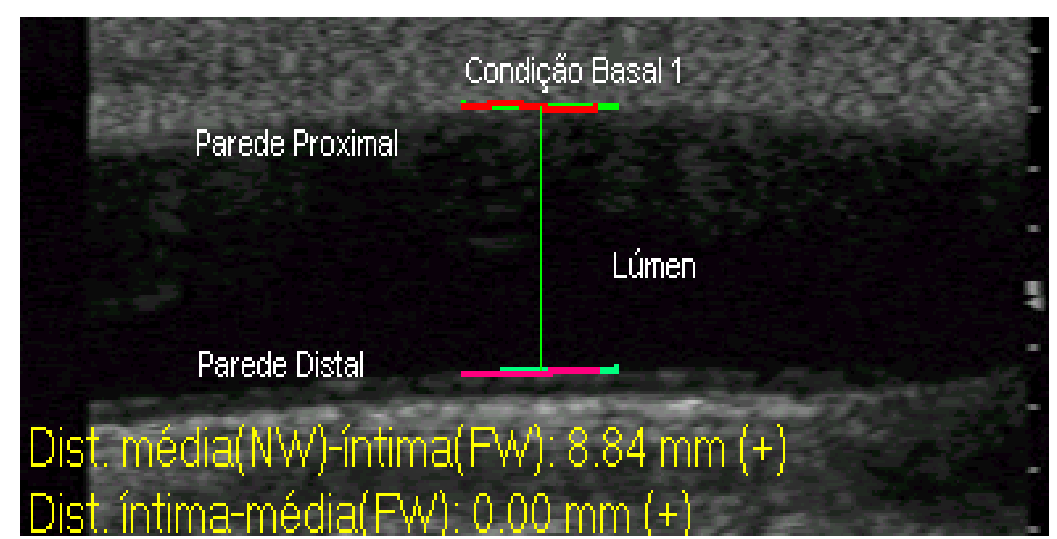

FIGURA 5. Representação fotográfica da artéria carótida comum em corte longitudinal, delimitando fronteiras para a medida do diâmetro vascular na condição BASAL 1. 


\subsubsection{Função Endotelial}

Houve equivalência na aferição das medidas do diâmetro e do índice de fluxo sistólico na condição BASAL e REPOUSO em relação ao momento analisado $(\mathrm{p}=1,0000)$ (Tabela 5, 6).

Entre os grupos, a variação percentual do diâmetro da artéria braquial demonstrou comportamento paralelo $(\mathrm{p}=0,6866)$, sem diferença entre suas médias ao longo das avaliações $(\mathrm{p}=0,2643)$. Em ambos os grupos, não houve diferença entre o MPRÉ e o M6 da \%DFM ( $\mathrm{p}=0,2234)$ e da \%DNM $(\mathrm{p}=0,0500)($ Tabela 5, Gráfico 10).

TABELA 5 - VARIAÇÃO PERCENTUAL DO DIÂMETRO DA ARTÉRIA BRAQUIAL DOS GRUPOS G $>50$ E G<50 NO MPRÉ E M6

\begin{tabular}{|c|c|c|c|c|}
\hline \multirow{2}{*}{ VARIÁVEL } & \multicolumn{2}{|c|}{$G<50$} & \multicolumn{2}{|c|}{$G>50$} \\
\hline & MPRÉ & M6 & MPRÉ & M6 \\
\hline BASAL (mm) & $4,38 \pm 0,59$ & $4,16 \pm 0,45$ & $5,08 \pm 0,94$ & $4,62 \pm 0,89$ \\
\hline \%DFM (\%) & $5,43 \pm 5,54$ & $7,15 \pm 6,82^{b}$ & $3,59 \pm 3,72^{\mathrm{a}}$ & $4,85 \pm 4,91^{b}$ \\
\hline REPOUSO (mm) & $4,39 \pm 0,59$ & $4,17 \pm 0,44$ & $5,06 \pm 0,94$ & $4,62 \pm 0,89$ \\
\hline \%DNM (\%) & $7,25 \pm 6,30$ & $11,53 \pm 10,19^{b}$ & $6,58 \pm 7,48^{\underline{a}}$ & $10,51 \pm 9,61^{b}$ \\
\hline
\end{tabular}

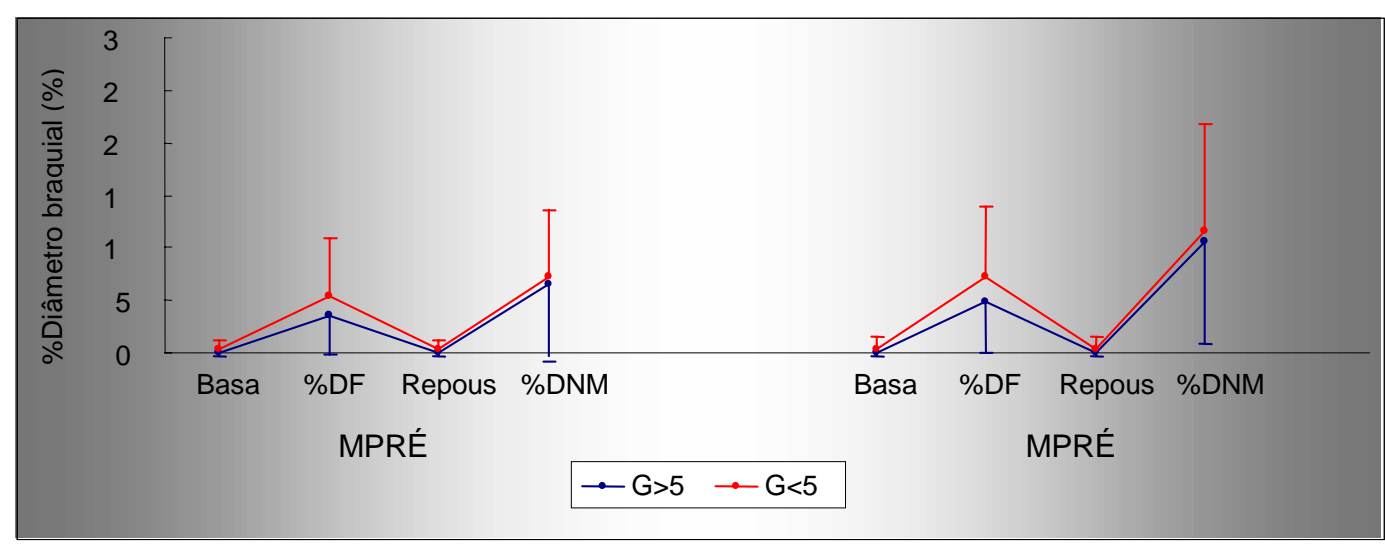

GRÁFICO 10. Variação percentual do diâmetro médio da artéria braquial e desvios-padrão em cada grupo, nas condições analisadas, no MPRÉ e M6 
O índice de fluxo sistólico não apresentou diferença de comportamento entre os grupos $(\mathrm{p}=0,3997)$ ou entre suas médias nos momentos avaliados $(\mathrm{p}=0,3992)$ (Tabela 6, Gráfico 11).

TABELA 6 - ÍNDICE DE FLUXO SISTÓLICO DA ARTÉRIA BRAQUIAL DOS GRUPOS G $>50$ E G $<50$ NO MPRÉ E M6

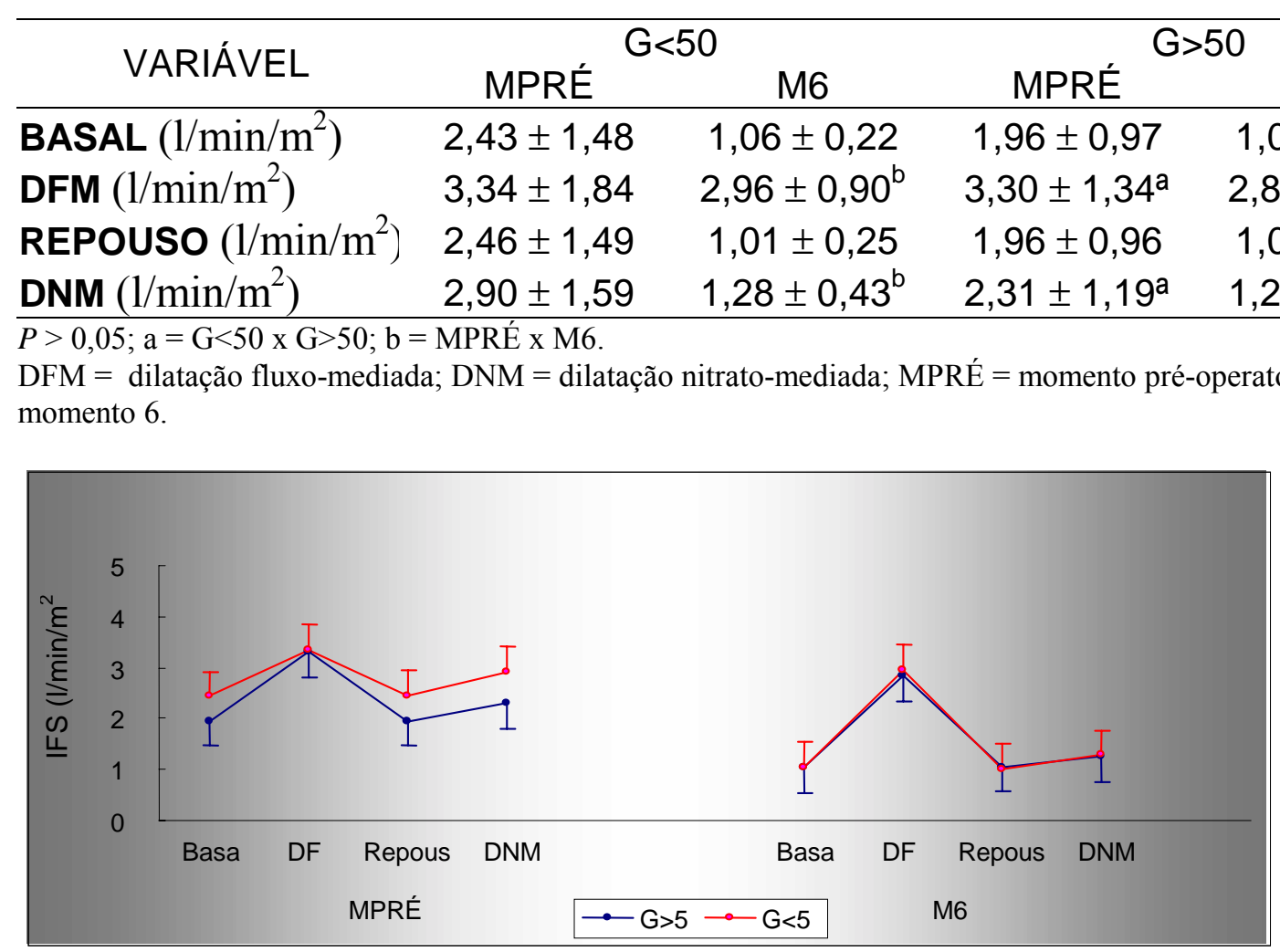

GRÁFICO 11. Índice de fluxo sistólico braquial médio e desvios-padrão em cada grupo, nas condições analisadas , no MPRÉ e M6

Os resultados individuais encontram-se no Anexo 5. 


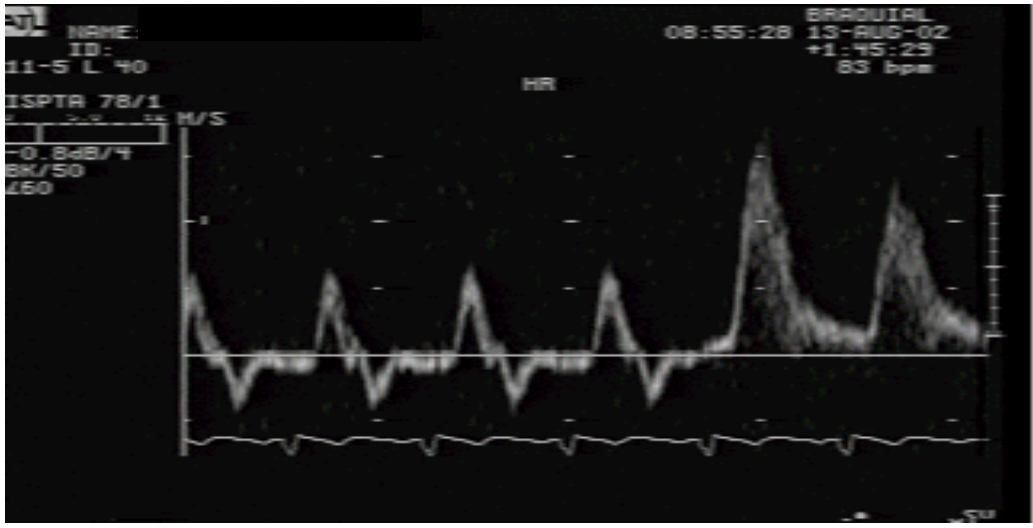

FIGURA 6. Representação fotográfica da curva de variação da velocidade do fluxo braquial com delineamento do pico sistólico após liberação da oclusão na condição DFM 


\subsection{Grupos de Estudo}

A média etária de 45 anos, cerca de $20 \%$ menor em comparação com casos análogos de insuficência aórtica (55 anos) descritos na literatura (Enriquez-Sarano \& Tajik, 2004), deve ser atribuída à grande prevalência de etiopatogenia reumática em nossa série. Nossa faixa etária mais jovem favorece a fidedignidade dos resultados laboratoriais, pois consegue diminuir a possibilidade da influência de alterações degenerativas pela senilidade, o que fortalece a consistência na interpretação dos mesmos.

Em relação à influência da idade sobre a insuficência aórtica, Wilson et al.(1992) foram pioneiros em valorizar a diminuição fisiológica da elasticidade da aorta com o envelhecimento no agravamento hemodinâmico e piora do quadro clínico do paciente. Mais recentemente, Delvin et al.(1999) alertaram para a existência de um comportamento heterogêneo da aorta em diferentes fases evolutivas da insuficência aórtica crônica. Ressalte-se entretanto a homogeneidade clínica dos pacientes em sua avaliação préoperatória pelo momento da indicação cirúrgica. Assim, apesar da diferença etária, não se pode deduzir que os pacientes do grupo $\mathrm{G}>50$ estavam em fase mais avançada da história natural da doença do que os do $\mathrm{G}<50$.

O número de casos equivalente em ambos os sexos está em discordância com a literatura, onde se nota envolvimento de insuficência aórtica pura predominantemente no sexo masculino, por possuir maior risco de 
exposição aos fatores causais mais comuns (Douglas, 1989; Darvill, 1963). No entanto, não é possível explicar este dado sem um desenho de estudo apropriado para análise de etiopatogenia.

Não é conhecida predileção por cor em insuficiência aórtica (Enriquez-Sarano \& Tajik, 2004; Leggett \& Otto, 1996). Fato confirmado em nossa casuística.

A presença de antecedente familiar de hipertensão arterial sistêmica tem pouco valor como dado isolado em decorrência da variabilidade na confiabilidade individual de aquisição de informação verbal, sem a efetiva participação dos membros hipertensos da família. Entretanto, quando vista em associação com outros achados clínico-laboratoriais, valoriza a tendência individual e do grupo em manifestar a doença.

\subsection{Pressão Arterial Diastólica}

Em insuficência aórtica crônica grave, a avaliação da pressão arterial permanece pouco valorizada no manejo dos pacientes, pois uma variável sujeita a interações tão complexas é difícil de ser confiável a não ser nos valores extremos e há dificuldade em se estabelecer parâmetro diagnóstico de hipertensão graças à alteração vascular inerente de pressão sistólica elevada pelo aumento no débito cardíaco e diastólica muito baixa pela incompetência da valva, por vezes com persistência dos sons até zero mmHg (Zezulka et al., 1992).

Este fato torna sua aferição diferenciada, com necessidade de conhecimento do fenômeno que a justifica, mas não a invalida. Pelo contrário, pacientes com insuficência aórtica possuem uma relação mais estreita que 
indivíduos normais entre o valor intra-arterial da pressão arterial diastólica e a medida obtida de forma não-invasiva no braço (London \& London, 1967), com tendência à aproximação do abafamento dos sons obtidos após a liberação da compressão braquial com a pressão diastólica intra-arterial, e não o seu desaparecimento (Goldstein \& Killip, 1962), o que comprova sua excelente analogia com o valor da fase IV dos sons de Korotkoff utilizada no registro.

De acordo com a literatura, a hipertensão arterial sistêmica é entidade mórbida com claro componente genético, na grande maioria dos casos sem etiologia determinada (Wilson \& Grim, 1991; Julius \& Jamerson, 1991), porém com perfil definido: incidência maior após os 40 anos de idade (Miall \& Lovell, 1967), predileção por indivíduos com antecedentes familiares de hipertensão (Kirkendall \& Nottenbohm, 1977), obesos (Kannel et al., 1967), de vida sedentária (Kahn et al., 2002) e cor negra (Debert et al., 1981).

Os $16(88,89 \%)$ pacientes do grupo $\mathrm{G}>50$ que atingiram de forma precoce e progressiva, uma vez corrigida a valvopatia, valores de pressão arterial diastólica considerados diagnósticos de hipertensão arterial sistêmica para a população geral (Andrade et al., 2004), distinguindo-se do grupo $\mathrm{G}<50$ em que apenas $2(12,50 \%)$ atingiram os mesmos critérios no pós-operatório $(p<0,001)$, confirmam o perfil da hipertensão em nossa série. Em que foi possível observar a partir da inclusão apenas de indivíduos sedentários e com baixo índice de massa corpórea, o predomínio no grupo $\mathrm{G}>50$ de indivíduos com maior faixa etária, presença de antecedente familiar de hipertensão arterial sistêmica e tendência ao maior número de não-brancos (Tabela 1 e Gráfico 1).

A associação em nossos casos entre hipertensão arterial sistêmica no pós-operatório com a maior faixa etária decorre provavelmente do maior 
tempo de exposição aos fatores que poderiam desencadeá-la (Miall \& Lovell, 1967). Ao tomar-se uma amostra de indivíduos com determinada idade, de uma população em que a hipertensão seja freqüente, a média da pressão arterial será mais alta que a de uma faixa etária menor. Por outro lado, ao se analisar uma amostra de indivíduos dessa mesma população, com pressão arterial mais elevada, forçosamente a média da idade será maior do que a de uma amostra com menores valores pressóricos. O que acontece não é o aumento individual da pressão arterial com a idade, mas o aumento da prevalência da hipertensão arterial com a idade.

Segundo a lei de Ohm, em que o fluxo de um vaso sangüíneo é determinado pela razão da diferença de pressão entre duas extremidades e o impedimento à sua progressão, estando o circuito arterial fechado e sem seqüestro de sangue através de fístulas artério-venosas, a pressão arterial sistêmica pode ser representada pela equação hidrodinâmica de Poiseuille e Hegen e resulta principalmente da interação entre o débito cardíaco e a resistência periférica. Mantendo-se o débito cardíaco constante com o paciente em repouso, a pressão arterial diastólica é conseqüência sobretudo da resistência periférica e se correlaciona com a complacência e distensibilidade arterial em sua fórmula, o que explica as diferenças encontradas entre os grupos $\mathrm{G}>50$ e $\mathrm{G}<50$.

\subsection{Variáveis Ecocardiográficas e Ventrículo-Radioisotópica}

A insuficiência aórtica crônica é valvopatia que se torna sintomática em fase avançada de sua história natural. Partindo-se do raciocínio clínico que considera fundamental evitar a desadaptação ventricular esquerda e obter a recuperação de sua função, ao longo dos anos 70 e 80 conduziram-se 
vários trabalhos prospectivos visando detectar índices laboratoriais que permitissem estratificar o risco cirúrgico e beneficiar a evolução pós-operatória (Yousof et al., 1988).

Demonstrou-se o dano miocárdico pós-operatório relacionado a aspectos do pré-operatório e valores de corte de certas variáveis foram afirmados como indicadores de alerta sobre o benefício cirúrgico de modo independente da qualidade de vida referida pelo paciente (Henry et al., 1980; Carabello et al., 1986).

$\mathrm{Na}$ década de 90, Starling et al.(1991) associaram dados de ecocardiografia, ventriculografia radioisotópica e cateterismo cardíaco com o objetivo de precisar o real momento do preocupante aparecimento de disfunção ventricular esquerda. Em estudo mais recente, Borer et al.(1998) incluíram a relação da variação percentual entre a fração de encurtamento e estresse sistólico final no repouso e exercício, infelizmente de difícil aplicação clínica.

Nossos resultados, quando analisados pelos valores de corte préoperatórios chamados "preocupantes" na literatura (Kumpuris et al., 1982; Gaasch et al., 1983; Stone et al., 1984; Bonow et al., 1985, 1988), mostram no MPRÉ fração de encurtamento e fração de ejeção do ventrículo esquerdo preservadas nos dois grupos e diferença quanto aos diâmetros ventriculares. O grupo $\mathrm{G}<50$ possuiu $\mathrm{DDVE} \geq 70 \mathrm{~mm}$, DSVE $\geq 55 \mathrm{~mm}, \mathrm{DDVE} / \mathrm{m}^{2} \geq 3,8 \mathrm{~mm}$ e DSVE $/ \mathrm{m}^{2} \geq 2,6 \mathrm{~mm}$, enquanto o grupo $\mathrm{G}>50$ exibiu valores considerados benignos (Tabela 3).

O encontro de valores de fração de ejeção do ventrículo esquerdo e de fração de encurtamento acima do limite inferior da normalidade no préoperatório e de disfunção sistólica discreta no pós-operatório deve ser creditado 
a variações proporcionalmente menores da dimensão diastólica. Neste ponto, cabe assinalar que os métodos radioisotópico e ultra-sonográfico de avaliação do desempenho ventricular esquerdo fundamentaram interpretações coincidentes sobre a fração de ejeção e a fração de encurtamento.

À semelhança do observado em outros estudos, houve uma queda pós-operatória acentuada dos diâmetros ventriculares a partir dos valores encontrados no MPRÉ em ambos os grupos, com redução significativamente menor do DDVE e DDVE / $\mathrm{m}^{2}$ no grupo G>50 (Gráfico 2, 3, 4, 5). Poder-se-ia conjecturar que os gatilhos do DDVE e DSVE sejam acionados sob estímulos distintos, ainda não esclarecidos. Em pacientes com tônus vascular aumentado e conseqüente alteração na pós-carga pulsátil, deve ocorrer o desencadeamento de um gatilho que iniba a regressão das dimensões diastólicas uma vez retirada a sobrecarga de volume da insuficência aórtica.

Como os índices disponíveis são incapazes de elucidar os mecanismos da desadaptação ventricular esquerda na insuficiência aórtica, pois são multi-influenciados (Bonow, 1998; Mahler et al., 1975; Bonow \& Marcus, 1991), observa-se a necessidade de se buscar novos parâmetros que auxiliem na deteminação do real momento de aparecimento da disfunção miocárdica.

Entende-se dessa maneira que é injustificado levar em consideração a utilização de um dado isolado como indicador seguro do momento ideal para o tratamento cirúrgico na insuficência aórtica. Deve-se entender que índices sofrem interferências de natureza matemática que não propriamente refletem o grau de contratilidade do ventrículo esquerdo. Neste aspecto, qualquer interpretação mais acurada não pode deixar de integrar uma série de fatores 
morfológicos e hemodinâmicos, como ventrículo esquerdo, valva aórtica e circulação periférica.

\subsection{Função Arterial}

O estudo da pós-carga pulsátil vem se desenvolvendo nos últimos 30 anos (Watt et al., 1976; Finkelstein \& Collins, 1982) e, desde a descrição inicial do papel do endotélio na modulação do tônus vascular por Furchgott \& Zawadzki (1980), vários estudos experimentais e clínicos o têm avaliado em diversos estados patológicos (Cocks et al., 1985; Anderson et al., 1989; Creager et al., 1990; Katz et al., 1992; Chowienczyk et al., 1993).

A avaliação da função arterial por meio de ultra-sonografia de alta resolução é uma técnica simples e de boa acurácia, podendo detectar mudanças no diâmetro das artérias sistêmicas de até $0,1 \mathrm{~mm}$. O método possui boa reprodutibilidade, pois o coeficiente de variação é de apenas $1,8 \%$, não parece sofrer interferência de variáveis tais como índice de massa corporal e sexo, e pode ser usado em avaliações seriadas e estudos de reversibilidade de disfunção endotelial (Sorensen et al., 1995; Smulyan et al., 2001).

\subsubsection{Pós-carga pulsátil}

A camada média da parede arterial é a principal determinante da pós-carga pulsátil vascular, sendo composta basicamente por colágeno e elastina, considerados materiais elásticos, e por músculo liso, que apesar de contribuir para a tensão da parede, não representa um material elástico. Os materiais elásticos existem em diferentes proporções ao longo da árvore arterial, com predomínio de elastina nos ramos proximais e de colágeno nos distais. 
Desta forma, são reconhecidas algumas limitações técnicas na medida dos parâmetros de elasticidade arterial, pois as fórmulas utilizadas em seu cálculo assumem que existe correlação constante e linear entre as alterações do diâmetro e da pressão. Porém, em níveis de baixa pressão, os elementos colágenos da artéria são minimamente recrutados e a tensão é absorvida pela elastina, passando a haver recrutamento progressivo das fibras colágenas (mais rígidas e resistentes) com o aumento dos níveis pressóricos, de tal forma que dentro de limites físiológicos a relação pressão-diâmetro é curvilínea. Essa variação é geralmente aceita em estudos clínicos como o nosso, considerando que as mudanças no diâmetro e na pressão arterial não superam $25 \%$.

Outro ponto de discussão é o fato de que um único vaso pode não ser representativo de todo o sistema arterial, posto que a elasticidade se modifica ao longo do trajeto arterial, sendo a aorta o segmento mais complacente e as artérias de pequeno calibre as menos complacentes (O'Rourke \& Brunner, 1992), possivelmente exigindo padronizações específicas para as diferentes artérias abordadas. Também pode ocasionar possível interferência nos resultados a medida do diâmetro ser realizada na carótida comum e a pressão arterial obtida na artéria braquial. Contudo, é proibitiva a abordagem direta da pressão arterial na carótida e a utilização da pressão obtida na artéria braquial fornece resultados plenamente aceitáveis.

Em nosso protocolo, foram excluídos os casos com idade superior a 65 anos, tendo em vista que essa situação promove o declínio da função arterial com a progressão da idade, refletindo alterações estruturais por diminuição na relação do conteúdo de colágeno e elastina (Berne \& Levy, 1990), e se adotou as normas preconizadas de padronização no preparo do paciente para a análise, 
com intuito de reduzir ao máximo a estimulação simpática por agentes externos (Boutouyrie et al., 1994; Corretti et al., 2002).

Em um estudo com 23 indivíduos normais entre homens e mulheres

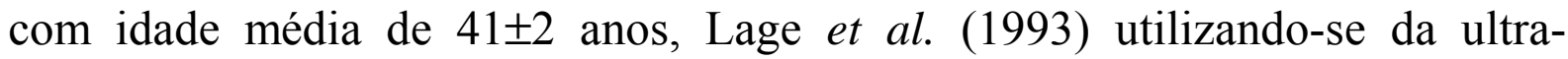
sonografia vascular de alta resolução encontraram valor médio de diâmetro carotídeo sistólico de 6,15 \pm 0,12 mm. Em outro trabalho, Lage et al. (1994) encontraram, em 33 voluntários normais de ambos os sexos e idade média de

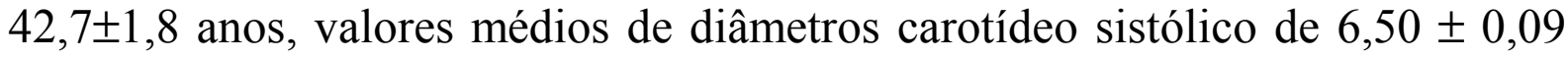

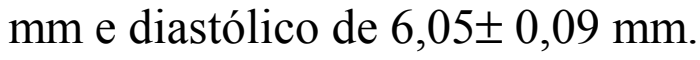

Anderson; Mark (1989) foram os primeiros a chamar atenção para as alterações mediadas pelo fluxo no diâmetro de grandes artérias em humanos, relacionando-os de forma positiva. A elevação do fluxo sangüíneo leva ao aumento do diâmetro arterial e vice-versa.

Em nossos pacientes, submetidos à análise pela mesma técnica, observamos aumento dos diâmetros carotídeos sistólico $(21,7 \%)$ e diastólico $(11,2 \%)$ nos dois grupos em relação à literatura. $\mathrm{O}$ aumento de diâmetro encontrado deve estar relacionado ao aumento significativo do fluxo na artéria carótida. Quanto maior o débito cardíaco, maior o fluxo sangüíneo para a artéria em questão, o que está de acordo com a fisiopatologia da doença.

Embora o ultra-som seja bastante fiel na determinação do diâmetro vascular, pacientes com reconhecida dilatação da carótida que não apresentem medidas acima do limite máximo normal são, portanto, considerados falsonegativos. A razão disto é que se um paciente tiver um diâmetro carotídeo qualquer que aumente em mais de $100 \%$, até $6,59 \mathrm{~mm}$, não será diagnosticado 
pelo ultra-som, já que se encontra ainda dentro do limite máximo para a população geral, ainda que sem dúvida alterado para este paciente.

Uma forma de aumentar a sensibilidade da ultra-sonografia é o emprego, não de valores absolutos, mas da relação entre os diâmetros através da pós-carga pulsátil, que sintetiza a interação de diâmetro, fluxo e pressão vascular. $\mathrm{Na}$ realidade, o sistema circulatório não é composto por um cilindro com diâmetro constante, e sim por estruturas visco-elásticas, cujos diâmetros variam com a flutuação da pressão e fluxo impostos pela ação ventricular intermitente a cada batimento cardíaco.

Sebban et al. (1981), observando a relação entre as propriedades mecânicas, pressão arterial sistólica, freqüência cardíaca e o consumo de oxigênio em mulheres idosas submetidas a diferentes níveis de exercício, determinaram que, com o avançar da idade, a redução da complacência arterial é o fator da resposta cardiovascular que mais se altera frente ao incremento do exercício físico.

Postula-se ser a pressão arterial sistêmica elevada um determinante no aumento da espessura do complexo médio-íntima da parede arterial, produzindo degeneração e dilatação arterial, comum a diversos estados nosológicos (Salonen \& Salonen, 1993), com repercussão na elasticidade arterial (Cohn et al., 1995, Weinberger et al., 2002). A degeneração não é fruto do estresse contínuo causado pela pressão arterial, mas pela repetitiva e cíclica mudança, como a gerada pelo maior estresse pulsátil encontrado na insuficência aórtica (Prokop et al., 1970; Rutan et al., 1988). Alterações estruturais e funcionais dos vasos de condutância interferem na capacidade do sistema arterial em atuar como câmara elástica distensível, que possibilita a conversão 
do fluxo sangüíneo pulsátil ejetado do ventrículo esquerdo em fluxo capilar praticamente contínuo na periferia (Bramwell \& Hill, 1922; O'Rourke \& Brunner, 1992).

A complacência e a distensibilidade arterial têm sido obtidas através de diferentes métodos e unidades de cálculo, o que ocasiona dificuldade na comparação entre os resultados. Mais recentemente, há uma tendência de diversos grupos em adotar a mesma metodologia escolhida para ser empregada em nossos pacientes e o Sistema Internacional como referência para medidas. Nosso laboratório, seguindo a mesma linha de pesquisa, possui publicação com 41 voluntários normais de ambos os sexos e idade média de $40 \pm 2$ anos em que foram obtidos valores considerados normais de 7,6 $\pm 0,4 \mathrm{~N}^{-1} \cdot \mathrm{m}^{4} \cdot 10^{-10}$ para complacência e de $27,2 \pm 1,4 \mathrm{~N}^{-1} \cdot \mathrm{m}^{2} \cdot 10^{-6}$ para distensibilidade (Kopel \& Lage, 1995).

Nossos resultados mostram que em pacientes com insuficência aórtica crônica grave sem disfunção do ventrículo esquerdo, a complacência e distensibilidade arterial estão associadas de forma inversa aos valores da pressão arterial diastólica. Os pacientes puderam assim, independentemente da lesão regurgitante aórtica, ser separados clinicamente em grupos com pós-carga normal ou inadequadamente aumentada, não obstante a presença de insuficência aórtica crônica grave, tendo em vista a relação entre aumento na pressão arterial diastólica e elevação da resistência periférica, e seu comportamento com a complacência e a distensibilidade (Gráfico 8 e 9).

Estes dados pontuam a importância de se dar maior atenção ao estudo da pós-carga pulsátil, que pode elevar o grau de fidedignidade na avaliação da insuficência aórtica e traz a perspectiva terapêutica no intuito de 
diminuir a pós-carga, alterar a periferia e minimizar as influências sobre a remodelação ventricular.

\subsubsection{Função Endotelial}

As artérias menores são menos complacentes, mas são mais sujeitas a alterações funcionais relacionadas ao tônus vasomotor da musculatura lisa da parede arterial (O'Rourke \& Brunner, 1992) por redução na capacidade vasodilatadora dependente do endotélio (Avolio et al., 1983; McVeigh et al., 1999).

O delicado equilíbrio entre vasodilatação e vasoconstrição é rompido em estados doentios, nos quais o endotélio se encontra lesado e com distúrbio de suas propriedades regulatórias. Este fato leva a uma liberação atenuada de óxido nítrico e aumentada de endotelina, com conseqüente vasoconstrição (Miller et al., 1986; Lerman et al., 1992). Uma interação entre o óxido nítrico e a endotelina é de potencial importância, tanto na fisiologia quanto na patologia das doenças cardiovasculares. Miller et al. (1995) demonstraram, em cães, que a concentração de endotelina pode ser rápida e efetivamente revertida pelo óxido nítrico. Esse achado foi, por sua vez, extendido por Lüscher et al. (1995) que demonstraram em humanos a vasoconstrição arterial induzida pela endotelina completamente inibida por óxido nítrico e mais ainda, que a endotelina pode liberar o óxido nítrico através da ativação de receptores específicos do endotélio.

Adicionalmente, as células endoteliais sintetizam outros fatores de relaxamento e substâncias contráteis. No entanto, diversos estudos confirmam o óxido nítrico como o principal determinante do tônus vascular basal (Griffith et 
al., 1989; Benjamin et al., 1989; Katz, 1997; Kiowski et al., 1998). Outro mecanismo de disfunção endotelial seria a degradação aumentada de óxido nítrico pelo ânion superóxido e produção de radicais livres, principalmente em decorrência da elevação da enzima NADH-oxidase (Munzel et al.,1999; Harrison, 1997). Estudos experimentais mostram que tanto a angiotensina II como o fator de necrose tumoral (alfa-TNF) podem estimular a atividade ou a expressão dessa enzima (Warnholtz et al., 1999; Griendling et al., 1994). Abrem-se assim perspectivas para o estudo da participação de fatores humorais e citocinas como parte do mecanismo determinante dessa disfunção (Opasich $e t$ al., 1999).

A função endotelial tem sido avaliada por método mais simples e capaz de sintetizar os mecanismos bioquímicos descritos acima através do uso de ultra-som de alta freqüência sobre a artéria braquial em intervalos de tempo fixos (1 minuto após oclusão e 3 minutos após nitrato) para a determinação de alterações dinâmicas no diâmetro e fluxo do vaso, assumindo-se a ausência de variabilidade temporal na resposta aos estímulos endotélio-dependente e endotélio-independente (Palinkas et al., 2002).

Langille \& O'Donnell (1986) mostraram que doenças crônicas que diminuem o fluxo sangüíneo arterial levam à diminuição do diâmetro arterial. Esta diminuição no diâmetro do vaso é vista apenas quando o endotélio está intacto. Após a retirada do endotélio do vaso, o diâmetro não se altera com a diminuição do fluxo sangüíneo, sugerindo que o efeito é endotélio-dependente, o que torna importante não a determinação do diâmetro absoluto, mas da variação percentual do diâmetro, equivalente à reserva vasodilatadora mediada pelo fluxo, reflexo da função endotelial. Assim, essas variáveis produzem medidas reprodutíveis da função endotelial (Leeson et al., 1997). 
O endotélio tem papel primário no processo de desenvolvimento da doença macrovascular e diversos fatores de risco, como diabetes mellitus, dislipidemia, hipertensão e tabagismo, têm sido significativamente relacionados com a disfunção endotelial por meio da DFM, o que faz com que sua influência em casos de cardiopatia isquêmica esteja bem definida (Hashimoto et al., 2003; Jadhav et al., 2003; Ercan et al., 2003). Por outro lado, é recente a demonstração de respostas vasodilatadoras alteradas em pacientes com miocardiopatia crônica sintomática, do tipo não isquêmico (Joannides et al., 1992; Bhagat et al., 1997).

Em nosso protocolo se excluíram os pacientes acima de 65 anos, porque aí ocorrem alterações funcionais por diminuição na produção de óxido nítrico pelo endotélio (Jensen-Urstad \& Rosfors, 1997), procurou-se adotar normas preconizadas de padronização no preparo para a análise com o intuito de reduzir a influência adrenérgica por agentes externos (Dietz et al., 1997; Corretti et al., 2002) e selecionar indivíduos sem fatores reconhecidos como indutores de disfunção endotelial (Quadro 1 e 2).

Os valores absolutos de diâmetro da artéria braquial na condição BASAL e REPOUSO foram maiores no MPRÉ, com regressão no M6 $(\mathrm{p}=0,0003)$. A mudança nos diâmetros esteve correlacionada à queda na velocidade do fluxo pela artéria braquial $(\mathrm{p}=0,0003)$, o que é condizente com a fisiopatologia da correção cirúrgica (Tabela 6 e Gráfico 11).

A dilatação endotélio-dependente ausente ou muito diminuída $(<6 \%)$ e a dilatação endotélio-independente normal $(>6 \%)$ nas artérias de condutância de todos os pacientes portadores de insuficência aórtica crônica 
grave podem ser explicadas pelo comprometimento do endotélio, sugerindo haver disfunção endotelial nos dois grupos (Sorensen et al., 1995) (Tabela 5).

Após o tratamento e conseqüente melhora hemodinâmica, houve melhora não significativa na função endotelial, pois a literatura considera apenas um aumento na dilatação arterial igual ou superior a $2 \%$, da fase sem tratamento para a fase pós tratamento, como indício de benefício pela terapêutica instituída (Sorensen et al., 1995) (Gráfico 10).

Em nosso conhecimento, este é o primeiro relato de disfunção endotelial em pacientes com insuficiência aórtica crônica grave. A disfunção endotelial, por redução na ação do óxido nítrico, é um sinal precoce de doença macro-vascular (Playford \& Watts, 1998). Sua detecção poderia permitir a instituição a tempo de medidas preventivas.

\subsection{Considerações Finais}

É polêmico o diagnóstico de hipertensão arterial sistêmica em casos de insuficência aórtica crônica grave. Enquanto alguns autores negam a possibilidade de sua coexistência, outros ao contrário afirmam ser alta a prevalência, cerca de 50\%, em pacientes com esta valvopatia.

A hipertensão arterial sistêmica atua não apenas na etiologia da insuficência aórtica, mas também na patogenia por comprometer um mecanismo de compensação natural com aumento no fluxo regurgitante, podendo estar implicada no surgimento de crises hipertensivas nas primeiras horas após a troca valvar e ser um fator no desgaste das valvas implantadas. 
É lícito conjecturar ser o portador de insuficência aórtica crônica grave que não manifeste a expressão hemodinâmica correspondente, definida por pressão arterial diastólica baixa, na ausência de disfunção do ventrículo esquerdo, seja em verdade hipertenso não diagnosticado devido à pseudonormalização da pressão arterial provocada pelo aumento do volume regurgitante. De fato, nossos resultados mostram que $89 \%$ dos pacientes com pressão arterial diastólica maior que $50 \mathrm{mmHg}$ tornaram-se hipertensos após a cirurgia $(p<0,001)$, o que aliado às alterações na função arterial e ao comportamento dos diâmetros ventriculares, vem a reforçar esta linha de pensamento, indicando a possibilidade dos valores de pressão arterial estarem subestimados nesta valvopatia, resultando em grande número de hipertensos falso-negativos.

Alguns autores defendem o ponto de vista de que as alterações iniciais da hipertensão arterial essencial seriam na resistência vascular e o débito cardíaco poderia estar elevado por uma hiperreatividade simpática. Outro enfoque para a patogenia é a de que o débito cardíaco persistentemente elevado, independente de ser por uma impropriedade autonômica com aumento da freqüência cardíaca e do inotropismo, ou devido ao maior retorno venoso pela volemia expandida, poderia induzir a alterações arteriolares.

$\mathrm{O}$ que se entende como determinante da pós-carga e do débito cardíaco, regulando a pressão arterial, é um mecanismo intrincado no qual interagem vários sistemas e, qualquer alteração que eleve o tônus vascular, pode conduzir ao aumento da pressão arterial, como tem sido demonstrado nas doenças renais, renovasculares, endócrinas, metabólicas, neurológicas e vasculares. 
Esses achados sugerem que a origem da hipertensão arterial essencial seria reflexo tanto do descontrole no débito cardíaco como no ajuste da resistência arteriolar a este débito e qualquer fator que o eleve cronicamente em um indivíduo suscetível, com incapacidade de reconhecer a elevação da pressão arterial ou ainda com hiperreatividade vascular por disfunção endotelial, poderia desencadear a hipertensão arterial sistêmica essencial.

Em nosso estudo, teve-se a oportunidade de acompanhar pacientes com insuficência aórtica grave, em que o distúrbio hemodinâmico atingiu o seu mais alto grau e foi ainda revertido após a cirurgia. A população nele participante demonstra que o estudo da função arterial pode elevar o grau de fidedignidade da avaliação clínica e laboratorial na insuficência aórtica e traz a perspectiva da influência farmacológica sobre a história natural com o uso de vasodilatadores arteriais no intuito de diminuir a influência da pós-carga, alterar a periferia e minimizar as influências sobre a remodelação ventricular.

A interação observada entre a morfologia e função do ventrículo esquerdo, valva aórtica, aorta e circulação periférica, fortalece o conceito de se ter em mente o sistema circulatório na avaliação da insuficência aórtica. Desta forma, o presente estudo afigurou-se como instrumento útil para a obtenção de informações sobre um componente freqüentemente negligenciado. 
- A complacência e a distensibilidade arterial foram maiores no grupo com menor pressão arterial diastólica em todos os momentos avaliados, permitindo separar sub-grupos através do exame clínico;

- A complacência e a distensibilidade arterial diminuíram após a correção cirúrgica da insuficiência aórtica em ambos os grupos, e de forma mais importante no grupo $\mathrm{G}<50$;

- A disfunção endotelial foi presente em insuficiência aórtica crônica sintomática independente do nível da pressão arterial diastólica e persistiu ao menos até o $6^{\circ}$ mês após a cirurgia. 


\section{ANEXOS}




\section{ANEXO 1 : GRUPOS DE ESTUDO}

\begin{tabular}{|c|c|c|c|c|c|}
\hline INICIAIS & GRUPO & $\begin{array}{l}\text { IDADE } \\
\text { (ANOS) }\end{array}$ & SEXO & COR & $\mathrm{AF}$ de HAS \\
\hline A.A.M.S. & $\begin{array}{c}G>50 \\
\end{array}$ & 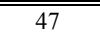 & Feminino & Branca & Positivo \\
\hline A.G. & $\mathrm{G}<50$ & 65 & Masculino & Branca & Negativo \\
\hline A.N. & $\mathrm{G}>50$ & 46 & Masculino & Branca & Negativo \\
\hline C.A.F. & $\mathrm{G}<50$ & 29 & Masculino & Branca & Negativo \\
\hline C.F.A. & $\mathrm{G}>50$ & 62 & Masculino & Branca & Negativo \\
\hline C.P.S. & $\mathrm{G}<50$ & 39 & Masculino & Branca & Negativo \\
\hline C.R.S. & $\mathrm{G}>50$ & 38 & Masculino & Não-Branca & Negativo \\
\hline D.E.S. & $\mathrm{G}<50$ & 19 & Masculino & Branca & Negativo \\
\hline D.L.B. & $\mathrm{G}<50$ & 57 & Masculino & Não-Branca & Negativo \\
\hline D.M. & $\mathrm{G}<50$ & 32 & Masculino & Branca & Negativo \\
\hline F.G.L. & $\mathrm{G}>50$ & 51 & Masculino & Branca & Negativo \\
\hline F.V.P. & $\mathrm{G}>50$ & 65 & Masculino & Não-Branca & Negativo \\
\hline G.R.S. & $\mathrm{G}>50$ & 50 & Feminino & Branca & Negativo \\
\hline J.A.L. & $\mathrm{G}<50$ & 49 & Masculino & Branca & Negativo \\
\hline J.B.L. & $\mathrm{G}>50$ & 54 & Masculino & Branca & Negativo \\
\hline J.C.H. & $\mathrm{G}>50$ & 59 & Masculino & Não-Branca & Negativo \\
\hline J.C.M. & $\mathrm{G}<50$ & 42 & Masculino & Branca & Negativo \\
\hline J.S.B. & $\mathrm{G}>50$ & 65 & Masculino & Não-Branca & Positivo \\
\hline J.S.L. & $\mathrm{G}<50$ & 35 & Masculino & Branca & Negativo \\
\hline L.A.F. & $\mathrm{G}<50$ & 23 & Masculino & Não-Branca & Negativo \\
\hline L.N.H. & $\mathrm{G}>50$ & 62 & Masculino & Branca & Negativo \\
\hline M.A.S. & $\mathrm{G}>50$ & 49 & Feminino & Não-Branca & Positivo \\
\hline M.C.F.G.P. & $\mathrm{G}>50$ & 53 & Feminino & Não-Branca & Negativo \\
\hline M.H.S. & $\mathrm{G}>50$ & 55 & Feminino & Não-Branca & Negativo \\
\hline M.P. & $\mathrm{G}<50$ & 57 & Feminino & Branca & Negativo \\
\hline N.J.P. & $\mathrm{G}>50$ & 44 & Masculino & Branca & Negativo \\
\hline O.B.O. & $\mathrm{G}>50$ & 65 & Masculino & Não-Branca & Positivo \\
\hline O.S.S. & $\mathrm{G}<50$ & 40 & Feminino & Branca & Negativo \\
\hline P.M.C. & $\mathrm{G}<50$ & 28 & Masculino & Não-Branca & Negativo \\
\hline P.S. & $\mathrm{G}>50$ & 55 & Masculino & Branca & Negativo \\
\hline R.C.G.A. & $\mathrm{G}<50$ & 36 & Masculino & Não-Branca & Negativo \\
\hline R.M.N. & $\mathrm{G}>50$ & 65 & Masculino & Branca & Positivo \\
\hline R.R.M. & $\mathrm{G}>50$ & 50 & Masculino & Não-Branca & Positivo \\
\hline S.R.C.L. & $\mathrm{G}<50$ & 33 & Feminino & Branca & Negativo \\
\hline V.J.S. & $\mathrm{G}>50$ & 47 & Masculino & Não-Branca & Positivo \\
\hline W.C.S. & $\mathrm{G}<50$ & 19 & Masculino & Não-Branca & Negativo \\
\hline
\end{tabular}


ANEXO 2 : PRESSÃO ARTERIAL DIASTÓLICA

\begin{tabular}{|c|c|c|c|c|c|}
\hline \multirow{2}{*}{ INICIAIS } & \multirow{2}{*}{ GRUPO } & \multicolumn{4}{|c|}{ PAD (mmHg) } \\
\hline & & MPRÉ & M1 & M3 & M6 \\
\hline A.A.M.S. & $\overline{G \mathrm{G}>50}$ & 96 & $\begin{array}{ll}100 \\
\end{array}$ & 100 & 106 \\
\hline A.G. & $\mathrm{G}<50$ & 44 & 68 & 70 & 70 \\
\hline A.N. & $\mathrm{G}>50$ & 61 & 100 & 92 & 95 \\
\hline C.A.F. & $\mathrm{G}<50$ & 43 & 80 & 78 & 82 \\
\hline C.F.A. & $\mathrm{G}>50$ & 50 & 85 & 80 & 83 \\
\hline C.P.S. & $\mathrm{G}<50$ & 48 & 60 & 60 & 66 \\
\hline C.R.S. & $\mathrm{G}>50$ & 55 & 100 & 100 & 95 \\
\hline D.E.S. & $\mathrm{G}<50$ & 38 & 60 & 58 & 66 \\
\hline D.L.B. & $\mathrm{G}<50$ & 45 & 100 & 98 & 110 \\
\hline D.M. & $\mathrm{G}<50$ & 46 & 70 & 62 & 65 \\
\hline F.G.L. & $\mathrm{G}>50$ & 59 & 90 & 86 & 87 \\
\hline F.V.P. & $\mathrm{G}>50$ & 53 & 95 & 95 & 91 \\
\hline G.R.S. & $\mathrm{G}>50$ & 67 & 90 & 100 & 88 \\
\hline J.A.L. & $\mathrm{G}<50$ & 50 & 86 & 90 & 106 \\
\hline J.B.L. & $\mathrm{G}>50$ & 80 & 100 & 90 & 94 \\
\hline J.C.H. & $\mathrm{G}>50$ & 57 & 100 & 90 & 95 \\
\hline J.C.M. & $\mathrm{G}<50$ & 49 & 90 & 78 & 84 \\
\hline J.S.B. & $\mathrm{G}>50$ & 98 & 102 & 110 & 108 \\
\hline J.S.L. & $\mathrm{G}<50$ & 41 & 83 & 82 & 83 \\
\hline L.A.F. & $\mathrm{G}<50$ & 47 & 70 & 70 & 69 \\
\hline L.N.H. & $\mathrm{G}>50$ & 75 & 107 & 100 & 89 \\
\hline M.A.S. & $\mathrm{G}>50$ & 94 & 90 & 90 & 91 \\
\hline M.C.F.G.P. & $\mathrm{G}>50$ & 62 & 86 & 86 & 82 \\
\hline M.H.S. & $\mathrm{G}>50$ & 71 & 89 & 90 & nd \\
\hline M.P. & $\mathrm{G}<50$ & 47 & 65 & 60 & 69 \\
\hline N.J.P. & $\mathrm{G}>50$ & 55 & nd & nd & nd \\
\hline O.B.O. & $\mathrm{G}>50$ & 90 & 130 & 127 & 128 \\
\hline O.S.S. & $G<50$ & 47 & 75 & 70 & 76 \\
\hline P.M.C. & $\mathrm{G}<50$ & 45 & 80 & 82 & 83 \\
\hline P.S. & $\mathrm{G}>50$ & 75 & 90 & 90 & 94 \\
\hline R.C.G.A. & $\mathrm{G}<50$ & 45 & 69 & 75 & 81 \\
\hline R.M.N. & $\mathrm{G}>50$ & 71 & 105 & 98 & 119 \\
\hline R.R.M. & $\mathrm{G}>50$ & 69 & 100 & 96 & 115 \\
\hline S.R.C.L. & $\mathrm{G}<50$ & 39 & 65 & 62 & 69 \\
\hline V.J.S. & $\mathrm{G}>50$ & 66 & 120 & 115 & 114 \\
\hline W.C.S. & $\mathrm{G}<50$ & 46 & 70 & 68 & 73 \\
\hline
\end{tabular}

$\mathrm{G}<50$

70 
ANEXO 3 : VARIÁVEIS ECOCARDIOGRÁFICAS E VENTRÍCULO-RADIOISOTÓPICA

\begin{tabular}{|c|c|c|c|c|c|c|c|c|c|c|c|c|c|}
\hline \multirow{2}{*}{ INICIAIS } & \multirow{2}{*}{ GRUPO } & \multicolumn{6}{|c|}{ MPRÉ } & \multicolumn{6}{|c|}{ M6 } \\
\hline & & DSVE & DDVE & DSVE $/ \mathrm{m}^{2}$ & DDVE $/ \mathrm{m}^{2}$ & $\Delta \mathrm{d}$ & FEVE & DSVE & DDVE & DSVE $/ \mathrm{m}^{2}$ & DDVE $/ \mathrm{m}^{2}$ & $\Delta \mathrm{d}$ & FEVE \\
\hline A.A.M.S. & $\mathrm{G}>50$ & 34 & 254 & $1,1,9$ & 3,0 & 37,0 & 58 & 38 & 253 & 2,36 & $3,3,29$ & 28,30 & 52 \\
\hline A.G. & $\mathrm{G}<50$ & 61 & 74 & 4,1 & 5,0 & 17,6 & 40 & 57 & 67 & 3,85 & 4,53 & 14,93 & 61 \\
\hline A.N. & $\mathrm{G}>50$ & 47 & 69 & 2,4 & 3,6 & 31,9 & 59 & 33 & 52 & 1,75 & 2,75 & 36,54 & 59 \\
\hline C.A.F. & $\mathrm{G}<50$ & 59 & 88 & 3,2 & 4,8 & 33,0 & 59 & 46 & 57 & 2,54 & 3,15 & 19,30 & 46 \\
\hline C.F.A. & $\mathrm{G}>50$ & 41 & 60 & 2,6 & 3,8 & 31,7 & 55 & 37 & 50 & 2,31 & 3,13 & 26,00 & 42 \\
\hline C.P.S. & $\mathrm{G}<50$ & 82 & 92 & 4,5 & 5,1 & 10,9 & 29 & 84 & 92 & 4,54 & 4,97 & 8,70 & 18 \\
\hline C.R.S. & $\mathrm{G}>50$ & 59 & 83 & 3,5 & 4,9 & 28,9 & 46 & 85 & 93 & 4,64 & 5,08 & 8,60 & 26 \\
\hline D.E.S. & $\mathrm{G}<50$ & 45 & 72 & 2,8 & 4,5 & 37,5 & 57 & 38 & 56 & 2,11 & 3,11 & 32,14 & 68 \\
\hline D.L.B. & $\mathrm{G}<50$ & 59 & 79 & 3,3 & 4,5 & 25,3 & 51 & 52 & 62 & 2,94 & 3,50 & 16,13 & 33 \\
\hline D.M. & $\mathrm{G}<50$ & 54 & 72 & 3,3 & 4,4 & 25,0 & 48 & 51 & 66 & 3,13 & 4,05 & 22,73 & 46 \\
\hline F.G.L. & $\mathrm{G}>50$ & 63 & 83 & 3,8 & 5,0 & 24,1 & 42 & 48 & 58 & 3,20 & 3,87 & 17,24 & 40 \\
\hline F.V.P. & $\mathrm{G}>50$ & 50 & 70 & 2,9 & 4,1 & 28,6 & 61 & 43 & 62 & 2,40 & 3,46 & 30,65 & 60 \\
\hline G.R.S. & $\mathrm{G}>50$ & 34 & 56 & 1,7 & 2,8 & 39,3 & 56 & 30 & 46 & 1,59 & 2,43 & 34,78 & 53 \\
\hline J.A.L. & $\mathrm{G}<50$ & 49 & 74 & 2,5 & 3,8 & 33,8 & 57 & 49 & 74 & 2,27 & 3,26 & 23,53 & 56 \\
\hline J.B.L. & $\mathrm{G}>50$ & 50 & 64 & 2,9 & 3,7 & 21,9 & 42 & 48 & 63 & 2,79 & 3,66 & 23,81 & 36 \\
\hline J.C.H. & $\mathrm{G}>50$ & 60 & 75 & 3,2 & 3,9 & 20,0 & 59 & 50 & 60 & 2,60 & 3,13 & 16,67 & 33 \\
\hline J.C.M. & $\mathrm{G}<50$ & 62 & 75 & 3,8 & 4,6 & 17,3 & 31 & 68 & 75 & 4,33 & 4,78 & 9,33 & 24 \\
\hline J.S.B. & $\mathrm{G}>50$ & 43 & 63 & 2,4 & 3,5 & 31,7 & 61 & 36 & 55 & 2,07 & 3,16 & 34,55 & 62 \\
\hline J.S.L. & $\mathrm{G}<50$ & 57 & 82 & 3,3 & 4,8 & 30,5 & 60 & 36 & 52 & 2,00 & 2,89 & 30,77 & 62 \\
\hline L.A.F. & $\mathrm{G}<50$ & 66 & 88 & 3,4 & 4,6 & 25,0 & 43 & 57 & 75 & 2,86 & 3,77 & 24,00 & 37 \\
\hline L.N.H. & $\mathrm{G}>50$ & 47 & 66 & 2,5 & 3,5 & 28,8 & 48 & 44 & 64 & 2,56 & 3,72 & 31,25 & 35 \\
\hline M.A.S. & $\mathrm{G}>50$ & 41 & 53 & 2,4 & 3,1 & 22,6 & 51 & 28 & 45 & 1,70 & 2,73 & 37,78 & 48 \\
\hline M.C.F.G.P. & $\mathrm{G}>50$ & 36 & 57 & 2,3 & 3,6 & 36,8 & 58 & 29 & 46 & 1,81 & 2,88 & 36,96 & 63 \\
\hline M.H.S. & $\mathrm{G}>50$ & 54 & 73 & 3,2 & 4,4 & 26,0 & 50 & nd & nd & nd & nd & nd & nd \\
\hline M.P. & $\mathrm{G}<50$ & 46 & 66 & 3,0 & 4,3 & 30,3 & 63 & 34 & 52 & 1,92 & 2,94 & 34,62 & 54 \\
\hline N.J.P. & $\mathrm{G}>50$ & 61 & 81 & 3,8 & 5,1 & 24,7 & 40 & nd & nd & nd & nd & nd & nd \\
\hline O.B.O. & $\mathrm{G}>50$ & 55 & 70 & 3,2 & 4,1 & 21,4 & 56 & 38 & 51 & 2,21 & 2,97 & 25,49 & 47 \\
\hline O.S.S. & $\mathrm{G}<50$ & 48 & 79 & 3,2 & 5,3 & 39,2 & 47 & 44 & 58 & 3,24 & 4,26 & 24,14 & 45 \\
\hline P.M.C. & $\mathrm{G}<50$ & 47 & 78 & 2,2 & 3,7 & 39,7 & 68 & 35 & 55 & 1,58 & 2,49 & 36,36 & 74 \\
\hline P.S. & $\mathrm{G}>50$ & 44 & 66 & 2,3 & 3,4 & 33,3 & 53 & 42 & 53 & 2,21 & 2,79 & 20,75 & 57 \\
\hline R.C.G.A. & $\mathrm{G}<50$ & 51 & 76 & 2,9 & 4,3 & 32,9 & 49 & 41 & 54 & 2,37 & 3,12 & 24,07 & 53 \\
\hline R.M.N. & $\mathrm{G}>50$ & 56 & 70 & 3,6 & 4,5 & 20,0 & 50 & 67 & 74 & 4,19 & 4,63 & 9,46 & 28 \\
\hline R.R.M. & $\mathrm{G}>50$ & 51 & 70 & 2,6 & 3,6 & 27,1 & 60 & 52 & 79 & 2,68 & 4,07 & 34,18 & 57 \\
\hline S.R.C.L. & $\mathrm{G}<50$ & 63 & 93 & 4,0 & 6,0 & 32,3 & 52 & 41 & 63 & 2,59 & 3,99 & 34,92 & 44 \\
\hline V.J.S. & $\mathrm{G}>50$ & 49 & 72 & 2,7 & 4,0 & 31,9 & 61 & 45 & 58 & 2,47 & 3,19 & 22,41 & 50 \\
\hline W.C.S. & $\mathrm{G}<50$ & 47 & 72 & 3,2 & 4,9 & 34,7 & 57 & 48 & 62 & 3,20 & 4,13 & 22,58 & 48 \\
\hline
\end{tabular}

ventrículo esquerdo e a superfície corporal; DDVE $/ \mathrm{m}^{2}=$ relação entre o diâmetro diastólico do ventrículo esquerdo e a superfície corporal $; \Delta \mathrm{d}=$ fração de encurtamento; FEVE = fração de ejeçãao do ventrículo esquerdo; nd = não disponível. 
ANEXO 4 : PÓS-CARGA PULSÁTIL EM ARTÉRIA CARÓTIDA NA CONDIÇÃO BASAL 1 E BASAL 2

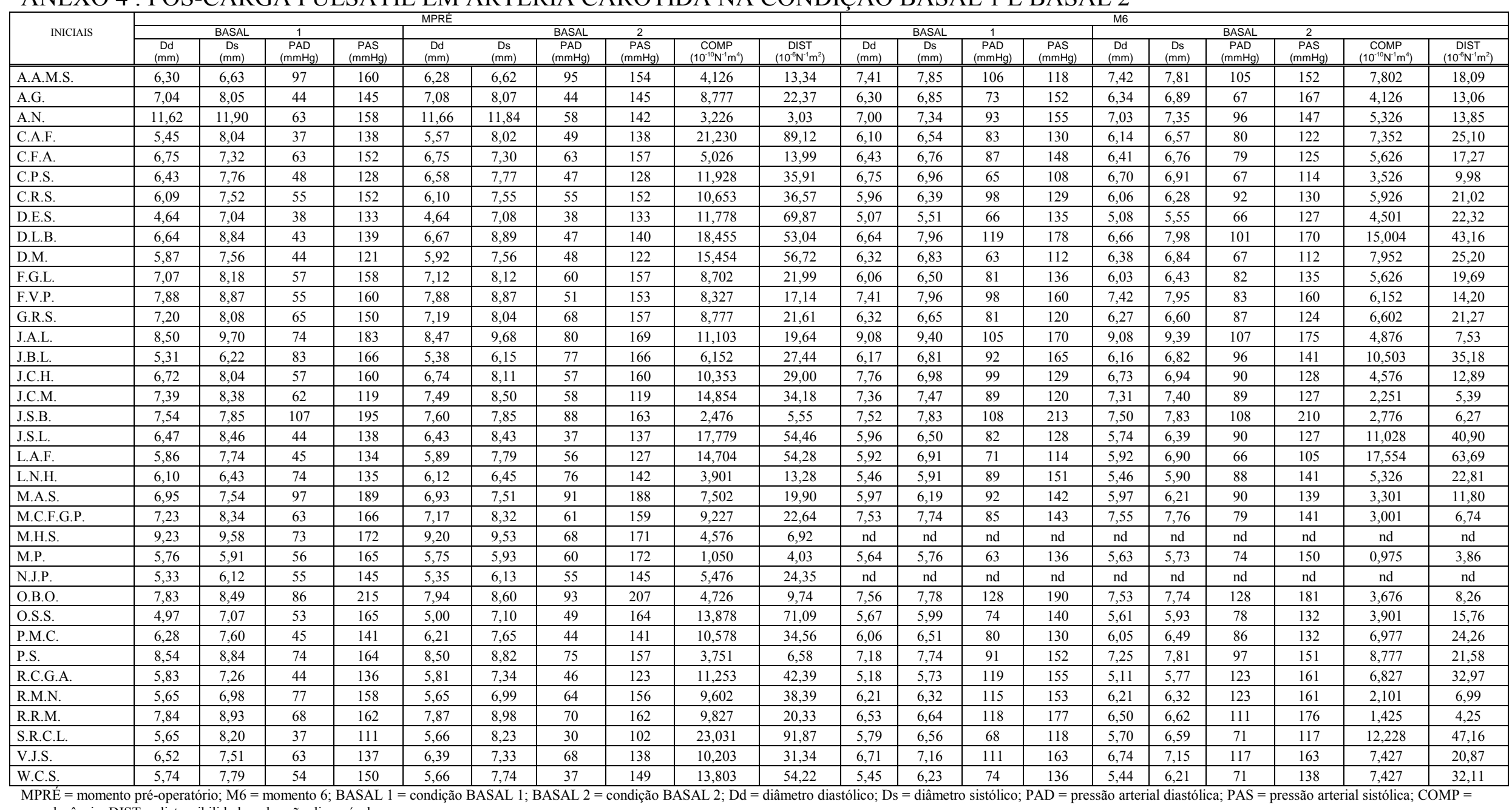

MPRE $=$ momento pré-operatório; $\mathrm{M} 6=$ momento 6 ; BASAL
complacência; DIST = distensibilidade; nd = não disponível. 
Anexos 58

ANEXO 5-1 : DIÂMETRO E FLUXO SANGÜÍNEO EM ARTÉRIA BRAQUIAL NA CONDICCÃO BASAL

\begin{tabular}{|c|c|c|c|c|c|c|c|c|c|c|}
\hline Iniciais & $\begin{array}{c}\text { Ds } \\
(\mathrm{mm})\end{array}$ & $\begin{array}{c}\text { AST } \\
\left(\mathrm{mm}^{2}\right)\end{array}$ & $\begin{array}{l}\text { MPRÉ } \\
\text { Vmáx } \\
(\mathrm{m} / \mathrm{s}) \\
\end{array}$ & $\begin{array}{c}\mathrm{SC} \\
\left(\mathrm{m}^{2}\right) \\
\end{array}$ & $\begin{array}{c}\text { IFS } \\
\left(1 / \mathrm{min} / \mathrm{m}^{2}\right) \\
\end{array}$ & $\begin{array}{c}\begin{array}{c}\text { Ds } \\
(\mathrm{mm})\end{array} \\
\end{array}$ & $\begin{array}{c}\text { AST } \\
\left(\mathrm{mm}^{2}\right) \\
\end{array}$ & $\begin{array}{r}\text { M6 } \\
\text { Vmáx } \\
(\mathrm{m} / \mathrm{s}) \\
\end{array}$ & $\begin{array}{c}\mathrm{SC} \\
\left(\mathrm{m}^{2}\right) \\
\end{array}$ & $\begin{array}{c}\text { IFS } \\
\left(1 / \mathrm{min} / \mathrm{m}^{2}\right) \\
\end{array}$ \\
\hline A.A.M.S. & 44,30 & $\begin{array}{l}58,09 \\
\end{array}$ & 0,54 & 1,83 & 1,03 & $\begin{array}{l}4,24 \\
\end{array}$ & $\begin{array}{c}56,48 \\
\end{array}$ & 0,39 & \begin{tabular}{ll|}
1,61 \\
\end{tabular} & 0,82 \\
\hline A.G. & 4,51 & 63,90 & 1,05 & 1,48 & 2,72 & 3,63 & 41,39 & 0,62 & 1,49 & 1,03 \\
\hline A.N. & 5,40 & 91,61 & 0,81 & 1,92 & 2,32 & 5,32 & 88,91 & 0,42 & 1,89 & 1,19 \\
\hline C.A.F. & 5,49 & 94,69 & 1,74 & 1,82 & 5,43 & 4,11 & 53,07 & 0,69 & 1,81 & 1,21 \\
\hline C.F.A. & 4,58 & 65,90 & 1 & 1,56 & 2,53 & 4,65 & 67,92 & 0,55 & 1,60 & 1,40 \\
\hline C.P.S. & 4,55 & 65,04 & 1,34 & 1,82 & 2,87 & 4,65 & 67,92 & 0,45 & 1,85 & 0,99 \\
\hline C.R.S. & 5,30 & 88,24 & 1,03 & 1,70 & 3,21 & 4,84 & 73,59 & 0,34 & 1,83 & 0,82 \\
\hline D.E.S. & 3,86 & 46,81 & 1,01 & 1,59 & 1,78 & 3,86 & 46,80 & 0,85 & 1,80 & 1,33 \\
\hline D.L.B. & 4,29 & 57,82 & 0,84 & 1,77 & 1,65 & 4,43 & 61,65 & 0,41 & 1,77 & 0,86 \\
\hline D.M. & 4,41 & 61,10 & 1,08 & 1,64 & 2,41 & 4,43 & 61,65 & 0,48 & 1,63 & 1,09 \\
\hline F.G.L. & 4,52 & 64,18 & 0,84 & 1,67 & 1,94 & 4,36 & 59,72 & 0,57 & 1,50 & 1,36 \\
\hline F.V.P. & 6,45 & 130,69 & 0,58 & 1,92 & 2,37 & 6,44 & 130,29 & 0,28 & 1,79 & 1,22 \\
\hline G.R.S. & 4,19 & 55,15 & 0,77 & 2,03 & 1,26 & 3,79 & 45,12 & 0,67 & 1,89 & 0,96 \\
\hline J.A.L. & 4,54 & 64,75 & 0,7 & 1,96 & 1,39 & 4,36 & 59,72 & 0,6 & 1,81 & 1,19 \\
\hline J.B.L. & 3,93 & 48,52 & 0,7 & 1,72 & 1,18 & 3,77 & 44,64 & 0,68 & 1,72 & 1,06 \\
\hline J.C.H. & 4,42 & 61,37 & 0,63 & 1,90 & 1,22 & 3,56 & 39,81 & 0,36 & 1,92 & 0,45 \\
\hline J.C.M. & 4,11 & 53,07 & 0,7 & 1,62 & 1,38 & 4,33 & 58,90 & 0,44 & 1,57 & 0,99 \\
\hline J.S.B. & 6,46 & 131,10 & 0,82 & 1,82 & 3,54 & 5,22 & 85,60 & 0,58 & 1,74 & 1,71 \\
\hline J.S.L. & 4,52 & 64,18 & 1,43 & 1,71 & 3,22 & 4,20 & 55,42 & 0,43 & 1,80 & 0,79 \\
\hline L.A.F. & 4,24 & 56,48 & 1,43 & 1,93 & 2,51 & 3,85 & 46,56 & 0,8 & 1,99 & 1,12 \\
\hline L.N.H. & 5,86 & 1,02 & 0,57 & 1,87 & 0,02 & 5,03 & 79,48 & 0,44 & 1,72 & 1,22 \\
\hline M.A.S. & 4,86 & 74,20 & 0,51 & 1,69 & 1,34 & 3,66 & 42,08 & 0,46 & 1,65 & 0,70 \\
\hline M.C.F.G.P. & 3,13 & 30,78 & 0,68 & 1,60 & 0,78 & 2,90 & 26,42 & 0,44 & 1,60 & 0,44 \\
\hline M.H.S. & 4,68 & 68,81 & 0,7 & 1,67 & 1,73 & nd & nd & nd & nd & nd \\
\hline M.P. & 4,21 & 55,68 & 0,82 & 1,52 & 1,80 & 3,32 & 34,63 & 0,52 & 1,77 & 0,61 \\
\hline N.J.P. & 4,65 & 67,93 & 0,83 & 1,60 & 2,11 & nd & nd & nd & nd & nd \\
\hline O.B.O. & 5,69 & 101,71 & 0,68 & 1,72 & 2,41 & 5,20 & 84,95 & 0,28 & 1,72 & 0,83 \\
\hline O.S.S. & 4,19 & 2,32 & 0,86 & 1,50 & 0,08 & 4,09 & 52,55 & 0,47 & 1,36 & 1,09 \\
\hline P.M.C. & 5,57 & 97,46 & 1,12 & 2,13 & 3,07 & 5,29 & 87,91 & 0,5 & 2,21 & 1,19 \\
\hline P.S. & 5,92 & 110,10 & 0,72 & 1,95 & 2,44 & 4,85 & 73,90 & 0,45 & 1,95 & 1,02 \\
\hline R.C.G.A. & 3,41 & 36,53 & 0,89 & 1,76 & 1,11 & 3,86 & 46,81 & 0,6 & 1,73 & 0,97 \\
\hline R.M.N. & 4,56 & 65,32 & 0,92 & 1,56 & 2,31 & 4,37 & 59,99 & 0,38 & 1,60 & 0,85 \\
\hline R.R.M. & 5,97 & 111,97 & 0,95 & 1,96 & 3,26 & 5,61 & 98,87 & 0,51 & 1,96 & 1,54 \\
\hline S.R.C.L. & 3,41 & 36,53 & 1,18 & 1,56 & 1,66 & 4,01 & 50,52 & 0,5 & 1,58 & 0,96 \\
\hline & 5,45 & 93,31 & 0,79 & 1,81 & 2,44 & 5,12 & 82,35 & 0,28 & 1,82 & 0,76 \\
\hline W.C.S. & 4,72 & 69,99 & 2,02 & 1,48 & 5,73 & 4,14 & 53,84 & 0,72 & 1,48 & 1,57 \\
\hline
\end{tabular}

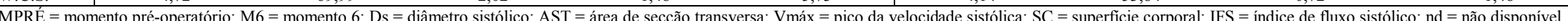


Anexos 59

ANEXO 5-2 : DIÂMETRO E FLUXO SANGÜÍNEO EM ARTÉRIA BRAQUIAL NA CONDIÇÃO DFM

\begin{tabular}{|c|c|c|c|c|c|c|c|c|c|c|}
\hline \multirow[b]{2}{*}{ Iniciais } & \multicolumn{6}{|c|}{ MPRÉ } & \multicolumn{4}{|c|}{ M6 } \\
\hline & $\begin{array}{c}\mathrm{Ds} \\
(\mathrm{mm}) \\
\end{array}$ & $\begin{array}{c}\text { AST } \\
\left(\mathrm{mm}^{2}\right)\end{array}$ & $\begin{array}{l}\text { Vmáx } \\
(\mathrm{m} / \mathrm{s})\end{array}$ & $\begin{array}{c}\mathrm{SC} \\
\left(\mathrm{m}^{2}\right) \\
\end{array}$ & $\begin{array}{c}\text { IFS } \\
\left(1 / \mathrm{min} / \mathrm{m}^{2}\right) \\
\end{array}$ & $\begin{array}{c}\text { Ds } \\
(\mathrm{mm})\end{array}$ & $\begin{array}{c}\text { AST } \\
\left(\mathrm{mm}^{2}\right) \\
\end{array}$ & $\begin{array}{l}\text { Vmáx } \\
(\mathrm{m} / \mathrm{s})\end{array}$ & $\begin{array}{c}\mathrm{SC} \\
\left(\mathrm{m}^{2}\right) \\
\end{array}$ & $\begin{array}{c}\text { IFS } \\
\left(1 / \mathrm{min} / \mathrm{m}^{2}\right) \\
\end{array}$ \\
\hline A.A.M.S. & 4,35 & 59,45 & 1,71 & 1,83 & 3,33 & 4,42 & 61,37 & 1,08 & 1,61 & 2,47 \\
\hline A.G. & 4,75 & 70,88 & 1,25 & 1,48 & 3,59 & 4,14 & 53,84 & 1,03 & 1,49 & 2,23 \\
\hline A.N. & 5,55 & 96,77 & 1,14 & 1,92 & 3,45 & 5,50 & 95,03 & 1,62 & 1,89 & 4,89 \\
\hline C.A.F. & 5,47 & 94,00 & 2,49 & 1,82 & 7,72 & 4,44 & 61,93 & 0,89 & 1,81 & 1,83 \\
\hline C.F.A. & 4,91 & 75,74 & 0,94 & 1,56 & 2,74 & 4,78 & 71,77 & 1,05 & 1,60 & 2,83 \\
\hline C.P.S. & 4,72 & 69,99 & 1,43 & 1,82 & 3,30 & 4,77 & 71,47 & 1,26 & 1,85 & 2,92 \\
\hline C.R.S. & 5,89 & 108,99 & 1,32 & 1,70 & 5,08 & 4,93 & 76,35 & 0,96 & 1,83 & 2,40 \\
\hline D.E.S. & 3,94 & 48,77 & 2,14 & 1,59 & 3,94 & 4,21 & 55,68 & 1,76 & 1,80 & 3,27 \\
\hline D.L.B. & 4,52 & 64,18 & 1,08 & 1,77 & 2,35 & 4,64 & 67,63 & 0,68 & 1,77 & 1,56 \\
\hline D.M. & 4,42 & 61,37 & 1,1 & 1,64 & 2,47 & 4,60 & 66,47 & 1,77 & 1,63 & 4,33 \\
\hline F.G.L. & 4,90 & 75,43 & 1,46 & 1,67 & 3,96 & 4,56 & 65,32 & 0,84 & 1,50 & 2,19 \\
\hline F.V.P. & 6,49 & 132,32 & 1,02 & 1,92 & 4,22 & 6,42 & 129,48 & 0,95 & 1,79 & 4,12 \\
\hline G.R.S. & 4,63 & 67,34 & 1,15 & 2,03 & 2,29 & 3,89 & 47,53 & 0,8 & 1,89 & 1,21 \\
\hline J.A.L. & 4,97 & 77,60 & 0,67 & 1,96 & 1,59 & 4,47 & 62,77 & 0,98 & 1,81 & 2,04 \\
\hline J.B.L. & 3,95 & 49,02 & 1,31 & 1,72 & 2,24 & 3,77 & 44,64 & 0,98 & 1,72 & 1,53 \\
\hline J.C.H. & 4,46 & 62,49 & 1,33 & 1,90 & 2,62 & 4,13 & 53,58 & 1,14 & 1,92 & 1,91 \\
\hline J.C.M. & 4,47 & 62,77 & 0,75 & 1,62 & 1,74 & 4,70 & 69,40 & 1,35 & 1,57 & 3,58 \\
\hline J.S.B. & 6,64 & 138,51 & 0,9 & 1,82 & 4,11 & 5,82 & 106,41 & 1,23 & 1,74 & 4,51 \\
\hline J.S.L. & 4,69 & 69,10 & 1,63 & 1,71 & 3,95 & 4,35 & 59,45 & 1,26 & 1,80 & 2,50 \\
\hline L.A.F. & 4,22 & 55,95 & 1,87 & 1,93 & 3,25 & 4,29 & 57,82 & 2,13 & 1,99 & 3,71 \\
\hline L.N.H. & 5,95 & 7,94 & 1,59 & 1,87 & 0,41 & 5,14 & 83,00 & 0,82 & 1,72 & 2,37 \\
\hline M.A.S. & 4,93 & 76,35 & 0,8 & 1,69 & 2,17 & 4,13 & 53,58 & 1,07 & 1,65 & 2,08 \\
\hline M.C.F.G.P. & 8,33 & 217,99 & 1,31 & 1,60 & 4,01 & 3,22 & 32,57 & 1,14 & 1,60 & 1,39 \\
\hline M.H.S. & 4,95 & 76,97 & 0,86 & 1,67 & 2,38 & nd & nd & nd & nd & nd \\
\hline M.P. & 4,68 & 68,81 & 1,24 & 1,52 & 3,37 & 4,23 & 56,21 & 1,13 & 1,77 & 2,15 \\
\hline N.J.P. & 4,90 & 75,43 & 1 & 1,60 & 2,83 & nd & nd & nd & nd & nd \\
\hline O.B.O. & 5,72 & 102,78 & 1,2 & 1,72 & 4,30 & 5,20 & 84,95 & 0,68 & 1,72 & 2,02 \\
\hline O.S.S. & 4,63 & 3,80 & 1,1 & 1,50 & 0,17 & 4,25 & 56,74 & 1,41 & 1,36 & 3,53 \\
\hline P.M.C. & 7,62 & 182,41 & 1,47 & 2,13 & 3,75 & 5,27 & 87,25 & 2 & 2,21 & 4,74 \\
\hline P.S. & 6,34 & 126,27 & 1,18 & 1,95 & 4,58 & 5,09 & 81,39 & 1,77 & 1,95 & 4,43 \\
\hline R.C.G.A. & 4,10 & 52,81 & 1,53 & 1,76 & 2,75 & 4,30 & 58,09 & 1,64 & 1,73 & 3,30 \\
\hline R.M.N. & 4,73 & 70,28 & 1,07 & 1,56 & 2,89 & 4,33 & 58,90 & 0,86 & 1,60 & 1,90 \\
\hline R.R.M. & 6,10 & 116,90 & 1,57 & 1,96 & 5,62 & 5,79 & 105,32 & 0,94 & 1,96 & 3,03 \\
\hline S.R.C.L. & 3,45 & 37,39 & 1,66 & 1,56 & 2,39 & 4,07 & 52,04 & 1,26 & 1,58 & 2,49 \\
\hline V.J.S. & 5,57 & 97,46 & 1,08 & 1,81 & 3,49 & 5,20 & 84,95 & 1,73 & 1,82 & 4,84 \\
\hline W.C.S. & 4,98 & 77,91 & 2,13 & 1,48 & 6,73 & 4,23 & 56,21 & 1,38 & 1,48 & 3,14 \\
\hline
\end{tabular}

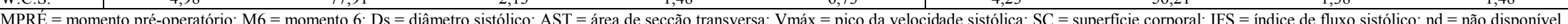


Anexos 60

ANEXO 5-3 : DIÂMETRO E FLUXO SANGÜÍNEO EM ARTÉRIA BRAQUIAL NA CONDIÇ̃̃O REPOUSO

\begin{tabular}{|c|c|c|c|c|c|c|c|c|c|c|}
\hline Iniciais & $\begin{array}{c}\mathrm{Ds} \\
(\mathrm{mm})\end{array}$ & $\begin{array}{c}\text { AST } \\
\left(\mathrm{mm}^{2}\right) \\
\end{array}$ & $\begin{array}{c}\text { MPRÉ } \\
\text { Vmáx } \\
(\mathrm{m} / \mathrm{s}) \\
\end{array}$ & $\begin{array}{c}\mathrm{SC} \\
\left(\mathrm{m}^{2}\right) \\
\end{array}$ & $\begin{array}{c}\text { IFS } \\
\left(1 / \mathrm{min} / \mathrm{m}^{2}\right) \\
\end{array}$ & $\begin{array}{c}\mathrm{Ds} \\
(\mathrm{mm}) \\
\end{array}$ & $\begin{array}{c}\mathrm{AST} \\
\left(\mathrm{mm}^{2}\right) \\
\end{array}$ & $\begin{array}{c}\text { M6 } \\
\text { Vmáx } \\
(\mathrm{m} / \mathrm{s}) \\
\end{array}$ & $\begin{array}{c}\mathrm{SC} \\
\left(\mathrm{m}^{2}\right) \\
\end{array}$ & $\begin{array}{c}\text { IFS } \\
\left(1 / \mathrm{min} / \mathrm{m}^{2}\right) \\
\end{array}$ \\
\hline A.A.M.S. & $\begin{array}{c}4,28 \\
\end{array}$ & 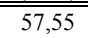 & $0,0,57$ & $\overline{c 1,83}$ & $\begin{array}{ll}1,08 \\
\end{array}$ & 4,23 & 56,21 & 0,39 & 21,61 & $\begin{array}{c}0,82 \\
\end{array}$ \\
\hline A.G. & 4,53 & 64,47 & 1,06 & 1,48 & 2,77 & 3,65 & 41,85 & 0,63 & 1,49 & 1,06 \\
\hline A.N. & 5,4 & 91,61 & 0,85 & 1,92 & 2,43 & 5,33 & 89,25 & 0,44 & 1,89 & 1,25 \\
\hline C.A.F. & 5,49 & 94,69 & 1,72 & 1,82 & 5,37 & 4,08 & 52,29 & 0,62 & 1,81 & 1,07 \\
\hline C.F.A. & 4,53 & 64,47 & 0,98 & 1,56 & 2,43 & 4,64 & 67,63 & 0,56 & 1,60 & 1,42 \\
\hline C.P.S. & 4,50 & 63,62 & 1,3 & 1,82 & 2,73 & 4,64 & 67,63 & 0,44 & 1,85 & 0,97 \\
\hline C.R.S. & 5,31 & 88,58 & 1 & 1,70 & 3,13 & 4,85 & 73,90 & 0,37 & 1,83 & 0,90 \\
\hline D.E.S. & 3,84 & 46,32 & 1,03 & 1,59 & 1,80 & 3,85 & 46,56 & 0,83 & 1,80 & 1,29 \\
\hline D.L.B. & 4,30 & 58,09 & 0,88 & 1,77 & 1,73 & 4,41 & 61,09 & 0,4 & 1,77 & 0,83 \\
\hline D.M. & 4,41 & 61,10 & 1,11 & 1,64 & 2,48 & 4,60 & 66,47 & 0,52 & 1,63 & 1,27 \\
\hline F.G.L. & 4,56 & 65,32 & 0,89 & 1,67 & 2,09 & 4,32 & 58,63 & 0,61 & 1,50 & 1,43 \\
\hline F.V.P. & 6,42 & 129,48 & 0,61 & 1,92 & 2,47 & 6,40 & 128,68 & 0,28 & 1,79 & 1,21 \\
\hline G.R.S. & 4,20 & 55,42 & 0,77 & 2,03 & 1,26 & 3,80 & 45,36 & 0,69 & 1,89 & 0,99 \\
\hline J.A.L. & 4,56 & 65,32 & 0,7 & 1,96 & 1,40 & 4,38 & 60,27 & 0,55 & 1,81 & 1,10 \\
\hline J.B.L. & 3,90 & 47,78 & 0,73 & 1,72 & 1,22 & 3,77 & 44,64 & 0,73 & 1,72 & 1,14 \\
\hline J.C.H. & 4,11 & 53,07 & 0,64 & 1,90 & 1,07 & 3,56 & 39,81 & 0,38 & 1,92 & 0,47 \\
\hline J.C.M. & 4,13 & 53,58 & 0,7 & 1,62 & 1,39 & 4,29 & 57,82 & 0,47 & 1,57 & 1,04 \\
\hline J.S.B. & 6,41 & 129,08 & 0,78 & 1,82 & 3,32 & 5,23 & 85,92 & 0,56 & 1,74 & 1,66 \\
\hline J.S.L. & 4,51 & 63,90 & 1,46 & 1,71 & 3,27 & 4,20 & 55,42 & 0,41 & 1,80 & 0,76 \\
\hline L.A.F. & 4,30 & 58,09 & 1,39 & 1,93 & 2,51 & 3,86 & 46,81 & 0,53 & 1,99 & 0,75 \\
\hline L.N.H. & 5,86 & 0,88 & 0,53 & 1,87 & 0,02 & 5,04 & 79,80 & 0,49 & 1,72 & 1,36 \\
\hline M.A.S. & 4,86 & 74,20 & 0,54 & 1,69 & 1,42 & 3,68 & 42,54 & 0,42 & 1,65 & 0,65 \\
\hline M.C.F.G.P. & 3,19 & 31,97 & 0,64 & 1,60 & 0,77 & 2,89 & 26,24 & 0,43 & 1,60 & 0,42 \\
\hline M.H.S. & 4,66 & 68,22 & 0,66 & 1,67 & 1,62 & nd & nd & nd & nd & nd \\
\hline M.P. & 4,19 & 55,15 & 0,82 & 1,52 & 1,79 & 3,33 & 34,84 & 0,46 & 1,77 & 0,54 \\
\hline N.J.P. & 4,66 & 68,22 & 0,8 & 1,60 & 2,05 & nd & nd & nd & nd & nd \\
\hline O.B.O. & 5,69 & 101,71 & 0,67 & 1,72 & 2,38 & 5,20 & 84,95 & 0,28 & 1,72 & 0,83 \\
\hline O.S.S. & 4,20 & 2,27 & 0,85 & 1,50 & 0,08 & 4,11 & 53,07 & 0,43 & 1,36 & 1,01 \\
\hline P.M.C. & 5,58 & 97,82 & 1,14 & 2,13 & 3,14 & 5,22 & 85,60 & 0,49 & 2,21 & 1,14 \\
\hline P.S. & 5,90 & 109,36 & 0,67 & 1,95 & 2,25 & 4,86 & 74,20 & 0,48 & 1,95 & 1,10 \\
\hline R.C.G.A. & 3,45 & 37,39 & 0,91 & 1,76 & 1,16 & 3,86 & 46,81 & 0,55 & 1,73 & 0,89 \\
\hline R.M.N. & nd & 116,90 & nd & nd & nd & 4,34 & 59,17 & 0,34 & 1,60 & 0,75 \\
\hline R.R.M. & 5,95 & 111,22 & 1 & 1,96 & 3,40 & 5,65 & 100,28 & 0,47 & 1,96 & 1,44 \\
\hline S.R.C.L. & 3,42 & 36,74 & 1,24 & 1,56 & 1,75 & 4,05 & 51,53 & 0,47 & 1,58 & 0,92 \\
\hline V.J.S. & 5,43 & 92,63 & 0,83 & 1,81 & 2,55 & 5,15 & 83,32 & 0,32 & 1,82 & 0,88 \\
\hline W.C.S. & 4,84 & 73,59 & 1,98 & 1,48 & 5,91 & 4,19 & 55,15 & 0,71 & 1,48 & 1,59 \\
\hline
\end{tabular}

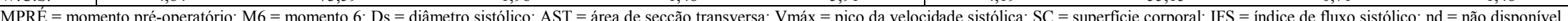


Anexos 61

ANEXO 5-4 : DIÂMETRO E FLUXO SANGÜÍNEO EM ARTÉRIA BRAQUIAL NA CONDIÇÃO DNM

\begin{tabular}{|c|c|c|c|c|c|c|c|c|c|c|}
\hline Iniciais & $\begin{array}{c}\text { Ds } \\
(\mathrm{mm})\end{array}$ & $\begin{array}{c}\text { AST } \\
\left(\mathrm{mm}^{2}\right) \\
\end{array}$ & $\begin{array}{l}\text { MPRE } \\
\text { Vmáx } \\
(\mathrm{m} / \mathrm{s}) \\
\end{array}$ & $\begin{array}{c}\mathrm{SC} \\
\left(\mathrm{m}^{2}\right) \\
\end{array}$ & $\begin{array}{c}\text { IFS } \\
\left(1 / \mathrm{min} / \mathrm{m}^{2}\right) \\
\end{array}$ & $\begin{array}{c}\text { Ds } \\
(\mathrm{mm})\end{array}$ & $\begin{array}{c}\text { AST } \\
\left(\mathrm{mm}^{2}\right)\end{array}$ & $\begin{array}{l}\text { M6 } \\
\text { Vmáx } \\
(\mathrm{m} / \mathrm{s}) \\
\end{array}$ & $\begin{array}{c}\mathrm{SC} \\
\left(\mathrm{m}^{2}\right) \\
\end{array}$ & $\begin{array}{c}\text { IFS } \\
\left(1 / \mathrm{min} / \mathrm{m}^{2}\right) \\
\end{array}$ \\
\hline A.A.M.S. & 4,55 & $\begin{array}{c}65,04 \\
\end{array}$ & 0,45 & $\begin{array}{ll}1,83 \\
\end{array}$ & $\begin{array}{c}0,96 \\
\end{array}$ & 44,69 & $\begin{array}{c}69,10 \\
\end{array}$ & 0,3 & 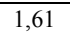 & 0,77 \\
\hline A.G. & 4,67 & 68,51 & 1,55 & 1,48 & 4,31 & 4,35 & 59,44 & 0,93 & 1,49 & 2,23 \\
\hline A.N. & 6,67 & 139,76 & 0,91 & 1,92 & 3,97 & 5,46 & 93,65 & 0,52 & 1,89 & 1,55 \\
\hline C.A.F. & 5,52 & 95,72 & 2 & 1,82 & 6,31 & 4,64 & 67,64 & 0,63 & 1,81 & 1,41 \\
\hline C.F.A. & 4,79 & 72,08 & 0,59 & 1,56 & 1,64 & 4,69 & 69,10 & 0,55 & 1,60 & 1,43 \\
\hline C.P.S. & 4,43 & 61,65 & 1,13 & 1,82 & 2,30 & 4,64 & 67,63 & 0,56 & 1,85 & 1,23 \\
\hline C.R.S. & 5,31 & 88,58 & 1,05 & 1,70 & 3,28 & 5,45 & 93,31 & 0,36 & 1,83 & 1,10 \\
\hline D.E.S. & 3,96 & 49,26 & 0,92 & 1,59 & 1,71 & 5,02 & 79,16 & 0,8 & 1,80 & 2,11 \\
\hline D.L.B. & 5,11 & 82,03 & 0,91 & 1,77 & 2,53 & 4,52 & 64,18 & 0,4 & 1,77 & 0,87 \\
\hline D.M. & 4,98 & 77,91 & 1,11 & 1,64 & 3,16 & 4,91 & 75,73 & 0,51 & 1,63 & 1,42 \\
\hline F.G.L. & 4,85 & 73,90 & 0,89 & 1,67 & 2,36 & 4,64 & 67,64 & 0,56 & 1,50 & 1,52 \\
\hline F.V.P. & 6,42 & 129,48 & 0,76 & 1,92 & 3,08 & 6,43 & 129,89 & 0,48 & 1,79 & 2,09 \\
\hline G.R.S. & 4,31 & 58,36 & 0,89 & 2,03 & 1,54 & 4,80 & 72,38 & 0,44 & 1,89 & 1,01 \\
\hline J.A.L. & 4,88 & 74,81 & 0,69 & 1,96 & 1,58 & 4,80 & 72,38 & 0,44 & 1,81 & 1,06 \\
\hline J.B.L. & 4,41 & 61,10 & 0,77 & 1,72 & 1,64 & 3,84 & 46,32 & 0,63 & 1,72 & 1,02 \\
\hline J.C.H. & 4,98 & 77,91 & 0,6 & 1,90 & 1,48 & 3,55 & 39,59 & 0,33 & 1,92 & 0,41 \\
\hline J.C.M. & 4,36 & 59,72 & 0,92 & 1,62 & 2,03 & 4,56 & 65,32 & 0,45 & 1,57 & 1,12 \\
\hline J.S.B. & 6,36 & 127,07 & 0,65 & 1,82 & 2,72 & 5,85 & 107,51 & 0,45 & 1,74 & 1,67 \\
\hline J.S.L. & 4,83 & 73,29 & 1,53 & 1,71 & 3,93 & 4,73 & 70,28 & 0,45 & 1,80 & 1,05 \\
\hline L.A.F. & 4,95 & 76,97 & 1,28 & 1,93 & 3,06 & 4,75 & 70,88 & 0,51 & 1,99 & 1,09 \\
\hline L.N.H. & 6,32 & 1,72 & 0,74 & 1,87 & 0,04 & 5,86 & 107,88 & 0,46 & 1,72 & 1,73 \\
\hline M.A.S. & 5,07 & 80,75 & 0,53 & 1,69 & 1,52 & 4,64 & 67,64 & 0,47 & 1,65 & 1,16 \\
\hline M.C.F.G.P. & 3,45 & 37,39 & 0,82 & 1,60 & 1,15 & 3,54 & 39,37 & 0,43 & 1,60 & 0,63 \\
\hline M.H.S. & 4,73 & 70,28 & 0,59 & 1,67 & 1,49 & nd & nd & nd & nd & nd \\
\hline M.P. & 4,65 & 67,93 & 0,98 & 1,52 & 2,63 & 4,41 & 61,10 & 0,33 & 1,77 & 0,68 \\
\hline N.J.P. & 4,87 & 74,51 & 0,82 & 1,60 & 2,29 & nd & nd & nd & nd & nd \\
\hline O.B.O. & 5,65 & 100,28 & 0,74 & 1,72 & 2,59 & 5,11 & 82,03 & 0,29 & 1,72 & 0,83 \\
\hline O.S.S. & 4,31 & 2,49 & 0,89 & 1,50 & 0,09 & 4,24 & 56,48 & 0,44 & 1,36 & 1,10 \\
\hline P.M.C. & 5,63 & 99,58 & 1,29 & 2,13 & 3,62 & 5,34 & 89,58 & 0,48 & 2,21 & 1,17 \\
\hline P.S. & 7,19 & 162,40 & 0,82 & 1,95 & 4,10 & 5,91 & 109,73 & 0,46 & 1,95 & 1,55 \\
\hline R.C.G.A. & 3,96 & 49,26 & 0,8 & 1,76 & 1,34 & 4,24 & 56,48 & 0,5 & 1,73 & 0,98 \\
\hline R.M.N. & nd & nd & nd & nd & nd & 4,93 & 76,35 & 0,37 & 1,60 & 1,06 \\
\hline R.R.M. & 6,09 & 116,51 & 1,17 & 1,96 & 4,17 & 5,99 & 112,72 & 0,43 & 1,96 & 1,48 \\
\hline S.R.C.L. & 3,67 & 42,31 & 1,32 & 1,56 & 2,15 & 4,35 & 59,45 & 0,51 & 1,58 & 1,15 \\
\hline V.J.S. & 5,43 & 92,63 & 0,97 & 1,81 & 2,98 & 5,79 & 105,32 & 0,38 & 1,82 & 1,32 \\
\hline W.C.S. & 4,94 & 76,66 & 1,81 & 1,48 & 5,63 & 4,22 & 55,95 & 0,78 & 1,48 & 1,77 \\
\hline
\end{tabular}

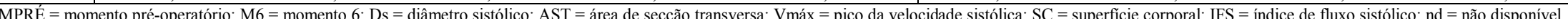


8 REFERÊNCIAS BIBLIOGRÁFICAS 
Ali MH, Schumacker PT. Endothelial responses to mechanical stress: where is the mechanosensor? Crit Care Med. 2002; 30:198-206.

Anderson EA, Mark AL. Flow-mediated and reflex changes in large peripheral artery tone in humans. Circulation. 1989; 79:93-100.

Andrade SE, Gurwitz JH, Field TS, Kelleher M, Majumdar SR, Reed G, Black R. Hypertension management: the care gap between clinical guidelines and clinical practice. Am J Manag Care. 2004; 10:481-6.

Arrowood JA, Feezor R, Fischer MR, Ravindra PV, Makhoul RG, Nixon JV. Determination of time to maximal flow-mediated, endothelial-dependent vasodilation response of the brachial artery. J Am Coll Cardiol. 1998; 31:10-32.

Ashuurn WL, Shelbert HR, Verba JW. Left ventricular ejection fraction - A review of several radionuclide angiografic approches using the scintillation camera. Prog Cardiovasc Dis. 1978; 20:267-84.

Avolio AP, Chen SG, Wang RP, Zhang CL, Li MF, O'Rourke MF. Effects of aging on changing arterial compliance and left ventricular load in a northern Chinese urban community. Circulation. 1983; 68:50-8.

Avolio AP, Deng FQ, Li WQ, Luo YF, Huang ZD, Hing LF, et al. Effects of aging on arterial distensibility in populations with high and low prevalence of hypertension: comparison between urban and rural communities in China. Circulation. 1985; 71:202-10.

Barber FE, Baker DW, Nation AWC, Strandness JR, et al. Ultrasonic duplex echo-Doppler scanner. Trans Biomed Eng. 1974; 21:109-13.

Benjamin N, Cockcroft JR, Collier JG, Dollery CT, Ritter JM, Webb DJ. Local inhibition of converting enzyme and vascular responses to angiotensin and bradykinin in the human forearm. $J$ Physiol. 1989; 412:543-55.

Berne RM, Levy MN. Principles of Physiology. St. Louis: The C. V. Mosby Company; 1990.p.74-102.

Bhagat K, Hingorani A, Vallance P. Flow associated or flow mediated dilatation? More than just semantics. Heart. 1997; 78:7-8. 
Bonow KM, Marcus R. Aortic regurgitation: The need for integrated physiology approach. J Am Coll Cardiol. 1991; 17:898-900.

Bonow KM. Clinical assessment of contractility in symetrically contracting left ventricle: Part 1. Modern Concepts of Cardiovasc. 1988; 57:29-33.

Bonow RO, Dodd JT, Maron BJ, et al. Long-term serial changes in left ventricular function and reversal of ventricular dilatation after valve replacement for chronic aortic regurgitation. Circulation. 1988; 78:1108-20.

Bonow RO, Picone AL, McIntosh CL, Jones M, Rosing DR, Maron BJ, Lakatos E, Clark RE, Epstein SE. Survival and functional results after valve replacement for aortic regurgitation from 1976 to 1983: impact of preoperative left ventricular fuction. Circulation. 1985; 72:1244-56.

Borer JS, Bacharach SL, Green MC, Hochreiter C, Wallis J, Holmes J. Assessment of ventricular function by radionuclide angiography: applications and results . Cardiology. 1984; 71:136-61.

Borer JS, Hochreiter C, Herrold EM, Supino P, Aschermann M, Wencker D, Devereux RB, Roman MJ, Szulc M, Kligfield P, Isom OW. Prediction of indications for valve replacement among asymptomatic or minimally symptomatic patients with chronic aortic regurgitation and normal left ventricular performance. Circulation. 1998; 97:525-34.

Boucher CA, Okada RD, Pohost GM. Current status of radionuclide imaging in valvular heart disease. Am J Cardiol. 1980; 46:1153-63.

Boutouyrie P, Lacolley P, Girerd X, Beck L, Safar M, Laurent S. Sympathetic activation decreases medium-sized arterial compliance in humans. Am J Physiol Heart Circ Physiol. 1994; 267:1368-76.

Bramwell JC, Hill AJ. Velocity of transmission of the pulse-wave and elasticity of arteries. Lancet. 1922; 1:891-2.

Carabello BA, Williams H, Gash AK. Hemodynamic predictors of outcome in patients undergoing valve replacement. Circulation. 1986; 74:1309-16.

Celermajer D. Endothelial function. Does it matter? Is it reversible? J Am Coll Cardiol. 1997; 30:325-33.

Cheitlin MD, et al. American College of Cardiology / American Heart Association Guidelines for the clinical application of echocardiography. Circulation. 1997; 95:1686-1744.

Chowienczyk PJ, Cockcroft JR, Ritter JM. Differential inhibition by NGmonomethyl-L-arginine of vasodilator effects of acetylcholine and methacholine in human forearm vasculature. Br J Pharmacol. 1993; 110:736-8. 
Cocks TM, Angus JA, Campbell JH, Campbell GR. Release and properties of endothelium-derived relaxing factor (EDRF) from endothelial cells in culture. $J$ Cell Physiol. 1985; 123:310-20.

Cohn JN, Finkelstein S, McVeigh G. Non-invasive pulse wave analysis for the detection of vascular disease. Hypertension. 1995; 26:503-8.

Corretti MC, Todd JA, Benjamin EJ, et al. Guidelines for the Ultrasound Assessment of Endothelial-Dependent Flow-Mediated Vasodilation of the Brachial Artery. J Am Coll Cardiol. 2002; 39:257-65.

Creager MA, Cooke JP, Mendelsohn ME, Gallagher SJ, Coleman SM, Loscalzo J, Dzau VJ. Impaired vasodilation of forearm resistance vessels in hypercholesterolemic humans. J Clin Invest. 1990; 86:228-34.

Darvill Junior FR. Aortic insufficiency of unusual etiology. JAMA. 1963; 184:753-7.

de Andrade CH, Santos Filho DV, Nacarato E, Oliveira Filho JA, Cirenza C, Lorena YG, Barcellini A. Identificação de hipertensão arterial em insuficiência aórtica. I Relação entre os níveis de pressão antes e após o implante valvar. Arq Bras Cardiol. 1985; 44:383-8.

Debert MBR, Franco RJS, Nunes SF, Ramos OL, et al. Hypertension and economic activities in São Paulo, Brazil. Hypertension. 1981; 3:233-37.

Delvin W, Petrusha J, Briesmiester BS, Montgomery D, Starling MR. Impact of vascular adaptation to chronic aortic regurgitation on left ventricular performance. Circulation. 1999; 99:1027-33.

Dietz NM, Engelke KA, Samuel TT, Fix RT, Joyner MJ. Evidence for nitric oxide-mediated sympathetic forearm vasodiolatation in humans. J Physiol. 1997; 498:531-40.

Douglas PS. Rheumatic heart disease and other valvular disorders in women. Cardiovasc Clin. 1989; 19:259-65.

Dubois D, Dubois EF. A formula to estimate the approximate surface area if height and weight be known. Arch Intern Med. 1916; 17:863-71.

Eaton GM, Cody RJ, Binkle YPF. Increased aortic impedance precedes peripheral vasoconstriction at the early stage of ventricular failure in the paced canine model. Circulation. 1993; 88:2714-21.

Enriquez-Sarano M, Tajik AJ. Clinical practice. Aortic regurgitation. $N$ Engl J Med. 2004; 351:1539-46. 
Ercan E, Tengiz I, Ercan HE, Nalbantgil I. Left ventricular hypertrophy and endothelial functions in patients with essential hypertension. Coron Artery Dis. 2003; 14:541-4.

Finkelstein SM, Cohn JN, Collins VR, Carlyle PF, Shelley WJ. Vascular hemodynamic impedance in congestive heart failure. Am J Cardiol. 1985; 55:423-7.

Finkelstein SM, Cohn JN. First - and third - order models for determining arterial compliance. J Hypertens. 1992; 10:11-4.

Finkelstein SM, Collins VR. Vascular hemodynamic impedance measurement. Prog Cardiovasc Dis. 1982; 24:401-18.

Forman R, Firth BG, Barnard MS. Prognostic significance of preoperative left ventricular ejection fraction and valve lesion in patients with aortic replacement. Am J Cardiol. 1980; 45:1120-5.

Furchgott R, Zawadzki D. The obligatory role of endothelial cells in the relaxion of arterial smooth muscle by acetylcholine. Nature Lond. 1980; 288:373-6.

Gaasch WH, Andrias CW, Levine HJ. Chronic aortic regurgitation: the effect of aortic valve replacement on left ventricular volume, mass and function. Circulation. 1978; 58:825-36.

Gaasch WH, Carroll JD, Levine HJ, Criscitiello MG. Chronic aortic regurgitation: prognostic value of left ventricular end-systolic dimension and end-diastolic radius/thickness ratio. J Am Coll Cardiol. 1983; 1:775-782.

Gallagher D, et al. How useful is BMI for comparison of body fatness across age, Sex and ethnic groups? Am J of Epidem. 1996; 143:228-39.

Genest J, Koiw E, Kuchel O, editores. Hypertension. Nova Iorque: McGrawHill; 1977.

Gerhard M, Roddy MA, Creager SJ, Creager MA. Aging progressively impairs endothelium-dependent vasodilation in forearm resistance vessels of humans. Hypertension. 1996; 27:849-53.

Goldman L, Hashimoto B, Cook EF, Loscalzo A. Comparative reproducibility and validity of systems for assessing cardiovascular functional class: advantages of a new specific activity scale. Circulation. 1981; 6:1227-34.

Goldstein S, Killip T. 3rd. Comparison of direct and indirect arterial pressures in aortic regurgitation. $N$ Engl J Med. 1962; 267:1121-4. 
Greenberg BH, Demots H, Murphy E, Rahimtoola SH. Mechanism for improved cardiac performance with arteriolar dilators in aortic insufficiency. Circulation. 1981; 63:263-8.

Griendling KK, Minieri CA, Ollerenshaw JD, Alexander RW. Angiotensin II stimulates NADH and NADPH oxidase activity in cultured vascular smooth muscle cells. Circ Res. 1994; 6:1141-8.

Griffith TM, Edwards DH, Davies RL, Harrison TJ, Evans KT. EDRF coordinates the behavior of vascular resistance vessels. Nature. 1987; 329:4425.

Griffith TM, Henderson AH. EDRF and the regulation of vascular tone. Int. J. Microcirc. Clin Exp. 1989; 4:383-96.

Gutierrez MA, Pilon PE, Lage SHG, et al. Assessment of carotid diameter and wall thickness in ultrasound images using active contours improved by a multiresolution technique. Progress in Biomedical Optics and Imaging. 2002; $3: 248-255$.

Harrison DG. Endothelial function and oxidant stress. Clin Cardiol. 1997; 11:11-7.

Hashimoto M, Akishita M, Eto M, et al. Modulation of endothelium-dependent flow-mediated dilatation of the brachial artery by Sex and menstrual cycle. Circulation. 1995; 92:3431-5.

Hashimoto M, Miyamoto Y, Matsuda Y, Akita H. New methods to evaluate endothelial function: Non-invasive method of evaluating endothelial function in humans. J Pharmacol. 2003; 93:405-8.

Henry WL, Bonow RO, Borer JS, Ware J.H. Observations on the optimum time for operative intervention for aortic regurgitation. I. Evaluation of results of aortic valve replacement in symptomatic patients. Circulation. 1980; 61:471-83.

Hirsch KK, Shalak TC, Peirce SM, Little CD. Vascular assembly in natural and engineered tissues. Ann N Y Acad Sci. 2002; 961:223-42.

Hoeks APG, Brands PJ, Reneman RS. Assessment of the arterial distension waveform using Doppler signal processing. J Hypertens. 1992; 10:19-22.

Hoeks APG, Ruissen CJ, Hick P, Reneman RS. Transcutaneous detection of relative changes in artery diameter. Ultrasound Med Biol. 1985; 11:51-9.

Jadhav UM, Sivaramakrishnan A, Kadam NN. Noninvasive assessment of endothelial dysfunction by brachial artery flow-mediated dilatation in prediction of coronary artery disease in Indian subjects. Indian Heart J. 2003; 55:44-8. 
Jensen-Urstad K, Rosfors S. A methodological study of arterial wall function using ultrasound technique. Clin Physiol. 1997; 17:557-67.

Joannides R, Haefili WE, Linder L, Pichard V, Bakkaki EH, Thuill YC, et al. Nitric oxide is responsible for flow-dependent dilatation in the peripheral vasculature of patients with congestive heart failure. J Am Coll Cardiol. 1992; 19:918-25.

Johns RA. Endothelium-derived relaxing factor: basic review and clinical implications. J Cardiothorac Vasc Anesth. 1991; 5:69-79.

Julius S, Jamerson K. Sympathetics, insulinresistance and coronary risk in hypertensi-on: the "chicken and egg" question. Am J Hypertens. 1991; 4: 59856025 .

Kahn EB, et al. The effectiveness of interventions to increase physical activity: a systematic review. Am J of Prev Med. 2002; 42:73-107.

Kannel WB, Brand N, Shinner JJ, Dawber TR, McNamara PM. The relation of adiposity to blood pressure and development of hypertension. Ann Intern Med. 1967; 67: 48-59.

Katz SD, Biasucci L, Sabba C, Strom JA, Jondeau G, Galvão M, Solomon S, Nikolic SD, Forman R, LeJemtel TH. Impaired endothelium-mediated vasodilation in the peripheral vasculature of patients with congestive heart failure. J Am Coll Cardiol. 1992; 19:918-25.

Katz SD. Mechanisms and implications of endothelial dysfunction in congestive heart failure. Curr Opin Cardiol. 1997; 12:259-64.

Keats TE, editor. Atlas of roentgenographic measurements, 3a ed. Chicago: Year book medical publishers; 1983.

Kelly R, Hayward C, Avolio AP, O'Rourke M. Noninvasive determination of age-related changes in the human arterial pulse. Circulation. 1989; 80: 1652-59.

Kiowski W, Sütsch G, Schalcher C, Brunner HP, Oechslin E. Endothelial control of vascular tone in chronic heart failure. J Cardiovasc Pharmacol. 1998; 32:67-73.

Kopel L, Lage SG. Avaliação das propriedades elásticas arteriais utilizando a ultra-sonografia de alta resolução vascular em indivíduos normais. Radiol Bras. $1995 ; 28: 131-35$.

Kopel L, Tarasoutchi F, Medeiros C, Carvalho RT, Grinberg M, Lage SG. Distensibilidade arterial como possível mecanismo compensatório na insuficiência aórtica crônica. Arq Bras Cardiol. 2001; 7:258-61. 
Krayenbuehl HP, Hess OM, Monrad ES, Schneider J, Mall G, Turina M. Left ventricular myocardial structure in aortic valve disease before, immediate, and late after aortic valve replacement. Circulation. 1989; 79:744-55.

Kumpuris AG, Quinones MA, Waggoner AD, Kanon DJ, Nelson JG, Miller RR. Importance of preoperative hypertrophy, wall stress and end-systolic dimension as echocardiographic predictors of normalization of left ventricular dilatation after valve replacement in chronic aortic insufficiency. Am J Cardiol. 1982; 49: 1091-1100.

Lage SG, Kopel L, Monachini MC, Medeiros CJ, Pileggi F, Polak JF, Creager MA. Carotid arterial compliance in patients with congestive heart failure secondary to idiopathic dilated cardiomyopathy. Am J Cardiol. 1994; 74: 691-5.

Lage SG, Polak JF, O'Leary DH, Creager MA. Relationship of arterial compliance to baroreflex function in hypertensive patients. Heart Circ Physiol. $1993 ; 34: 232-7$.

Langille BL, O'Donnell F. Reductions in arterial diameter produced by chronic decreases in blood flow are endothelium-dependent. Science. 1986; 231: 405-7.

Laskey WK, Parker HG, Ferrari VA Kussmaul WG, Noordergraaf A. Estimation of total systemic arterial compliance in humans. J Appl Physiol. 1990; 69: 112-9.

Laurent S, Lacoulley P, Brunel P, Laloux B, Pannier B, Safar M. Flowdependent vasodilation of brachial artery in essential hypertension. Am $J$ Physiol. 1990; 258: 1004-11.

Leeson P, Thorne S, Donald A, Mullen M, Clarkson P, Deanfield J. Noninvasive measurement of endothelial function: effect on brachial artery dilatation of graded endothelial dependent and independent stimuli. Heart. 1997; 78: 22-7.

Leggett M, Otto CM. Aortic valve disease. Curr Opin Cardiol. 1996; 11: 120-5. Lerman A, Sandok EK, Hildebrand Junior FL, Burnett Junior JC.Inhibition of endothelium-derived relaxing factor enhances endothelin-mediated vasoconstriction. Circulation. 1992; 5: 1894-8.

London SB, London RE. Critique of indirect diastolic end point. "Muffling" vs "Last" Sound. Arch Intern Med. 1967; 1: 39-49.

Lowendtein CJ, Dinerman JL, Snyder SH. Nitric oxide: a physiological messenger. Ann Inter Med. 1994; 120: 227-37. 
Lüscher TF, Wenzel RR, Noll G. Local regulation of the coronary circulation in health and disease: role of nitric oxide and endothelin. Eur Heart J. 1995; 16: 51-8.

Mahler F, Roo J Jr, O'Rourke RA, Covell JW. Effects of changes in preload, afterload, and inotropic state on isovolumic and ejection phase measures of contractility in the conscious dog. Am J Cardiol. 1975; 35:626-34.

McVeigh GE, Bratelli CW, Morgan DJ. Age-related abnormalities in artrial compliance identified by pressure pulse contour analysis. Hypertens. 1999; 33: 1392-8.

Merillon JP, Motte G, Fruchaud J, Masquet C, Gourgon R. Evaluation of the elasticity and characteristic impedance of the ascending aorta in man. Cardiovasc Res. 1978; 12: 401-06.

Merrilon JP, Fontenier G, Lerault JF, Jaffrin MY, Chastre J, Assayag P, Molte G, Gourgon R. Aortic input impedance in heart failure: comparison with normal subjects and its changes during vasodilator therapy. Eur Heart J. 1984; 5: 44755.

Miall WE, Lovell HG. Relation between change of blood pressure and age. $\mathrm{Br}$ Med J. 1967; 2: 660-64.

Miller VM, Aarhus LL, Vanhoutte PM. Modulation of endothelium-dependent responses by chronic alterations of blood flow. Am J Physiol Heart Circ Physiol. 1986; 251: 520-7.

Miller VM, Michener SR. Modulation of contractions to and receptors for endothelins in canine veins.Am J Physiol. 1995; 268: 345-50.

Milnor WR. Arterial impedance as ventricular afterload. Circ Res. 1975; 36: 565-70.

Munzel T, Hink U, Heitzer T, Meinertz T. Role for NADPH/NADH oxidase in the modulation of vascular tone. Ann N Y Acad Sci. 1999; 874:386-400.

O'Rourke MF, Brunner HR. Introduction to arterial compliance and function. $J$ Hypertens. 1992; 10:3-5.

Opasich C, Ambrosino N, Felicetti G, Aquilani R, Pasini E, Bergitto D, Mazza A, Cobelli F, Tavazzi L. Heart failure-related myopathy. Clinical and pathophysiological insights. Eur Heart J. 1999; 16:1191-200.

Palinkas A, Toth E, Venneri L, Rigo F, Csanady M, Picano E. Temporal heterogeneity of endothelium-dependent and -independent dilatation of brachial artery in patients with coronary artery disease. Int J Cardiovasc Imaging. 2002; 18: 337-42. 
Pepine CJ, Nichols WW, Conti CR. Aortic input impedance in heart failure. Circulation. 1978; 58:460-5.

Pickering TG. Blood pressure measurement and detection of hypertension. Lancet. 1994; 344:31.

Playford DA, Watts GF. Special article: non-invasive measurement of endothelial function. Clin Exp Pharmacol Physiol. 1998; 25:640-3.

Pomerantzeff PMA, Puig LB, Grinberg M, Tarasoutchi F, Jatene AD, et al. Fisics-InCor bovine pericardial bioprostheses: 15 year results. Heart Surg Forum. 1997; 1:130-35.

Prokop E, Palmer RF, Wheat MW. Hydrodynamic forces in dissecting aneurysms. Circ Res. 1970; 27:121-7.

Ramsey MW, Goodfellow J, Jones CJH, Luddington LA, Lewis MJ, Henderson AH. Endothelial control of arterial distensibility is impaired in chronic heart failure. Circulation. 1995; 92:3212-19.

Razzolini R, Ramondo A, Isabella G, Cardaioli P, Vacari D, Carasi M, De Leo A, Chioin R, Suga H, Dalla-Volta S. Analytical expression of effective afterload in aortic and mitral regurgitation. Jpn Heart J. 1999; 40:295-309.

Razzolini R, Zennaro M, Ramondo A, Isabella G, Cardaioli P, Martini M, Campisi F, Chioin R. Measurement of systemic resistances in aortic regurgitation. Jpn Heart J. 1994; 35:733-43.

Romhilt DW, Estes EH. Point-score system for the ECG diagnosis of left ventricular hypertrophy. Am Heart J. 1968; 75:752.

Rosner B, editor. Fundamentals of Biostatistics. 3. ed. Boston: PWS Publishers, 1986.

Ross Junior J. Afterload mismatch in aortic and mitral valve disease: Implications for surgical therapy. J Am Coll Cardiol. 1985; 5:811-26.

Ross Junior R. Afterload mismatch and preload reserve: a conceptual framework for the analysis of ventricular function. Prog Cardiovasc Dis. 1976; 18:255-64.

Rubanyi GM, Romero JC, Vanhoutte PM. Flow-induced release of endothelium-derived relaxing factor. Am J Physiol. 1986; 250:1145-7.

Rutan GH, Kuller LH, Neaton JD, Wentworth DN, McDonald RH, McFateSmith W.Mortality associated with diastolic hypertension and isolated systolic hypertension among men screened for the Multiple Risk Factor Intervention Trial. Circulation. 1988; 77:504-14. 
Safar ME, Levy BI, London GM. Arterial structure in hypertension and the effects of angiotensin converting enzyme inhibition. J Hypertens Suppl. 1992; 10:51-7.

Safar ME, Peronneau PA, Levenson JA, Toto-Moukouo JA, Simon AC. Pulsed Doppler: diameter, blood flow velocity and volumic flow of the brachial artery in sustained essential hypertension. Circulation. 1981; 63:393-400.

Salonen JT, Salonen R. Ultrasound B-mode imaging in observational studies of atherosclerosis progression. Circulation. 1993; 8756-65.

Satcher D, editor. Physical activity and health: a report of the surgeon general. Washington: National Center for Chronic Disease Prevention and Health Promotion; 1996.

Schller NB, Shah PM, Crawford M, Demaria A, Devereux R. Recommendations for quantitation of the ventricle by two dimensional echocardiography: American Society of Echocardiography Committee on Standards Subcommittee. J Am Soc Echocardiogr. 1989; 2:358-67.

Sconamiglio R, Rahimtoola SH, Fasoli G, et al. Nifedipine in asymptomatic patients with severe aortic regurgitation and normal left ventricular function. $N$ Engl J Med. 1994; 331:689.

Sebban C, Berthaux P, Lenoir H, Eugene M, Venet R, Memim Y, De La Fuente $\mathrm{X}$, Reisner C. Arterial compliance, systolic pressure and heart rate in elderly women at rest and on exercise. Gerontology. 1981; 27:271-80.

Smulyan H, Asmar RG, Rudnicki A, London GM, Safar ME. Comparative effects of aging in men and women on the properties of the arterial tree. $J A m$ Coll Cardiol. 2001; 37:1374-80.

Sorensen KE, Celermajer DS, Spiegelhalter DJ, Georgakopoulos D, Robinson J, Thomas O, Deanfield JE. Non-invasive measurement of human endothelium dependent arterial responses: accuracy and reproductibility. Br Heart J. 1995; 74:247-53.

Starling MR, Kish MM, Montgomery DG, Gross MD. Mechanisms for left ventricular systolic dysfunction in aortic regurgitation: importance for predicting the response to aortic valve replacement. J Am Coll Cardiol. 1991; 17:887-97.

Stevenson LW, Fonarow GC. Endothelin and the vascular choir in heart failure. J Am Coll Cardiol. 1992; 20:854-7. 
Stone PH, Clark RD, Goldschlager N, Selzer A, Cohn K. Determinants of prognosis in patients with aortic regurgitation who undergo aortic valve replacement. J Am Coll Cardiol. 1984; 3:1118-26.

Timm NH, editor. Multivariate Analysis with Applications in Educations and Psychology. Monterrey: Brooks \& Cole, 1975.

Vallance P, Collier J, Moncada S. Effects of endothelium-derived nitric oxide on peripheral arterial tone in man. Lancet. 1989; 2:997-1000.

Van Merode T, Hick PJ, Hoecks AP, Rahn KH, Reneman RS. Carotid artery wall properties in normotensive and borderline hypertensive subjects of various ages. Ultrasound Med Biol. 1988; 14:563-69.

Vapaatolo H, Mervaal E. Clinically important factors influencing endothelial function. Med Sci Monit. 2001; 7:1075-85.

Warnholtz A, Nickenig G, Schulz E, Macharzina R, Brasen JH, Skatchkov M, Heitzer T, Stasch JP, Griendling KK, Harrison DG, Bohm M, Meinertz T, Munzel T. Increased NADH-oxidase-mediated superoxide production in the early stages of atherosclerosis: evidence for involvement of the reninangiotensin system. Circulation. 1999; 15:2027-33.

Watt Junior TB, Burrus CS. Arterial pressure contour analysis for estimating human vascular properties. J Appl Physiol. 1976, 40:171-6.

Weaver WF, Wilson CS, Rourke T Caudill CC. Mid-diastolic aortic valve opening in severe acute aortic regurgitation. Circulation. 1977; 55:112.

Weber F, Anlauf M, Hirche H, Roggenbuck U, Philipp T. Differences in blood pressure values by simultaneous auscultation of Korotkoff sounds inside the cuff and in the antecubital fossa. J Hum Hypertens. 1999; 13:695-700.

Weinberger MH, Fineberg NS, Fineberg SE. Effects of age, race, gender, blood pressure and estrogen on arterial compliance. Am J Hypertens. 2002; 15:358-63.

Welch Junior GH, Braunwald E, Sarnoff SJ. Hemodynamic effects of quantitatively varied experimental aortic regurgitation. Circ Res. 1957; 5:54651.

Wilson RA, McDonald RW, Bristow D, Cheitlin M. Correlates of aortic distensibility in chronic regurgitation and relation to progression to surgery. $J$ Am Coll Cardiol. 1992; 19:733-38.

Wilson TW, Grim CD. Biohistory of slavery and blood pressure differences in blacks today: a hypothesis. Hypertension. 1991; 17:122-28. 
Wisenbaugh T, Spann JF, Carabello BA. Differences in myocardial performance and load between patients with similar amounts of chronic aortic versus crhonic mitral regurgitation. J Am Coll Cardiol. 1984; 3:916-23.

Yin FC, Ting CT. Compliance changes in physiological and pathological states. J Hypertens. 1992; 10:31-3.

Yousof AM, Mohammed MMJ, Khan N, Shuhaiber H, Cherian G. Chronic severe aortic regurgitation: a prospective follow-up of 60 asymptomatic patients. Am Heart J. 1988; 116:1262-7.

Zezulka A, Mackinnon J, Beevers DG. Hypertension in aortic valve disease and its response to valve replacement. Postgrad Med J. 1992; 68:180-5. 


\section{HOSPITAL DAS CLÍNICAS}

$D A$

FACULDADE DE MEDICINA DA UNIVERSIDADE DE SÃO PAULO

TERMO DE CONSENTIMENTO LIVRE E ESCLARECIDO

(Instruções para preenchimento no verso)

I - DADOS DE IDENTIFICAÇÃO DO SUJEITO DA PESQUISA OU RESPONSÁVEL LEGAL

1. NOME DO PACIENTE

DOCUMENTO DE IDENTIDADE № :

SEXO : .M $\mathrm{F}$

DATA NASCIMENTO:

№

APTO:

ENDEREÇO

CIDADE

BAIRRO:

TELEFONE: DDD

..)

2.RESPONSÁVEL LEGAL

NATUREZA (grau de parentesco, tutor, curador etc.)

DOCUMENTO DE IDENTIDADE :

SEXO: $M \quad F$

DATA NASCIMENTO.:

ENDEREÇO:

APTO:

BAIRRO:

CIDADE:

CEP:

TELEFONE: DDD

..).

\section{II - DADOS SOBRE A PESQUISA CIENTÍFICA}

1. TÍTULO DO PROTOCOLO DE PESQUISA Pós-carga pulsátil das Artérias de Condução em Pacientes com Insuficiência Aórtica Crônica

2. PESQUISADOR: Dr.Roberto Chaves Castro

CARGO/FUNÇÃO: Médico Cardiologista Pesquisador

INSCRIÇÃO CONSELHO REGIONAL: № 86.653

UNIDADE DO HCFMUSP: Instituto do Coração - Unidade Clínica de Valvopatia

3. AVALIAÇÃO DO RISCO DA PESQUISA:

$\begin{array}{lll}\text { SEM RISCO } & \text { RISCO MÍNIMO } & \text { RISCO MÉDIO } \mathbf{X} \\ \text { RISCO BAIXO } & \text { RISCO MAIOR } & \end{array}$

(probabilidade de que o indivíduo sofra algum dano como conseqüência imediata ou tardia do estudo)

4.DURAÇÃO DA PESQUISA : 2 anos 


\section{III - REGISTRO DAS EXPLICAÇÕES DO PESQUISADOR AO PACIENTE OU SEU REPRESENTANTE LEGAL SOBRE A PESQUISA, CONSIGNANDO:}

1. Justificativa e os objetivos da pesquisa ; 2. procedimentos que serão utilizados e propósitos, incluindo a identificação dos procedimentos que são experimentais; 3. desconfortos e riscos esperados; 4. benefícios que poderão ser obtidos; 5 . procedimentos alternativos que possam ser vantajosos para o indivíduo.

1. Verificar o tamanho da artéria do pescoço e do braço esquerdo em pacientes com necessidade de troca de válvula aórtica

2. A pressão arterial vai ser medida no ambulatório antes da cirurgia e no 10,30 e 60 mês depois da troca da válvula. Também será feito exame de ultra-som (exame semelhante ao da mulher grávida para ver o bebê) da artéria do pescoço e do braço esquerdo antes e depois da cirurgia

3. A cirurgia vai ser feita pelo médico operador quando tiver a necessidade e chegar a vez de trocar a válvula

4. A medida da pressão arterial e o ultra-som não provocam dor, não tiram sangue ou dão qualquer tipo de problema para a saúde.

5. A cirurgia de troca da válvula tem riscos desde reação com a anestesia, derrame na cabeça ou outra parte do corpo, infarto, até a parada do coração e a morte

6. Se a pressão arterial estiver alta e a artéria pouco dilatada, isto poderá ajudar no futuro os pacientes tanto durante a cirurgia como no tratamento mais cedo da pressão alta

7. Você será beneficiado pela pesquisa com o diagnóstico precoce da pressão alta depois da cirurgia

\section{IV - ESCLARECIMENTOS DADOS PELO PESQUISADOR SOBRE GARANTIAS DO SUJEITO DA PESQUISA:}

1. Acesso, a qualquer tempo, às informações sobre procedimentos, riscos e benefícios relacionados à pesquisa, inclusive para dirimir eventuais dúvidas.

2. Liberdade de retirar seu consentimento a qualquer momento e de deixar de participar do estudo, sem que isto traga prejuízo à continuidade da assistência.

3. Salvaguarda da confidencialidade, sigilo e privacidade.

4. Disponibilidade de assistência no HCFMUSP, por eventuais danos à saúde, decorrentes da pesquisa.

5. Viabilidade de indenização por eventuais danos à saúde decorrentes da pesquisa.

\section{INFORMAÇÕES DE NOMES, ENDEREÇOS E TELEFONES DOS RESPONSÁVEIS PELO ACOMPANHAMENTO DA PESQUISA, PARA CONTATO EM CASO DE INTERCORRÊNCIAS CLÍNICAS E REAÇÕES ADVERSAS:}

Prof. Dr. Max Grinberg 5056/ 5343

Dr. Roberto Chaves Castro
Instituto do Coração - Av. Dr. Éneas de Carvalho Aguiar, 44 AB - 3069Idem

\section{OBSERVAÇÕES COMPLEMENTARES: \\ VII - CONSENTIMENTO PÓS-ESCLARECIDO}

Declaro que, após convenientemente esclarecido pelo pesquisador e ter entendido o que me foi explicado, consinto em participar do presente Protocolo de Pesquisa
São Paulo,
de
de 200 
